Wrix wi nif. Library

53

1979

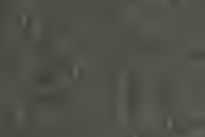

(1)

7

$\pi$

8 11

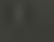

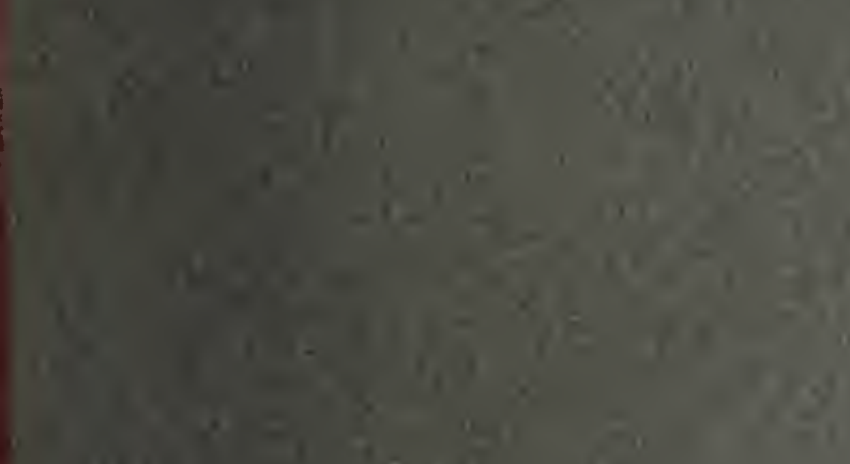

$\min$

$x^{2}+x^{2}+x^{2}$

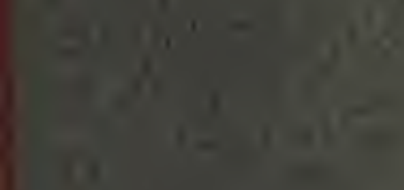

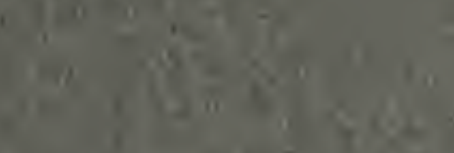

$x^{2}$

$\therefore$

15xan.

$a^{2} y$

$x^{2}+y^{2}=4,25$

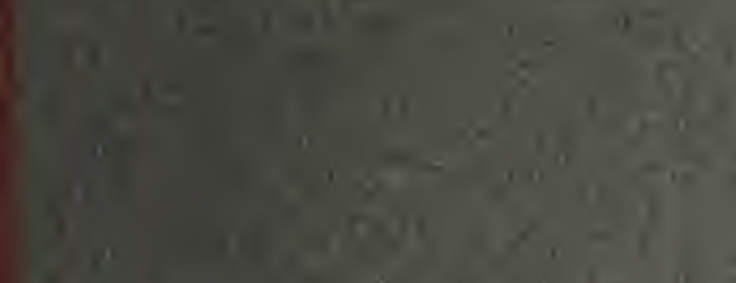

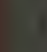





\section{Beiträge zur Kenntnifs der Organisation der Infusorien und ihrer geographischen Verbreitung, besonders in Sibirien.}

Von

Hrn. EHRENBERG.

[Gelesen in der Akademie der Wissenschaften am 4. und 18. März 1830, mit Zusätzen gedruckt am 13. August.]

M

an ist in der neuesten Zeit gencigt gewesen, eine Grenze für die kleinsten materiellen Theilchen aller organischen und anorganischen Körper, welche die alten Philosophen Atomen nannten, innerhalb unsers, durch optische Instrumente vergröfserten Gesichtskrcises festzustellen. Die zoologischen Monaden, welche in absteigendem Verhältnils ohngefähr bis zur Gröfse von einem $\frac{1}{12000}$ Zoll, oder $\frac{1}{1000}$ bis $\frac{1}{1500}$ Linie bekannt waren, sind zuerst, ohne Einschränkung, das einfache Material des Thierreichs genannt worden, aus dessen Arieinanderfügen jedes Wachsen und Zeugen bestehe. Andere haben dieselbe Idee auf das Pflanzenreich ausgedehnt, und den neuesten Beobachtungen zufolge gab es freiwillig bewegte, aber von den zoologischen Monaden verschiedene, Atome oder Molecülen von der Gröfse eines $\frac{1}{30000}$ Zolles oder einer $\frac{1}{2 j 00}$ Linie, welche bei sämmtlichen organischen und anorganischen Naturkörpern gleichartig zu finden seien. Die glücklich erläuternde Darstellungsweise der Chemiker nach Berzelius mag an diesem neuesten Streben grofsen Antheil haben. Robert Brown's, des verdienstvollen englischen Botanikers letzte, darauf Bezug habende, von vielen angefochtene Beobachtungen sind bekannt, und werden schon durch ihre Anregung zur widerlegenden Beobachtung, wie der bekannte Schatz im Weinberge, ihren Nutzen nicht verfehlen. Ich übergebe hiermit andere Beobachtungen, welche jene, durch Robert Brown bei manchem vielleicht doch genäherte Idee wieder so weit in entgegengesetzter Richtung in die Ferne leiten, als sie sich zu nähern irgend geschienen. Seitdem ich nämlich im Phys. Abhandl. 1830. 
Jahre 1820 durch direktc Beobachtungen zuerst deutlich nachwies, dafs die Pilze und Schimmel, deren Entstehung bis dahin dem Walten der generatio aequivoca oder primiliva ganz Preis gegeben war, wirklich keimende Saamen tragen $\left({ }^{1}\right)$, was zu erweisen weder die hypothesischen Bestimmungen namhafter Botaniker, noch Micheli's bekannte Versuche hinreichend waren, habe ich mich noch vielfach mit Betrachtung dieser und ähnlicher kleiner Organismen beschäftigt, und ich habe sogar auf meinen Reisen mich sehr angelegentlich bemüht, ihr Verhältnifs zur Gesammtmasse der Organismen in 3 Welttheilen auszumitteln, und in einer früheren Vorlesung hatte ich bereits die Ehre, der Akademie die Resultate der mit Dr. Hemprich in Afrika und Arabien gemachten, hierauf Bezug habenden Beobachtungen vorzulegen. Obwohl ich die Schwicrigkeiten einer scharfen Beobachtung und systematischen Bestimmung dieser, durch Müller's vortreffliche Vorarbeiten bei weitem nicht erschöpften, durch die neueren zahlreichen $\mathrm{Zu}$ sätze und systematischen Umänderungen aber mehr verworrenen als aufgeklärten Formen sehr grofs fand, so war mir doch die Basis aller organischen Bildungen, und selbst des Menschen, auf der die schaffende Natur noch immerfort ihre Werkstätte der matcriellen Form-Entwicklung aufgeschlagen zu haben schien, und die sie, manchem Denker und Beobachter zufolge, selbst als lebendiges Material zur Zusammensetzung höherer Lebensformen zu benutzen schien, gar zu wichtig, als dafs ich es nicht für eine der Zeit und MÏhe werthe Sache hätte halten sollen, die Geheimnisse des Lebens in diesen einfachsten Formen mit Aufopferung jener zu belauschen. Die Resultate meiner Beobachtungen sind glücklich und zahlreich. Herrn Baron Alexander von Humboldt's Reise nach den russischen Provinzen bis an die chinesische Dzungarei, an welcher Theil zu nehmen ich die chrenvolle und freundliche Aufforderung erhielt, und die mitten in einem verhängnifsvollen Kricge von Sr. Majestät dem Kaiser von Rufsland auf das liberalste begünstigt und von allen berïhrten russischen Behörden auf das thätigste unterstützt wurde, gab mir Gelegenlieit, wieder einen sehr bedeutenden Theil der Erdoberfläche kennen zu leruen, und ich habe dabei nicht unterlassen, auch auf die geographischen Verhältnisse der kleinsten Formen des organischen Lebens in jenen grofsen Länderstrecken meine Aufmerksamkeit

(') Nova Acta Acad. Leopold. Carol. X. Pars I. p. 157. 1820. De mycetogenesi epistola. 
unausgesetzt zu verwenden. Dicse neuen zahlreichen Beobachtungen aber hatten nicht nur den Erfolg, dafs ich eine. ansehnliche Menge noch. unbekannter Formen entdcckte und eine Übersicht der gesuchten geographischen Verhältnisse wirklich erhielt, sondern sie hatten den noch weit einflufsreicheren Erfolg, dåfs sie mich durch Vergleichung meiner früher in Afrika und Europa gemachten Bcobachtungen auf die Spur des Formenwcchsels dieser Körper lciteten. Das regelmäfsige Zusammenleben gewisscr, bisher als verschiedene Gattungen ganz getrennter, Formen in den verschiedenartigsten geographischen Verhältnissen erweckte in mir die Idee des Formenwechsels eines und desselben Thiercs, und meine auf diesen Gesichtspunkt hingelenkte Beobachtung bestätigte bald die gewonnene Ansicht. In der vertrauensvollen Aussicht, bestimmte wichtige Resultate auf diesem Wege zu erlangen, beschäftigte ich mich nach meiner Rückkehr nach Berlin`von Neuem mit Beobachtung der bisher, wohl anch der Feinheit und Schwierigkeit der Untersuchungen halber, fast ganz unberücksichtigten allmähligen Entwicklung dieser kleinen Organismen, und nahm auch einen schon oft vergeblich geprüften Versuch wieder auf, durch gefärbte Nahrungsstoffe den innern Bau derselben anschaulich zu machen. Diese Untersuchungen waren im nächsten Zusammenhange mit meiren übrigen Arbeiten, und so begann ich denn eine Revision sämmtlicher bei Berlin lebender Infusorien, die mich zu den festen Gesetzen ihrer kaum geahneten organischen Ausbildung und Form-Entwicklung leitete, welche es möglich machen, diese Formen künftig mit weit mehr Schärfe zu bezeichnen, und die, wie ich hoffe, eine Dunkelheit aufhellen helfen, welche bisher zu um so gröfseren Irrthümern führte, je mehr man geneigt war, in sie die Basis der physiologischen Systeme zu legen.

Da die Resultate meiner Beobachtungen mich nöthigen, einen ganz neuen Weg für die Systematik der Formen einzuschlagen, an deren Namen sich dieselben knüpfen, so würde ich unverständlich werden, wenn ich nicht die Hauptpunkte der frühcren schon bekannten Systematik zuvor übersichtlich und in Kürze beurtheilcnd anführen wollte. Ich gehe demnach zu einer geschichtlichen Einleitung über.

Das Studium der Infusionsthiere zerfällt in zwei sehr bestimmt geschiedene Perioden. Die crste war die vorbereitende Periode der reinen gemüthlichen Anschauung, und währte von der Entdeckung des Microscops 
bis zum Erscheinen der Systematik von Otto Friedrich Müller. Die Sehriften dieser Periode führen zuweilen im Titel die Ausdrücke ,, Belustigungen" und , Ergötzungen," oder sie bewundern und rühmen die Kraft des Mieroscops, die künstliche Zusammensetzung unglaublich kleiner Naturkörper und die Gröfse Gottes in diesen Erscheinungen, während die Gegenstände der Beobachtung diesen Zwecken gewöhnlich untergeordnet sind. Die zweite Periode ist die systematisirende, welche mit Müller begann, und einen directen Gegensatz gegen die erstere bildet. Obwohl die Microscope seit langer Zeit sehr verbessert und noch mehr verbreitet sind, so ist doch in der letzteren Periode bis zum heutigen Tage unverhältnifsmäfsig wenig wissenschaftlich beobachtet, und noch weniger genaues Material dem übernommenen zugefügt worden, aber desto mehr sind Speculationen und systematische Versuche auf die älteren Beobachtungen gegründet worden. Nitzsch ist der einzige neuere physiologische Beobachter der Infusorien unter den Deutsehen geblieben, und seine von den Ausländern übersehenen scharfsichtigen Untersuchungen über den Darmkanal und die Augen der Cercarien, und über den Formenwechsel der prismatischen Bacillarien, wurden zum Theil durch v. B a er bestätigt, welcher auch den, von Müller (p. 88.), schon als papilla hyalina und weiblichen Geschlechtstheil angegebenen, Mund des $\mathrm{Pa}$ ramaeciums als Saugnapf wieder erkannte. In Frankreich hat D u trochet nur eine Form der Räderthierchen, aber nicht glücklich zu erläuteren versucht, Prevost und Dumas haben sich um die Kenntnifs der Verhältnisse, nicht aber um die Structur der Saamenthierchen verdient gemacht, und Duges hat nur die schon längst detaillirt beschriebene Organisation der Älchen-Vibrionen, durch gute Zeichnungen und Anatonieen vor Augen gelegt und bestätigt. In England beschränkten sich die physiologischen Infusorienbeobachtungen ebenfalls auf die Struetur der $̈$ llchen im Weitzen, welche Bauer und Home erläuterten.

Da die Beobaehter vor O. F. Müller keine feste Grenze für den Begriff der Infusionsthierehen hatten, und zum Theil Larven höherer zweiflüglieher, oder netzflüglicher Insecten und krebsartige Sehaalthiere mit untel denselben beschrieben und abbildeten, so war es nicht befremdend, dafs sic im Allgemeinen von einem Darmkanal, Mund nnd Eierstoek dieser Formen sprachen, und der erste Eindruek der microscopisehen Erscheinungen, weleher einen Mierocosmus, im Gegensatz der mit blofsen Augen siehtbaren 
Welt festsetzte, beflügelte langezeit die erhitzte Phantasie einseitiger Beobachter, und man bewunderte die Gefrälsigkeit, List und Schärfe der Sinne der Infusionsthierchen mit vielen Einzelheiten ihrer Eingeweide, deren Anwesenheit man später in Zweifel zog und gänzlich läugnete.

Buffon hielt die Saamenthierchen und Infusorien für structurlose, blofs belebte Materie, und der umsichtige Linn é verschmähte, weil er nicht im Besitz eines guten Microscops war, und wahrscheinlich auch, weil er die groben Mifsgriffe der Beobachter sah, fast alle Resultate des Microscops.

Otto Friedrich Müller, welcher gegen das Ende des $1 S^{\text {ten }} \mathrm{Jahr}$ hunderts und das seines Lebens, vor nun 50 Jahren, zuerst eine systematische wissenschaftliche Betrachtung der Infusorien versuchte, schied zunächst alles Fremdartige von den Formen, welche ihm wirklich eine eigenthümliche, bisher nicht geschiedene Gruppe der thierischen Wesen zu bilden schienen, jedoch war es ihm selbst unmöglich, eine festere Grenze für dieselbe festzustellen, als dafs er in der Vorrede zu seinem classischen Werke: Animalcula infusoria cet. p. II. erklärte, dafs er mit diesem Namen alle solche Wasserthiere verstehe, die er in den übrigen Ordnungen, besonders der $6^{\text {ten }}$ Linneischen Thierklasse, welche die Würmer umfafste, nicht unterbringen könne, und hieran schlofs er die wirklichen wenigen Aufgufsthierchen, denen er keine Organisation zugesteht, deren lebendige Beweglichkeit sich aber zu der der Thiere gesellte. Eine strengere Bestimmung des Begriffs der Infusionsthiere hat Müller nicht gegeben. Dabei geht aus seiner sehr fleifsigen und wahrhaften Arbeit hervor, dafs es ihm im Kleinen, wie Linné im Grofsen erging, dafs er nämlich die Vorzüge des allseitig entwickelnden natürlichen Systems erkannte, ohne in sich die Kraft zu dessen Ausführung zu fühlen. Müller sah die Wichtigkeit der Beachtung der inneren Structur der Infusorien und ihrer oft deutlichen grofsen Ausbildung ein, konnte es aber nicht über sich gewinnen, dieselbe zun Grunde einer systematischen Abtheilung und Übersicht zu benutzen. Mit Recht wundert man sich, wenn man in Müller's Werke liest, dafs er Thiere, deren MIundöffnung, Verdauungs - und Fortpflanzungsorgane, deren Augen sogar er umständlich beschreibt, doch mit anderen in eine und dieselbe Gattung stellt, von denen er selbst sagt, dafs sie weder einen Darmkanal, noch die weitere höhere Ausbildung des Körpers besitzen. Diese wichtigen Charaktere erzähit er nur nebenbei in der ausführlichen Beschreibung des Thieres. So stehen z. B. 
die so hoch ausgebildeten Formen der Furcularien und Räderthiere mit den weit einfacheren Vorticellen, die auf spiralförmig zusammenschnellenden Fäden sitzen, in einer und derselben Gattung Vorticella. Die Essig- und Flufs-Älchen, deren Darm und Lebendig-Gebähren er beschreibt, stehen mit den einfachsten Stabthicrchen, an welchen er keine Spur von Organen und kaum eine Spur des Lebens erkannte, in derselben Gattung Vibrio, was noch widernatürlicher ist, als wenn man die Frösche, wegen gewisser unläugbarer äufserer Formähnlichkeit, zu den Affen und Menschen gesellte. Ähnliche Beispiele geben die Gattungen Paramaecium, Kolpoda, Cercaria, aus deren letzteren allein der verdienstvolle Nitzsch schon im Jahre 1816, zwölf besondere Thiergattungen bildete, die der französische Gelehrte Bory de St. Vincent 1822, ohne jene deutsche Arbeit zu kennen, ziemlich ebenso absonderte und noch vermehrte. Auf gleiche Weise verhält es sich mit der Gattung Trichoda und fast allen übrigen. Müller trennte zwar in der Vorrede zu seinem lateinischen Werke p. VII. die Infusorien, ohne äussere noch innere Organisation, von denen mit einer weiteren Ausbildung bestimmt ab, und nannte die zusammengesetzten Bullaria (wahrscheinlich der blasenartigen inneren Structur halber), während die einfacheren den Namen Infusoria behalten sollten, allein er selbst hatte keine deutliche Vorstellung von der Structur irgend einer dieser Formen, und spricht sich in der Vorrede p. XII. deutlich dahin aus, dafs er glaube, die Infusorien nähren sich nur vom Wasser, und dafs alle Beobachtungen, welche sich auf ein Verschlingen von Nahrung beziehen, obwohl er deren selbst gemacht habe, nur aus der strudelnden, durch die Wimperı der Vorticellen erzeugten, Wasserbewegung, und aus einer Neigung zum Tasten und scheinbaren Nagen der Trichoden entstanden und auf Täuschung beruhe, dafs alle in den Strudel gezogenen Körperchen aus demselben wieder herausgeworfen werden, und er nie das wirkliche Verschlingen eines noch so kleinen Thierchens oder Körperchens beobachtet habe. Aus dicsem Grunde hielt Müller nicht für rathsam, Beobachtungen von inneren Organen zur Basis für seine Systematik zu benutzen, sondern er bediente sich nur der Verschiedenheiten des Äufseren zu Abtheilungen. Auch haben die späteren Schriftsteller den Namen Bullaria, gleich dem Autor desselben, gar nicht berücksichtigt, obwohl man die beiden von Müller vorgezeichneten Abtheilungen mit anderen Grenzen umsehrieben und anders benannt, wirklich eingeführt hat. So überliefs 
O. F. Müller, indem er 378 Arten von Infusorien feststellte, und diese nach dem Mangel oder dem Dasein äufserer Organe, und nach der Körperform in 2 gröfsere Gruppen (Familıen) und in 17 Gattungen vertheilte, bei seinem Tode im Jahre 1785 diefs Feld der Wissenschaft den späteren Forschern.

Als Systematiker benutzten hierauf Gmelin, Lamarck und Cuvier das gegebene Material ohne eigene Beobachtungen, pafsten es, der erstere seinen litterarischen Sammlungen, die letzteren den ihren Systemen zum Grunde liegenden Ideen an, und trugen zur Befestigung und Verbreitung der neuen von Linné verschmähten Lehre mehr, als zu deren weitcrer Ausbildung bei.

Einige wenige zweifelhaft neue Formen fügten im Jahre 1802 die französischen Gelehrten Girod Chantran und Bosc hinzu, aber einen neuen lebendigen Anstofs erhielt die junge Wissenschaft erst durch den ehrwürdigen Baier von Paula Schrank, welcher im Jahre 1803 im dritten Theile der Fauna boica 68 neue Infusorienarten beschrieb, und die bekannten in 4 Gattungen mehr zertheilte, wic er es schon durch frühere $A$ bhandlungen vorbereitet hatte. Nicht in gleichem Maafse ward aber durch Schrank die anatomisch-physiologische Kenntnifs dieser Thierformen befördert, sondern es leiteten ihn dieselben Principien, welche Müller befolgte, und die äufsere Form bildete überall den Hauptcharakter der Thiere, deren Structur und Entwicklungskreise ihm unbekannt blieben.

Trevïranus Biologie 2. Th. nahm 1803 den Kampf der Partheien über die generatio spontanea, welcher der scharfsichtige Müller anfangs abhold war, dann aber seine Stimme auch zuertheilte (Anim. infus. Praefatio ad fincm.), lebhaft wieder auf, und entschied sich dafür, dafs besonders die Infusorien den Beweis liefern, dafs es Organismen gebe, welche nicht aus Eiern oder Keimen entstehen, und dafs jedes Individium der organischen lebenden Körper nach dem Tode in andere und namentlich diese infusorischen Lebensformen übergehe, dafs hingegen aus anorganischen Stoffen nie lebende Organismen hervorgingen. - Dafs es im Allgemeinen eine unzerstörbare lebensfähige Materie und Lebenskraft gebe, welche erstcre, an sich formlos, auf äufsere Einflüsse unaufhörlich sich in wechselnde Formen gestalte. - Diese mit eigenen Beobachtungen vermehrte Zusammenstellung der bisherigenn Erfahrungen und Meinungen, mag wohl mit erweckend auf 
die Ideen gewirkt haben, welche 2 Jahre später Oken in seinem Buche von der Zeugung weit bestimmter aussprach.

Oken erklärte im Jahre 1805, wie es schon Buffon that, 'die Infusorien geradehin für das Material aller organischen Körper, hielt sie aber nicht, wie Buffon, für blofse structurlos belebte Materie, sondern für wirkliche höchst einfache Thiere, und unterscheidet sich von Treviranus besonders darin, daf's: er nicht die Infusorien als erste animalische Entwicklungsstufe der belebten formlosen Materie ansieht und diesè in den Schimmelformen eine erste vegetative Entwicklungsstufe zur Seite stellt, sondern er hält sie für die Materie aller organischen, sowohl animalischen als vegetaiblischen Körper selbst, welcher in ihrer Einfachheit die Form und Natur des Infusoriums zukomme, und so erklärt er denn alles Wachsen für einen Zusatz, alles Abnehmen für ein Entweichen von Infusorien. Diese Ansicht ist besonders deshalb nicht haltbar, weil der Grundsatz, dafs die Infusorien durch Vereinigung mehrerer Individuen neue Körper bildeten, von der Erfahrung nicht bestätigt wird. Zwar bilden sich durch willkührliche Vereinigung mehrerer Individuen zuweilen Haufen, aber diese Haufen lösen sich auch wieder in Individuen auf, und verschmelzen nicht weiter zu gröfseren Formen.

Im Jahre 1812 wurden Dutrochet's Beobachtungen über die Structur der Räderthierchen in die Annules du Museum zu Paris, in den XIX. Band aufgenommen, und sie bildeten eine Zeit lang die Basis für die Systematik dieser Formen, obwohl sie mehr ideal als naturgemäfs sind, und Schaeffer's und Müller's Beobachtungen über mehrere Formen derselben nicht erreichen. Sowoll La marck als Savigny, Cuvier und S chweigger schenkten ihnen Vertrauen. Nur wiesen die Systematiker die beabsichtigte Stellung zu den Mollusken zurück.

Es folgten hierauf neue Versuche zur systematischen Anordnung der Infusorien. Im Jahre 1815 trennte Lamarck in seinem Werke: Histoire naturelle des animaux sans vertèbres, die Infusorien in 2 Thierklassen. Er entfernte die einfacheren, ohne Spur einer Organisation (wie er es sich irrig dachte), zu einer eigenen ersten (niedrigsten) Thierklasse, und die mit äufsern oder innern Organen versehenen. stellte er als erste Ordnung in die zweite'schon zusammengesetztere Thierklasse der Polypen. Diese Abtheilungen, so 'richtig ihre philosophische Basis war,' sind jedoch nicht weniger. 
naturwidrig, als die von Müller. Einerseits hat Lamarck jene Thiere für einfaeh und structurlos gehalten, die es gar nicht sind, und andrerseits hat er bei den Unterabtheilungen nicht dieselbe Strenge in der Anwendurg der philosophischen Grundsätze beibehalten, und nicht ebenfalls die sichtbare und von den Bcobachtern bestäligte gröfsere oder geringere innerc Organisation zur Basis derselben benutzt. Er stellte die Vortieellen u. s. w., deren gröfscre Einfachhcit cr zugesteht, in dic Nähe der Brachionen, und wenn er auch durch Zweifcl die Kauorgane der letzteren zu entferncn suchte, so blieben doch die grofsen Eier, welche noch andcre Organe nothwendig machten. Um den Fehler der Inconsequenz gut zu machen, beging er den andern, und erklärte die Eier für Gemmen (II. p. 33.), obwohl Corti das Ausschlüpfen der Jungen aus der Eischaale schon längst beschrieben und abgebildet hatte. Die zu den ferneren Abtheilungen gewählte äufsere Körperform sammt den äufseren Organen, leiteten zu denselben Irrthümern, welche $M \ddot{u}$ üle $\mathrm{r}$ begangen hatte.

In gleichem Jahre erschien Oken's Handbuch der Naturgeschichte. Da findet man die Infusorien als die erste Ordnung der Geschlechtsthiere, oder der ersten Thierklasse, nach einem eigenen philosophischen Princip in viele Gattungen zerspalten, deren Eigenthümlichkeit nicht selten idéal ist. Besonderes Gewicht wird auch hier auf die generatio prinitiva und die Verbindung kleinerer zu gröfseren Formen gelcgt. Die philosophische ernste Consequenz hat der Natürlichkeit geschadet, aber die Organisation ist, so weit sie deutlich bekannt war, besser als von den früheren Systematikern beaehtet worden. Einige Formen sind mit richtigem Vorgefühl zu neuen Gattungen erhoben worden, in andern Fällen ist dies weniger glücklich geschehen. Vibrio aceti ist, dem wissensehaftlichen Bedürfnifs gemäfs, von der Gattung Vibrio gesondert, und nur z.u hoch, in die Gattung Gordius, gestellt worden. Eigene Beobachtungen von systematischem oder physiologischem Einflufs sind über diese Thiergruppe nicht daselbst mitgetheilt worden, und die Benutzung besonders des von. Müller gegebenen Materials hat aueh die Mehrzahl von dessen Irrthümern herbeigeführt.

Georg Cuvier, welcher in seinem bekannten elassischen Werke: $L e$ règne aninal distribué d'après son organisation, im Jahre 1817. vier grofse Abtheilungen des Thicrreichs annahm, theilte die Zoophyten, als die vierte einfaehste Abtheilung, in 5 Klassen. Die fünfte Zoophyten-Klasse und die Phys. Abhandl. 1830. 
letzte des ganzen Thierreichs bilden bei ihm die Infusorien. Diese werden in 2 Ordnungen getheilt, deren erste die noch mit vermuthlichem Darmund andern inneren unbestimmten Organen versehenen Räderthierchen unter dem Namen Rotiféres umfafst. Cuvier ertheilt, Savigny's Bestätigung der Dutroehetsehen Beobachtungen zufolge, dieser Gruppe rücksichtlich des Darmkanals die Structur der Ascidien, als ob der Mund hinten im Grunde der Scheide (bei Tubicolaria) läge, die Analöffnung aber sich vorn befände. Die Räderorgane hält er für vermuthliche Respirationsorgane. Die zweite Ordnung ist überschrieben: Infusoires lıomogènes, um sie als einen Sammelplatz der, wie er glaubt, proteischen und chaotisehen Formen der übrigen Infusorien zu betrachten, über deren Wesen er sich nur zweifelhaft äufsert, denen er aber weder Eingeweide noch einen Mund zugesteht. Es sind dieselben Formen, von denen mir gelungen ist nachzuweisen, dafs alle eine Mehrzahl von Magen, einige bis 120 besitzen.

Je unsicherer die Basis war, auf welche bis dahin die Systematiker bauten, und je ungenügender mithin die systematischen Versuche, selbst für Combinationen ausgezeichneter Naturforscher ausfielen, desto wichtiger und dankenswerther war der Beitrag zur Infusorienkunde von Nitzs ch, Professor in Halle im Jahre 1816. Es wurde durch diese Untersuchungen festgestellt, dafs die Cerearien Müller's (eine Gattung von Infusionsthierchen), so ganz verschiedenartige Thiere umfasse, dafs dieselben von Nitzsch in 12 Gattungen vertheilt wurden. Dafs Wichtigste aber war, dafs bei den eigentliehen Cercarien von ihm ein Darmkanal mit Mundöffnung und 3 schwarzen augenähnlichen Punkten, mit grofser Wahrscheinlichkeit nachgewiesen wurde. Aueh bei Cercaria viridis (welche ich später als zur Gattung Euglena gehörig, bezciehnet habe), sah Nitzsch das Auge zuerst. Hieran schlossen sich nicht minder wichtige Beobachtungen über die bisher ganz verkannte Form der Bacillarien, wobei der sehr verdienstvolle Verfasser nur auf die weniger glückliehe Idee verfiel, als gebe es pflanzliehe und thierisehe Körper, die in eine und dieselbe naturhistorische Gattung gehörten. Vielfache eigene Erfahrungen haben mir gezeigt, dafs die als unbeweglich, also pflanzlich, angesehenen Baeillarien sich ebenfalls bewegen und sich ganz an die Natur der übrigen anschliefsen, und dafs die ganz unbeweglichen nur abgestorben sind.

Im Jahre 1819 und 1820 theilte Schwe igger, damals Professor in Königsberg, sehr interessante Zusammenstellungen und Beobaehtungen über die 
niederen Thiere mit. In seinem Buche Beobachtungen über naturhistorische Reisen sowohl, besonders in den dazu gefügten Tabellen, als auch in seinem Handbuche der Naturgeschichte der skeletlosen Thiere, trennt er die Klasse der Zoophyten, welche Lamarck's Polypenklasse mit Zusatz der Infusorien entspricht (s. p. 236.), in 2 Ordnungen. Die erste enthält Thiere, welche aus einer einfachen Substanz gebildet sind, die andere solche, welche aus wenigstens 2 verschiedenen Substanzen gebildet werden, wie z. B. die Corallen. Jene erste Ordnung der homogenen Thiere theilt Schweigger in 6 Abtheilungen, von denen 4 von Müller's Infusorien erfüllt sind, während 2 den kleinen weichen und nackten Armpolypen angehören. Fast sämmtliche Müllersche Infusorien gehören aber, wie bisher, als structurlos zu der ersten Abtheilung; die zweite, welche für zusammengesetzte gliedlose Thierchen bestimmt ist, enthält nur die Essigälchen, nach der schon bekannt gewesenen, zuerst von $\mathrm{Oken}$ gewürdigten Structur, nebst den Cercarien, welche, wie sie Nitzsch kennen gelehrt hatte, Augen und Darmkanal zeigen. Die dritte Abtheilung cnthält einige behaarte von ihm unrichtig beurtheilte Thierchen ohne Räderorgane, und die vierte Abtheilung umfafst die Räderthierchen mit den Schild führenden Brachionen.

Diesen Schweiggerschen Abtheilungen, woran sich im Handbuche eine ungemein fleifsige Zusammenstellung aller physiologischen Beobachtungen bis auf seine Zeit knüpft, liegt eine erfahrungsvolle Anschauung und eine physiologische Ansicht zum Grunde, mit welcher er, die Kenntnisse seiner Vorgänger benutzend, die wahre wissenschaftliche Ansicht dieser Thierformen förderte, obwohl er den wahren Bau der Infusorien bei weitem nicht erschöpfte, ja oft auch nicht ahnete. Rücksichtlich der Ernährung und Fortpflanzung sagt Schweigger p. 245. des Handbuchs; „Infusorien bestehen blofs aus Schleim ohne irgend ein inneres Organ. Die Ernährung kann daher nicht anders, als durch die Oberfläche geschehen. Dieselbe Ernährungsweise haben auch die Infusoria vasculosa, ohne jedoch darauf beschränkt zu sein. An einigen (Cercarien nämlich) sah Nitzsch eine Saugmündung u. s. w." Rücksichtlich der Fortpflanzung sondert Schweigger die Entstchung der Infusorien von ihrer Vermelırung, als 2 geschiedene Begriffe, ab, er sagt p. 267: ,Infusorien sind organische Materie, welche bei Desorganisation thierischer, oder vegetabilischer Körper frei wird, je nach 
dem Grade des in ihr befindlichen Lebens und der Art ihrer chemischen Mischung, kommt sie als Infusorium von dieser oder jener Gestalt zum Vorschein. P. 275. desselben Werkes nimımt er als Beobachter doch die Bildung organischer Körper aus Infusorien an. Über die Vermehrung sagt er p. 249: ,, Ungekünstelt scheint jede Vermehrung der Infusorien als freiwillige Zerstückelung betrachtet werden zu können, entweder der äufseren Substanz, wie bei der Trennung der Paramaecien und Bacillarien, oder der inneren Substanz, wie bei Vibrio und Volvox." (Hieraus erkennt man, wie wenig deutlich seine Idee in Betreff der Structur des Vibrio war). Die ovalen Körper in den Paramaecien hält Schweigger p. 250. ,, nicht für Eier (wie die frühern es thaten), weil keine Befruchtungsorgane da sind, sondern für zweifelhafte Körper, die nach dem Tode der Paramaecien als Infusorien andrer Art fortleben." Ich werde zeigen, dafs die Körper, von denen Schw eigg er spricht, die Magen der Paramaecien sind.

Im Jahre 1820 vereinigte Goldfufs in seinem Handbuche der Zoologie die Essigale wieder mit den Vibrionen, und that demnach den Schritt wieder zurück, welchen man vorwärts gethan hatte, überdies bildete er nach den Abbildungen der früheren Beobachter einige neue Gattungen, und erklärte mit Schweigger die Bläschen im Innern der Paramaecien und andern Infusorien für eigene zur Bildung jener Thiere gehörige Monaden, welche nach dem Tode jener ihr selbstständiges Leben lebten.

Ich erwähne noch die Ansichten und Arbeiten ausländischer Naturforscher neuerer Zeit.

Mattéo Losano beschrieb im Jahre 1823 eine grofse Zahl neuer italienischer Infusorienformen in den Abhandlungen der Akademie zu Turin im XXIX. Bande. Die Gattung Proleus, von welcher Müller zwei, und Schrank 4 Arten verzeichnet hatten, ward zu 69 Arten erweitert, und die Gattung Kolpoda, von der NIüller 16 Arten beschrieb, und die seitdem nicht vermehrt, sondern durch Entfernen einiger Formen in andere Gattungen vermindert worden war, erweiterte Losana zu 64 Arten. Leider zeugen die ganz unbrauchbaren Abbildungen, dafs der Verfasser dieser Arbeit jede ganz unbedeutende Formverschiedenheit für Art-Charakter hielt, und weder von der Entwicklung dieser Thiere, noch von ihrer Structur richtige Ansichten hatte. 
Im Jahıre 1824 sprach Nitzsch sich im Artikel Brachionus in der Encyclopädie von Ersch und Gruber dahin aus, dafs diese Infusorien in ihrer Structur den Entomostracis glichen, was einen Gegensatz gegen Savigny's Beobachtungen bildet, aber der Wahrheit mehr gemäfs ist.

Im Jahre 1825 erschien wieder ein eigenthümlicher systematischer Versuch von Latreille, dem verdienstvollen Entomologen Frankreichs. Latreille theilt nicht mit Cuvier das ganze Thierreich in 4 Hauptreihen, sondern nur in 3. Der dritten Reihe, welche die niedrigsten Thiere umfafst, giebt er den Namen Acephala, kopflose Thiere, weil er meint, es fehle allen bisher als Entozoen, Echinodermen, Acalephen, Polypen und Infusorien verzeichneten Thieren, wenn auch von jenen einige hie und da Spuren von Nerven zeigten, doch ein eigentliches Hirnganglion. Er rechnet zu diesen auch die Ascidien. Diese Reihe der Acephalen theilt Latreille in 2 Raçen, deren erste er, weil sie sich durch eigentliche Verdauungsorgane charakterisirt, Gastrica nennt.

Die Animalia gastrica werden in 8, in 3 Verzweigungen geschiedene Klassen getheilt. Die achte Klasse, welche der dritten Verzweigung, oder den Pflanzenthieren angehört, hat 2 Ordnungen. Die erste enthält die Armpolypen, wozu die Seefedern und eigentlichen Corallenpolypen gehören, und die zweite ist nur für Räderthierchen oder Infusorien bestimmt, welche einen Darmkanal haben sollen. Die Anordnung ist ganz der ähnlich, die Schweigger mit dem Namen Monolyla ciliata belegt hatte; Latreille nennt sie aber Trichostoma. Die übrigen Infusorien, welche nicht Räderthiere sind, also bei weitem die Mehrzahl der Formen, trennt Latreille ganz ab und stellt sie als zweite Raçe der Acephalen an das Ende des Thierreichs, mit dem Namen Agastrica (magenlose Thiere), und bezeichnet sie folgendermaafsen: ,,Diese Thiere sind sehr einfach; sie zeigen keine Spur eines Darmkanals, und daher auch weder Mund noch Analöffnung. Ihre Ernährung geschieht durch Aufsaugen mit der Haut. Man kann sie mit belebten und beweglichen Eiern vergleichen, oder mit Pflanzenzellen, welche einen thierischen Charakter tragen." Die Essig- ̈̈lchen und Cercarien werden rücksichtlich ihrer Ausbildung nicht beachtet, ebenso werden die vielen zerstreuten Beobachtungen über die Structur einzelner anderer Formen mit Stillschweigen übergangen. Bei den Thierchen, welche Herr Latreille 
magenlose Thiere (Agastrica) nennt, sind, wie ich schon erwähnte, bis 120 Magen zu erkennen.

Zuletzt hat sich Herr Bory de St. Vincent der Systematik der Infusorien sehr ausführlich, aber nicht eben glücklicher angenommen. Das neueste allgemeinere ist von ihm $1826 \mathrm{im}$ Dictionnaire classique mitgetheilt worden. Er zicht für die Infusionsthiere den schon öfter, auch von Müller, verworfenen Namen Microscopiques vor, sieht sie als eine eigene zusammenhängende Klasse der Zoophyten an, und theilt dieselben Thiere, welche Müller in 2 Familien und 17 Gattungen vertheilt hatte, ohne durch neue Beobachtungen ihre Anzahl bedeutend gemehrt zu haben, in 5 Ordnungen, 17 Familien und 82 Gattungen, je nach der Anwesenheit und Verschiedenheit der äufseren Organe und der Körperform. Von der ganzen Klasse giebt der, als fleifsiger Schriftsteller sehr bekannte Verfasser dieser Arbeit folgende Kennzeichen an, welche ich mit einigen Bemerkungen begleite:

\section{B ory.}

Infusorien (Microscopiques) sind: dem blofsen Auge unsichtbare, mehr oder weniger durchsichtige Thiere ohne Glieder (membres) -

an denen man bisher weder wahre Augen, noch selbst deren Spuren erkennen konnte -

Sie können sich in allen Theilen oder in einzelnen Theilen zusammenziehen - haben sichtlich einen Tast$\operatorname{sinn}-$

ernähren sich nur durch Aufsaugung -

\section{Bemerkungen.}

Nicht wenige $\Lambda$ rten sind mit blofsem Auge wirklich deutlich sichtbar.

Viele haben schwanz - und halsförmige Körpertheile, auch andere äufsere Organe, die man kaum anders als Glieder nennen kann z. B. das männliche Organ im Nacken der Räderthiere, welches bei einigen doppelt ist, und die Räderorgane.

Viele besitzen deutliche Augen von 1 bis 12 an Zahl, meist mit rothem Pigment, meist 1 , 2 und 4.

Die Ernährung ist wahrscheinlich nirgends durch Aufsaugen, läfst sich bei der Mehrzahl aber durch ein bestimmtes Schlingen mit einem Munde nachweisen. 
ihre Erzeugung scheint sich durch Theilung oder Auswerfen von Keimen zu bedingen, wenn sie nicht aus den Urstoffen geschieht; -

sie leben nur im Wasser.
Die Fortplanzung der Art geschieht wahrscheinlich nirgends durch Theilung oder Keime, sondern diese dienen nur zur Vervielfältigung der Individuen. Vielseitig lälst sich nachweisen, dafs wirkliche befruchtete Eier gelegt werden, und bei den kleineren, der Beobachtung weniger zugänglichen Formen, spricht die Analogie vorläufig für dasselbe.

Es geht hieraus hervor, dafs Herr Bory de St. Vincent, wie die früheren Systematiker, eine innere Organisation dieser Körper entweder gar nicht annimmt, oder doch nicht für so bestimmt und richtig hält, dafs die Systematik sie speciell berücksichtigen müfste. Aus der grofsen Zahl seiner übrigen im Dictionnaire classique verstreuten ganz speciellen Mittheilungen geht aber hervor, dafs er über dieselbe im Zweifel geblieben, indem er nur historisch zuweilen und auf Autorität andrer Beobachter ihrer Erwähnung thut. Bei der ersten und zweiten Ordnung, die 52 Gattungen, also beinah $\frac{3}{4}$ aller Formen umfassen, wird bemerkt, dafs weder ein Mund noch innere Organe existiren, bei den übrigen werden Mund und Darm zwar genannt, aber nie umständlich beschrieben, und beim Arlicle Rotifére (Dict. class.) ergiebt sich, dafs der Verfasser die Räderorgane mit La marck irrig für den Rand einer grofsen Mundöffnung ansieht, und dafs er ein Herz anzunehmen geneigt ist, ja sogar als von ihm beobachtet angiebt, was offenbar nur durch Verwechslung des Eierstockes mit dem Darmkanal, und des letzteren mit einem Herzen entstanden sein kann, selbst wenn die Maxillen richtig erkannt worden wären. Hiermit hängt auch die sehr bestimmt ausgesprochene Idee zusammen, als gehöre das Räderorgan der Räderthierchen zu einem Respirationssystem, die von Cuvier zuerst, aber nur vermuthungsweise aufgestellt worden war. Selbst die Existenz der grofsen Augen des Rolifer vulgaris bezweifelt Herr B ory nach p.686. desselben Artikels.

Aus diesen kurzen Mittheilungen über die ausführliche Arbcit des Herrn Bory de St. Vincent geht hervor, dafs diese neuesten Bemühungen desselben über die ganze Gruppe der Infusorien ausschliefslich auf systematische Zerlegung und neue Zusammenfügung der bekannten Müllerschen Formen in Gattungen und Arten hinzielten, und, ohne sich auf neue Beobachtungen über Structur und Entwicklung der Formen zu gründen, beson- 
ders den Zweek hatten, alle äufseren Formverschiedenheiten scharf zu sondern, und so die Übersicht der Formen zu erleichtern. Dafs es hierbei zu einigen sonderbaren Irrthümern kommen mufste, und dafs Müllers Irrthümer dadureh noch schneidender hervortreten mufsten, war nicht zu verhindern; so finden wir denn auch Thiere, welche etwas gegessen haben, deshalb nicht blofs mit Müller für eine andere Thierart gehalten, sondern zu einer andern Thiergattung crhoben, als die Hungrigen derselben Art, denn sie hatten dadurch ein anderes Ansehen bekommen (Monas: Opluthalmoplanis). Bei andern bildet der durch Theilung geschiedene Vorderthcil andere Arten und Gattungen, als der Hintertheil und das Ganze, jedes für sich. Die Jungen bilden, zuweilen selbst mchrfach, andcre Gattungen, als die Alten einer und derselben Art, und die verschiedencn Verwandlungen eines und desselben Thieres sind sogar in verschiedene Reiehe der Natur gestellt worden (Yorticella, Urceolaria u. s.w.). Dieses Unterlassen von Entwicklungs - und Structurbeobachtungen entschuldigt auch die Wiederholung der Müllerschen Infusorienabbildungen im Dictionnaire classique, obwohl sie für das Bedürfnifs einer neuern Systematik nicht mehr ausreichend sind.

Aus cinem mehr physiologischen Gesichtspunkte, erhielt die Wissensehaft in der neuesten Zcit Beiträge zur Kenntnifs der niedern Thiere vom Professor v. Bacr aus Königsberg (Nova Acta Acad. Caes. Leop. Carol. X.2.p. 702. 1826 -1827.), welche für die Infusorien rein systematisch sind, aber nicht ohne Einflufs blieben. Von Baer bemerkt p. 337 : , Wer wollte wohl ernstlich läugnen, dafs auch die niedrigste Thierklasse ,, übereinstimmend mit den übrigen, nach der Organisation bestimmt werden ,, müsse? Da nun der erste wesentliche Schritt zu einer gröfseren organischen ,, Ausbildung des Thierleibes wohl ohne Zweifel in der Entwicklung des Ge,,gensatzes einer inneren verdauenden Fläche und einer äufseren begrenzen, , den Fläche besteht, so kann man Lamarek wohl beipflichten, wenn er ,, das Fehlen einer verdauenden Höhle und einer Mundöffnung als Charakter ,, der ersten Thierklasse betrachtet." Nach diesem sebr cinfachen und vollkommenen richtigen Grundsatze hcifst es weiter: ,, Allein man darf diese , erste Thierklasse, die auch die Benennung Infusoria mit einer anderen, ,, etwa Protozoa nach Goldfufs, vertauschen müfste, nicht so begrenzen ,, wie Müller scine Infusorien begrenzt hat." - , Es scheint uns vielmehr, , dafs viele Hauptformen der niedern Thiere ihre Prototypen unter den 
„,Infusorien finden. Da giebt es faden- und kugelförmige, kreisrunde und , ,änglichflache." Nach p. 739. wird nun zuerst festgesetzt, dafs man unterscheiden müsse, ,, verschiedene Organisationstypen von den verschiedenen , Stufen der Ausbildung des Thierkörpers." Nachdem diese Idee durch Beispiele aus den verschiedenen Formen des Thierreichs erläutert worden, liest man p. 746: , Es scheinen deutlich 4 Haupttypen sich zu offenbaren, der „, Typus der in die Länge gezogenen gegliederten Thiere (der Längentypus), „, der Typus der strahlenförmigen (der Flächentypus), der Typus der Mollus, , ken (der Massentypus) und der der Wirbelthiere. Die letzteren vereinigen , , den gegliederten - und Molluskentypus in sich, in ihren animalischen und „, vegetativen Formen. Ja man könnte im Kopfe noch eine Andeutung des ,, strahlenförmigen Typus erkennen." Hierauf macht Professor Baer auf die Ähnlichkeit seiner Gruppen der Thiere mit der von Cuvier's Regne animal aufmerksam; und tadelt nur, dafs Cuvier an den gegliederten Thieren und den Mollusken aufser dem Typus ihrer Organisation, noch einen gewissen Grad der Ausbildung verlangt, und nennt diefs eine Forderung, die man nur an die einzelnen Klassen machen sollte, dessen Folge sei, dafs alle niedrig organisirte Thiere der strahligen Form anheim fallen, obgleich sehr viele nicht strahlig gebaut seien. Er erklärt sich ferner: ,, man darf von diesen „,Prototypen nicht verlangen, dafs die Einzelheiten der Theile z. B. des ,,Darm - und Nervensystems so seien, wie auf höheren Stufen; denn D arm , und Nervensystem sind nicht immer da; wenn nur der allge„,meine Charakter sich erkennen'läfst (pag. 747.)." So soll sich durch Linéola (Vibrio lineola), Vibrio (aceti), Gordius, Nais, der Weg zu den Ringwürmern, Insecten und Krebsen finden; durch $C$ yclidium und Berenice zu den Rhizostomen und L a marck's Stelleriden; durch Bursaria endlich und Vorticella versatilis zu den Mollusken; die Wirbelthiere sollen keinen Repräsentanten des Typus bei deı Infusorien haben. Hierauf hat denn Herr v. Baer die Gruppe der Infusorien ganz aufgelöst, indem ihre Formen als unvollkommene Vorbilder und Prototypen der übrigen Thierabtheilungen angesehen und ihnen zugesellt werden sollen.

Die Entwicklung dieser Ansichten zeugt überall von des Verf. bekannter geistreicher Beobachtung der Natur, aber am wenigsten glücklich waren gewifs die ebengenannten systematischen Ideen. Schwerlich dürfte die Wissenschaft die niedersten, und am Ende alle Thiere nach dem Längentypus, Phys. Abhandl. 1830. 
Flächentypus und Massentypus, was doch mit einfacheren Worten nur heifst, nach dem sie lang, breit oder dick sind je abtheilen, Darm- und Nervensystem als untergeordnet und Nebensache ansehen wollen, und anstatt die bei den Infusorien vielfach erkannten Spuren einer Organisation beobachtend zu verfolgen, und weiter in einen organischen Zusammenhang mit den durch sie bezeichneten Thierkörpern zu bringen, einer Idee zu Gẹfallen, die Beobachtung für vollendet ansehen, die Organisation der Thiere aber für unvollständig und rudimentarisch halten.

Weit wichtiger ist es gewifs, dafs Herr v. Baer die Aufmerksamkeit auf die Mundstelle des Paramaeciums leitete, obwohl er selbst, seiner philosophischen Ansichten halber, pag. 756. wieder irre daran wird, .und dafs er von Neuem auf Eichhorn's Beobachtung der gröfseren Ausbildung von Trichoda Sol hinweist. Was aber die Vereinigung der mundlosen Acalephen mit den Infusorien betrifft, welche er vorschlägt, so würde ich nicht unbedingt dazu rathen. Wer viele Acalephen zu sehen Gelegenheit hatte, wie ich sie selbst gehabt habe, weifs aus Erfahrung, dafs man mehr verstümmelte findet, als vollständig erhaltene, die aber doch ebenso, wie die vollständigen, ihre Lebensthätigkeit fortsetzen. Demnach dürfte vielmehr anzurathen sein, solche Formen, welche bei sonst anwesenden verbindenden Charakeren etwas ihrer Familie wicderstrebendes an Einfachheit zeigen, als unvollkommen beobachtet anzusehen, und vielmehr zu einer genauern Beobachtung derselben aufzufordern, als sich mit deren systematischen Stellung zu bemühen.

Mit ganz ähnlichen Idcen trat, fast gleichzeitig, aber doch um 1 Jahr später (deñn v. Bacr's Abhaudlung ward 1826 abgeliefert, wie die Vorrede zeigt) Dr. Leuckart auf, und seine kleine Schrift: Versuch einer naturgemäfsen Eintheilung der Helminthen u. s. w. 1827. ist, wie jene interessante Arbeit des Prof. Baer, voll von nützlichen Einzelheiten und Beobachtungen für die Erweiterung der Naturgeschichte. Die Idee der Prototypen, welche man iu dieser Rücksicht nicht glücklich nennen kann, herrscht in ihr ebenfalls; und pag. 41. findet man ibre Anwendung auf die Zerstörung der Infusoriengruppe, so wie auch pag. 40. die Metamorphose der Infusorien in Conferven und andere Algen gebilligt, ja sogar in der Anmerkung auf die Pilze übergetragen wird. Neues, was aus eigener Beobachtung für diese Formen gegeben wäre, findet sich nicht, sondern Bory de St. Vineent's Arbeit über die Infusorien ist überall zum Grunde gelegt. 
Die besondere Bezichung der Arbeit auf die Eingeweidewürmer stellt eine Gruppe der Infusorien als Crypthelminthen auf, wie schon zuerst Götze und dann von Olfers es vor längerer Zeit angeregt hatten, welche Idee von Le uckart jedoch auf neue Weise viel specieller ausgeführt wird (p. 17.).

An diese Schriften schliefst sich nun Reichenbachs Arbeit in seiner Ausgabe von Hemprichs Grundrifs der Naturgeschichte im Jahre 1829. Was jene systematisirenden Schriften vorgeschlagen hatten, wird durch Reichenbach in einem Lehrbuche der Naturgeschichte wirklich eingeführt. Die Gruppe der Infusorien wird völlig aufgelöst. Würmer heifsen die erste Thierklasse. Saamenthierchen und Blutkügelchen bilden die erste Familie der Vermes Agami, und heilsen Prololii. Die zweite, dritte und vierte Familie bilden die Entozoen. Die zweite Thierklasse ist überschrieben: Mollusca. Die erste Ordnung derselben enthält als Mollusca radicita: Corallen, Tubularien, Hydren, Actinien, Medusen und Echinodermen. Die zweite Ordnung heifst Mollusea palliala, und umfafst Infusorien, Salpen, Ascidien, Testaceen, Cirrhopoden und Gasteropoden. Die Infusorien werden zum Theil unbedeckte Acephalen genannt. Proteus M. schliefst sich an Salpa und die Ascidien. Die Glockenpolypen (Vorticella M.) sind weit getrennt, und bilden die erste Gruppe der Cephalopoden. Clio macht den Übergang von Vorticella zum Nautilus und Dintenfisch.

Zwischen die übrigen Formen der Müllerschen Infusorien tritt die zweite Oberabtheilung des Thierreichs, die der Gelenkthiere. Diese zerfallen in Vielgelenkthiere (Polyneria) und Kerbthiere (Insecta). Die erste Ordnung der Polymerien sind die Ringelthiere (Annulala), welche mit $V_{i}$ brio aceli anfangen, und durch Gordius zu Planaria und Lumbrirus übergehen. Cercaria, Nais, Nereis und Aplurodia bilden die vierte Familie derselben Thierordnung. Die zweite Ordnung umfafst die Krebsthiere (Carcinoidea, Crustacea) welche mit den Räderthierchen (Rotifer), als ihren nackten Formen anfangen, wozu Cypris, Cylleriua und Zoë gezogen werden.

Da diese Anordnungen nicht neue umständliche Beobachtungen einer ausgebildeten Structur der Infusorien aussprechen, sondern vielmehr die Idee der Prototypen verfolgen, so haben offeibbà die angezeigten Schriften einen bedeutenden Einflufs auf diefs Handbuch ausgeübt, wodurch Hemprichs Ansichten in ihrem Grunde verándert sind. Der grofse Fleifs des über mein Urtheil hinausragenden, mir befreundeten Botanikers ist, wie 
überall, so auch hier klar zu erkennen, aber Göthe sagt, dafs ihm Schiller einst geantwortet habe: Wie kann jemals Erfahrung gegeben werden, die einer Idee angemessen sein sollte? Morphol. I. p. 95.

Die neuesten Bereicherungen sind von Herrn Morren aus den Niederlanden, welcher in diesem Jahre aus der, von Bory de St. Vincent mit einigen $M$ üllerschen Infusorien gebildeten Gattung Lciodina 2 Gattungen gemacht hat, allein da die bekannteren der von ihm beschriebenen Thiere meiner Erfahrung nach Räderorgane, Darmkanal, Augen und Nerven besitzen, der Abhandlung zufolge aber von dem allen nichts, nicht einmal der Darmkanal erkannt wurde, so kann die Arbeit nicht von Einflufs auf die Systematik sein.

Eben so verhält es sich mit einer ganz erstaunenswerthen Menge neuer Infusorien von Herrn Losana in den Memorie di Turino im letzten XXX. Bande, wo wieder 50 Arten der Gattung Volvox, 77 Arten der Gattung Cyclidium, 28 Arten der Gattung Paramaecium und 26 Arten einer neuen Gattung Oplarium beschrieben uud abgebildet werden, von denen nur wenige der Wissenschaft zu Gute kommen dürften, da ihre Charaktere sich nur auf die äufsere Form gründen, welche wechselnd ist, und die $\mathrm{Ab}$ bildungen ganz ungenügend sind. Bydragen door van Hall caet. V.2.

Somit glaube ich den jetzigen Stand der Kenntnisse in dieser Abtheilung der Naturgeschichte im Wesentlichen bezeichnet, die vielseitigen Bemühügen ausgezeichneter neuerer Gelehrten zur Aufhellung des Gegenstandes dargethan und eine Vergleichung des Neuen und Einflufsreichen meiner folgenden Beobachtungen übersichtlich und leicht gemacht zu haben

\section{I.}

Über die Ernährung und deren Organe bei den Infusorien nach neuen Beobachtungen.

Bisher stimmten die neuesten Schriftsteller und Beobachter darin überein, dafs die Infusorien durch Aufsaugung mit ihrer ganzen äufsern Fläche sich nährten und dafs wenige mit Mundöffnung versehene zusammengesetztere sich neben der allgemeinen Resorbtion durch einen eigenen inneren Apparat, aber nicht ausschliefslich durch diesen ernährten. Ich gehe nun 
zur Beschreibung der Ernährungsorgane der einfachsten Infusorien über, und spreche zuerst den Satz aus:

,Alle wahren Infusorien, auch die kleinsten Monaden, ,, sind nicht structurloser Schleim, sondern organisirte, ,, wenigstens mit Mund und innerem Ernährungsapparat ,, deutlich versehene Thierkörper.

\section{Beobachtungsmethode.}

Bei den Räderthieren waren zwar die neuesten Beobachter darin übereinstimmend, dafs man ihnen innere Organe, und namentlich einen Darmkanal, und zuweilen einen Eierstock zugesteht, allein noch sind die Meinungen widersdrechend rücksichtlich der Form, und Herr Bory de St. Vincent spricht nur zweifelhaft von derselben und ohne klare Ansicht. Herr Savigny, der feine Zergliederer der Ascidien, fand die Structur der Räderthiere, wahrscheinlich durch Dutrochet verleitet, analog der der Ascidien, und der ebenfalls trefflich beobachtende Nitzsch schliefst die Brachionen den Entomostracis an. Zufolge Savigny's Beobachtungen, welche Guvier in seine Systematik des Thierreichs aufnahm und über die ganze Familie ausdehnte, liegt die Analöffnurg vorn, der Mund im Innern einer sackförmigen Bekleidung des Körpers nach hinten. Die von Nitzsch beobachtete Analogie der Entomostraca würde dies umkehren. Baker und viele ältere Beobachter sprachen schon deutlich vom Darm der Räderthiere, und Müller sah sogar seine Spur bei Paramaecium und Arten der Gattung Leucophra. Die Abbildungen jener älteren Beobachter entsprechen aber ihren bestimmten Ausdrücken nicht und zeugen von der Unklarheit des Beobachteten. Feinere Infusorien erkannten alle Beobachter für belebten structurlosen Schleim, und einige bewiesen sogar dessen naturgemäfse Nothwendigkeit.

Nach vieljährigen Beobachtungen dieser kleinen, für die Grundsätze der Physiologie, und da sie in so unbegreiflicher Menge vorhanden sind, wahrscheinlich für den Haushalt der Natur höchst wichtigen Thiere bin ich erst spät auf ein sehr nahe liegendes Nittel gekommen, durch welches es mir bald gelang, mit Sicherheit über den innern Bau derselben zu entscheiden, und dies Resultat ist es hauptsächlich, welches ich der Akademie vorzutragen die Ehre haben wollte. Ich habe durch Anwendung von färbenden orga- 
nis chen Substanzen als Nahrungsmittel für die Infusorien bewirkt, dafs sich bei allen von O.F. MIüller richtig verzeichneten Gattungen dieser Thiergruppe ein deutliches zusammengesetztes Ernährungsorgan erkennen liefs. Zwar wurde schon in früherer Zeit, gleich Trembley's Versuchen mit Färbung der Armpolypen, auch mit diesen Thierchen von Gleichen ein Färbeversuch angestellt; diescr blieb aber mehr ein Scherz und ohne Erfolg für die Kenntnifs der Structur dieser Wesen. Schon vor 10 Jahren versuchtc ich öfters durch. Farbesubstanzen den Ernährungsapparat der Infusorien kenntlich zu machen, es mifslang jedoch immer, weil ich nur metallische, erdige oder gekochte Farbesubstanzen wählte, welche entweder die Thiere bald tödteten, oder zu Nahrungsstoffen für dieselben nicht geeignet waren. Ich wendete auch Indigo und Lackfarbe an, bedachte aber nicht, dafs zubereitete erkäufliche Farben dicser Art mit Blciweils versetzt zu sein pflegen. In der neucren Zeit ficl mir ein, dafs dieser Zusatz wohl das Hindernifs sein könnte, und ich stellte deshalb Versuche mit reiner Indigofarbe und reinem Karmin an. Dies gelang aufs Glücklichste. Im Zusehen verzehrten die gestielten Vorliccllen diese Nahrung und füllten in wenigen Minuten zu meiner Überraschung eine Anzahl runder kleiner Magen damit an, welche mir bis dahin nie deutlich geworden waren. So erkannte ich allmählich in kurzer Zeit bei allen Thierchen, welche mir Infusionen und Frühjahr reichlich boten, den Verlauf ganz bestimmter Ernährungsorgane. Es bedarf mithin zu diesen Versuchen organisclier Farbesubstanzen, welche sich nicht zu innig, nicht chemisch mit dem Wasser verbinden und die das eigentliche Element der Thiere, das meteorische Wasser, nicht verändern, sóndern nur, als mechanisch beigemischte sehr feine Körperchen, trüben. Viele sogenannte Tuschfarben sind mit Bleiweifs $\left({ }^{1}\right)$ versetzt, und werden darum von den Thierchen oft ganz, oft lange Zeit verschmäht. Reiner Indigo, Karmin und Saftgrün sind 3 sehr durchsichtige, im Microscop deutlich zu erkennende Farben, welche mir den oft geprüften Dienst nie versagen.

Rücksichtlich des Instruments jst zu bemerken, dafs ich ein Microscop von Chevallier besitze, und mit demselben diese Beobachtung leicht zur

( $\left.{ }^{1}\right)$ Man erkennt Bleiweifsfarben dadurch sogleich, dafs man ein wenig aurgelöste Farbe auf ein Glastăfelchen bringt und etwas Wasser darüber ablaufen läfst. Das schwere Weifs bleibt als Bodensatz liegen. 
klaren Anschauung bringen kann. Nur bei einer Vergröfserung von 300 bis 400 mal im Durchmesser (die Chevallierschen Microscope für 80 Rthlr. erlauben eine Vergröfserung von 800 mal in Durchmesser), erkennt man die Infusorien so deutlich, dafs ihre Structur mit Hülfe jener Methode ganz sichtbar wird. : Mit geringern, obwohl klaren, oder mit unklaren Vergröfserungen habe ich mir oft fruchtlose Mühe gegeben, es andern deutlich zu machen, obwohl ich es selbst erkannte. Das unmittelbare Sonnenlicht mufs man vermeiden. Am Stiele festsitzende Glockenpolypen (Vorticellen) sind für die erste Beobachtung die besten Formen. Übung lehrt auch die beweglichsten Thierchen belauschen, indem man mit der Hand das Objectglas so bewegt, dafs ihr Lauf nie aus dem Gesichtsfelde geht. Ein Augenblick der Ruhe giebt bald ein fafsliches Bild, das man bis zur Klarheit sich wiederholt.

Aufser vielen systematischen Resultaten sind besonders folgende anatomische und physiologische von mir erlangt worden:

1. Es existirt keine Aneignung fester oder gefärbter flüssiger Stoffe durch die allgemeine Körperbedeckung. Die allgemein angenommene Hautresorbtion flüssiger ungefärbter Stoffe bei den Infusorien läfst sich weder factisch beweisen, noch jetzt mehr wahrscheinlich machen, da eine deutliche Aufnahme fester Stoffe und Ernährung durch ein Schlingen mit einem Mund ihre Nothwendigkeit entfernt. Auch nach wochenlangem Aufenthalte mehrerer Generationen in gefärbtem Wasser bleibt der Körper durchsichtig, während die Magensäcke im Innern von Nahrungsstoff strotzen.

2. Alle kleineren Infusorien, deren Gröfse nicht unter $\frac{1}{1500}$ einer Pariser. Linie ist, also nicht durch Kleinheit sich der Kraft unserer optischen Instrumente entzieht, zeigen, wie die gröfseren, unter günstigen Verhältnissen einen inneren mit Farbe angefüllten Ernährungsapparat. Bei den Monaden läfst sich ein Mund, oft mit Wimpern, unterscheiden, mit welchem 2 bis 6 Magen in Verbindung stehen. In Monas termo, deren Gröfse bis $\frac{1}{1500}-\frac{1}{2000}$ Linie beträgt $\left({ }^{1}\right)$, erkannte ich noch 4 rund angefüllte Magen, und glaubte sogar auch zuweilen 6 zu sehen, welche ersteren noch nicht die Hälfte des Thierchens nach hinten einnahmen. Ein solcher Magen der Monas termo ist demnach etwa $\frac{1}{6000}$ einer Linie grofs. Wahrscheinlich hat sie einen Kranz von

(') Ich messe mit einem Glasmicrometer von Dollond, welches einen $\frac{1}{10000}$ Zoll direct angiebt. 
10 bis 20 Wimpcrn um den Mund, wie Monas pulvisculus und die übrigen gröfseren MLonaden, und giebt man den einzelnen Farbetheilchen, womit sich die Magen allmälig füllen, auch keine grofse Zahl, so ist es doch aller Wahrscheinlichkeit gemäfs, dafs jeder sich durch eine Mehrzahl von Atomen füllt. Ist aber jeder Magen nur durch 3 Farben - Atome gefüllt, welche der. sichtbaren Rundung wegen wenigstens anzunehmen sein müfsten, so giebt das schon einen Beweis für die Existenz von materiellen, frei im Wasser schwimmenden festen Theilchen, welche wir nicht läugnen können, die $\frac{1}{36000}$ einer Linie, oder $\frac{1}{432000}$ eincs Zolles im Durchmesser haben. Es ist ferner meinen Beobachtungen zufolge sehr wahrscheinlich, dafs die Gattung Monas und mehrere an sie angrenzende gar nicht als eigene Thierformen aufzustellen sind, sondern dafs sie die Jugendzustände der Kolpoden, Paramaecien u. s. w. sind, die, wie die Rhizomorphen und Byssen der Pilze, oft, aufser einer Theilung, gar nicht zur Entwicklung kommen mögen. Ihre Entwicklung mag von der günstigen chemischen Beschaffenheit des Wassers u. s. w. abhängen. Ist aber diese, bis jetzt noch hypothetische, Behauptung nicht gegründet, oder nur auf einen Theil derselben anwendbar, giebt es also selbstständige Thicre so geringer Gröfse, so fordert die Analogie, dafs wir Eierstöcke bei den Monaden annehmen, wie sie bei Kolpoda sind. Nun verhalten sich die Durchmesser der fadenförmigen netzartig verstrickten Fasern des Eierstockes der Kolpoda, welche die Eier enthalten, oder aus aneinander gereiheten Eiern bestehen, zum Mutterthiere, wie $40 \mathrm{zu}$ 1, daher dürften wir junge Monaden zu suchen haben, welche $\frac{1}{60000}$ einer Linie oder $\frac{1}{720000}$ eines Zolles im Durchmesser haben und auch Magen besitzen. Ich übergehe die Wände dieser Monaden - Magen und spiele nicht weiter mit Zahlen, öffne nur das Gesichtsfeld in diese Tiefe des organis chen Lebens.

Diefs von Monas termo. Monas lens von Müller hat diesen Namen nur in der Fastenzeit, wenn sie ganz nüchtern ist, hatte sie abcr etwas gespeist, so nannte sie Müller Monas atomus, und Bóry de St. Vincent stellte die gesättigten in einen höheren Rang, in die Gattung Ophthalmoplanis, indem er den Mlagen als ein Auge bezeichnete. Die hungrigen liefs er in der Gattung Monas.

Bei den Gattungen Enchelys, Paramaecium, Kolpoda caet. existirt ein den ganzen Körper durchlaufcnder, mit vielen Blindsäcken versehener Darmkanal in Form einer Traube, zuweilen gerade, zuweilen spiralförmig gekrümmt. 
Die Gattung Enchelys hat vorn eine Öffnung mit Wimpern und dic Analöffnung am entgegengesetzten Ende. Die Gattung Paramaecium hat den ebenfalls mit Wimpern besetzten Mund in der Mitte ihrer Körperlänge, und daneben nach hinten zu, nicht am Ende, dic Auswurfsöffnung. Die Gattung Kolpoda besteht aus sehr verschiedenen Thieren. Kolpoda cucullus hat die Structur der Paramaecien. Kolpoda cucullulus hat eine schiefe grofse, von einer gewimperten Lippe überragte Mundöffnung, wodurch sie sich an die Formen der Gattung Trachelius von Schrank anschliefst, und, wie diese, ebenfalls eine hintere Auswurfsöffnung. Sie ist übrigens .ein und dasselbe Thier mit Trichoda aurantia MIüller, welche nur den Vorzug hat, dafs sie etwas Pomeranzenfarbiges zu sich genommen. Der abstechenden Farbe wegen, sind bei der gesättigten die Wimpern deutlicher zu erkennen, daher hat sie Müller unterschieden, und Bory de St. Vincent aus ihr̈, mit anderen sehr verschiedenen Thierarten, die Gattung Plagiotricha gebildet. Bei all den genannten Formen sind die Blindsäcke des Darmkanals, oder die Magen, bisher entweder mit Müller für Eier, oder mit B ory de St. Vincent für einen zweiten organischen Urstoff, oder mit $\mathrm{S} c h w e i g g e r$ für innere zur Individualität des Thieres gehörige, nach dem Tode desselben aber frei werdende Monaden u. dergl. gehalten worden. Ich zählte solcher beliebig blau, roth, oder grün sich im Zusehen anfüllender Blindsäcke bei Paramaecium Chrysalis und Aurelia 100 bis 200, und sah noch Raum für andere. Unangefüllt sind diese Blindsäcke, wegen farbloser Durchsichtigkeit, wegen fadenförmig zusammengezogener Form und kleinen Durchmessers nicht zu unterscheiden, jedoch kann sie das Thier auch mit Wasser füllen, und dann erscheinen sie als die farblosen Blasen, welche wohl die meisten bisher für Eier, oder verschluckte Monaden hielten. Ihre Veränderlichkeit in Zahl und Form, welche Schweigg er über ihre Natur zweifelhaft machte, ist nun wohl zu begreiffen. Angefüllt mit festem Nahrungsstoffe erscheinen diese Magensäcke wie abgeschlossene Kuggeln, indem der Verbindungskanal, welcher zum Darm geht, sich zuschnürt und durchsichtig wird. Auch sind die Magensäcke einer willkührlichen Ausdehnung fähig, und füllen sich bei Raubthieren daher zuweilen mit ganz unverhältnifsmäfsig grofsen Stäbchenthieren und dergl. Wird einer stärker ausgefüllt, so verhindert seine Erweiterung, dafs die benachbarten gefüllt werden, daher sieht man immer mehr Magen, wo dieselben kleiner und gleichförmiger erscheinen, weniger, wo einzelne gröfser Plyss. Abhandl. 1830. 
sind. Die Analöffnung erkennt man leicht und mit Überzeugung durch die Ausleerungen gesättigter Thiere.

Die Gattungen Trichoda, Leucophra, Kerona von Müller haben dieselbe Structur. Ihre Trennung von Bory de St. Vincent ist meist unglücklich und naturwidrig. Nur die Stellung des Mundes und der Auswurfsöffnung, nicht die vielen Abänderungen unterworfene Körperform giebt Charaktere, wo nicht verschiedenartige deutliche äufsere Organe zu Hülfe kommen. Bory's Gattungen Ploesconia, Coccudina u. dergl. sind ganz mit Unrecht zu den Brachionen gestellt. Sie gehören zu den Polygastricis.

Eine eigenthümliche Organisation haben die Vorticellen, welche auf spiralförmig zusammenschnellenden Fäden sitzen. Sie haben keine Öffnung in der Mitte ihres Wirbelorgans, wie man allgemein glaubte, sondern sie haben seitlich am obern Rande eine Grube, in der sich Mund und Analöffnung befinden. Der Darm mit vielen (ich zählte bis 36) Blindsäcken versehen, verläuft zirkelförmig im Körper. Das Wirbelorgan besteht aus 2 Kreisen von Wimpern. Der Stiel hat bei vielen Arten einen inneren Spiralfaden, bei andern nicht, bei einigen ist er gerieft. Der Gattung Tickel von Oken, oder Opercularia von Goldfufs, welche man aus Eichhorn entnommen, liegt eine Täuschung zu Grunde. Sie haben keinen Deckel, sondern der allen gestielten Vorticellen gemeinschaftliche mittlere Discus hebt sich nur bei ihnen mehr, weil sie den Mund weiter aufmachen, als andere, den man daher auch deutlicher sieht. Bei der Gattung Stentor (Vorticella polymorpha, stentorea), sah schon Müller den Verlauf des Darmkanals, erkannte ihn aber nicht.

3. Aufser dem zusammengesetzten Ernährungsapparat sind diese kleineren Infusorien mit einer zelligen Masse erfüllt, welche Kolpoda cucullus in Absätzen durch die Analöffnung auswirft, und die ich für einen Eierstock halten zu müssen glaube. Ich rechne zur Eierstockausscheidung auch das bekannte plötzliche Zerfliefsen der lebendigen Infusorien in einen feinkörnigen Schleim. Der Tod der Coccus-Mütter giebt eine entfernte Analogie für diese Erscheinung, die nicht krankhaft sein kann.

4. Aus meinen Beobachtungen über die Entwicklung der Infusorien ergiebt sich, dafs dieselbe grofse Formverschiedenheiten bedingt, welche zwar einen festen Cyclus haben, bisher aber ganz unbeachtet blieben, und zu grofsen Irrthümern Anlafs gegeben haben. Ich habe mich überzeugt, dafs 
12 Müllersche Arten der Gattung Vorticella, nur verschiedene Zustände eines und desselben dreizehnten Thieres sind, und aus diesen sind von Lamarck, Schrank und besonders B ory de St. Vincent sechs verschiedene Gattungen gebildet worden, nämlich die Gattungen Ecclissa, Rinella, Kerobalana, Urceolaria, Craterina und Oplırydia, welches verschiedene Zustände der Vorticella convallaria sind. Nur für die Gattung Oplirydia bleibt die zufällig mit hineingezogene, von den übrigen ganz abweichende Vorticella versatilis Müller, eine besondere Form. Aus diesen, jetzt nicht weiter auszuführenden Mittheilungen ergiebt sich wohl schon hinlänglich, dafs die ganze Systematik der Infusionsthiere einer radicalen Reform bedarf.

Ich habe bisher nicht von den Räderthierchen gesprochen, weil diese eine eigene natürliche Thierklasse zu bilden scheinen. Ihre Beobachtung hat mir ebenfalls vielen Stoff zu Mittheilungen von grofsem Interesse gegeben, welche ich durch Erläuterung der Structur der gemeinen Hydatina senta (Vorticella senta Müller), als Typus, übersichtlich machen will, wobei ich nur bemerke, dafs ich viele Resultate durch wirkliches Zerlegen dieser kleinen selten $\frac{1}{6}$ Linie grofsen Thierchen, mit dem Messer gewonnen habe, obwohl sich vieles schon mittelst der Durchsichtigkeit des Körpers, nur nicht so zur Überzeugung erkennen läfst.

\section{I.}

Muskularsystem der Iydatina senta.

Der Körper der HJdatina senta besteht aus einer doppelten durchsichtigen Membran, einer nackten und weichen äufsern und einer innern. Die äufsere Haut ist einfach und mit der innern vermuthlich durch einen durchsichtigen, sehr dehnbaren Zellstoff verbunden, dessen Anwesenheit anzunehmen nothwendig erscheint, wegen der oft eintretenden Entfernung der beiden Membranen durch die Muskelwirkung, und ihrer erfolgenden gleichartigen Wiedervereinigung. An die innere Membran heften sich 4 Paar strahlenförmig, von den entgegengesetzten Enden des Thieres ausgehende Muskeln, welche deutlich bandförmig und gestreift sind, und sich mit erweiterten Enden in der Mitte des Thieres anheften. Diese 8 Muskeln sind ihrer Lage nach:

\section{Ein oberer Rückenmuskel,}


Ein oberer Bauchmuskel,

- unterer

- oberer rechter Seitenmuskel,

- unterer -

- oberer linker Scitenmuskel,

- unterer -

Die 4 obern oder vordçrn Muskeln entspringen am breiten Kopftheile, zwischen den Scheiden der Räderorgane, so dafs der Rückenmüskel etwas mehr gegen die Mitte, die übrigen näher am Rande entspringen. Die 4 untern oder hintern Muskeln heften sich ans hintere Ende der Bauchhaut, da, wo die Schwanzzange hindurchgeht. Der Vereinigungspunkt der 4 Muskelpaare, wo sich ihre erweiterten Enden in der Längenrichtung an die Bedeckungen heften, ist zwischen dem vierten und fünften Zweigpaare des Rückengcfäfses, genau in der Mitte des Thieres. Bei Eosphora Najas sind die Ansätze noch länger, und erstrecken sich vom zweiten Gefäfspaare bis zum sechsten, auch bei Rotifer und Philodina sind sie sehr lang: Überdiefs gehören dem Muskelsystcm noch 17 Scheiden für die Räderorgane, welche um den Mund im nicht völlig geschlossenen Kreise liegen, und mit deren Hülfe die Wimpcrn bewegt oder eingezogen werden. Es sind 9 äufsere und 8 innere. Auf ähnliche Weise wirken 2 Muskelscheiden, welche die beiden Glieder der Schwanzzange umhüllen. Sämmtliche Muskelscheiden sah ich deutlich durch feine Bänder, mit ihrem Grunde an die innere Körperhaut befestigt. Vier dicke und kurze Muskelparthieen, welche den freien Schlundkopf bilden, ein Kranzmuskel der Cloake und ein Muskelorgan als Saamenschneller, beschliefsen die Reihe dieser Gebilde, soweit sie mir bis jetzt anschaulich wurde. Die Zangenbewegung der Schwanzzange scheint nur durch kräftiges Einziehen und Ausstrecken bewirkt zu werden. Ausdehnung scheint Erschlaffung zu sein.

II.

- Das Gefälss ystem der Hydalina senin.

Man erkennt ohne Schwierigkeit in diesem Thiere 9 Queerlinien, welche ebensoviel Körperringe zu bilden scheinen, wie wir sie bei den Gliederwürmern zu schen gewolnnt sind. Bei schärferer andauernder Beobachtung erkennt man, dafs diese Queerlinien nur der innern, nicht der äufsern 
Körperbedeckung angehören, und dafs sie einen Gefäfsdurchmesser haben. Ehe man sich noch zugesteht, dafs sie Gefälse sind, ist man geneigt, sie für Queermuskeln zu halten. Die unverhältnifsmäfsige Zartheit des Durchmessers aber, gegen die Stärke und deutliche streifige Zusammensetzung der Längsmuskeln, denen sie entgegenwirken sollten; die grofse Entfernung der zarten Doppellinien von einander, und ihre Verbindung durch einen feinen Kanal in der Mitte des Rückens, welchen letzteren man durch die Mund-und Afterlage erkennt; der gröfsere Durchmesser derselben in der Nähe des Längskanals, und die Analogie anderer niederer Thiere, erlauben und nöthigen, in diesen Theilen ein Rückengefäfs mit 9 sich im rechten Winkel entgegengesetzten Gefäfspaaren, zu erkennen. Zuweilen glaubte ich überdiefs deutliche Verbindungskanäle der einzelnen Gefäfspaare zu sehen, doch wurden sie unsichtbar, wenn die Haut sich spannte, und sie blieben mir daher zweifelhaft. Jedoch ist es sehr wahrscheinlich, dafs eine noch weit gröfsere, sehr feine Gefäfsverzweigung statt findet. Die Saftbewegungen und der Herzschlag aber, welchen schon Corti bei den Räderthierchen und Brachionen gesehen zu haben meinte, beruhen auf Täuschung. Man sah den zitternden Kanal, welcher vom Munde zum Schlundkopfe geht, besonders bei der Familie der Zygotrochen, für ein Herz an. Ebenșo kann die Beobachtung Gruithuysen's, welcher Saftbewegung in Paramaecium Aurelia gesehen zu haben glaubt, nur Darmbewegung meinen. Kleine locale zitternde Bewegungen, bald hier bald da, habe ich oft bei Räderthierchen gesehen, halte sie aber für Muskelwirkungen. Einer eigenthümlichen rotirenden Bewegung ist besonders die innere Darmhaut fähig, was ich auch bei Nais sah. Auch sah ich zuweilen ein Fluctuiren zwischen den Organen, in der freien Bauchhöhle und Wimpern an der Aufsenseite des Darmkanals.

\section{III.}

Das Ernährungssystem der Hydatina.

Der vollständige Darmkanal dieses Thieres besteht zuerst aus einem kugelförmigen muskulösen Schlundkopfe, an dem 2 gezahnte Kiefer befestigt sind, und dessen Öffnung vorn in der Mitte der Räderorgane etwas gegen den Bauch befindlich ist. Ich zählte jederseits 6 zweispitzige Zähnchen, die linienförmig sind, und durch ein Band von 2 Wurzeln oder Fortsätzen festgehalten werden. Auf den Schlundkopf folgt ein deutlich verengerter 
Schlund (oesoplagus), welcher in einen sogleich sehr verdickten Darm ohne Magen übergeht, und conisch abnehmend nach hinten sich verläuft. Bei geringer Nahrung ist der Darm runzlich. Der Mastdarm endet nicht frei nach aufsen, sondern in eine Cloake gemeinschaftlich mit dem Eiergange, und an der Stelle ihrer Einmündung ist ein Kranzmuskel (splincter). Die äufsere Auswurfsöffnung ist auf dem Rücken des Thieres, dicht über dem achten Zwivigpaare des Rückengefäfses. Diese Structur erleidet bei den eigentlichen Räderthieren, den ZJgotrochis nudis, die Ausnahme, dafs der Darm bei diesen einen. mittleren, dünneren und spiralförmig gekrümmten Kanal zeigt, wenn er mit Farbe gefüllt wird. Auch ist die Einrichtung der Cloake so, dafs diese in eine Blase ausgedehnt werden kann, in der sich die Auswurfsstoffe noch einige Zeit verweilen. Der Sphincter ist ebenfalls durch seine Wirkung zu erkennen, doch zu durchsichtig, um sehr deutlich an sich erkannt zu werden. Die ZJgotrocha loricata sind den Polytrochis ähnlich, nicht jenen, zeigen aber fast alle eine Strictur in der Mitte des Darmes, welche einen vordern Theil absondert, den man Magen nennen könnte. Über die Stelle der Analmündung und der Mündung des Eierkanals, belebren überall die Ausleerungen mit völliger Gewifsheit.

Zum Ernährungsapparat gehören wahrscheinlich noch 2 weifse drüsige Körper, welche am Anfange des Darmes 2 Ohren oder Hörner bilden, und die durch Farbe, Form und Anheftungsweise mit der Bauchspeicheldrüse (Pancreas) höherer Thiere mehr Ähnlichkeit haben, als mit den Gallengefäfsen und der Leber der niedern Thiere. Sie sind fest an dem Darm geheftet, und haben an ihrem vordern Ende noch ein dünnes Band, welches sie an die innere Körperhaut befestigt. Beim Zerlegen des Thieres bleiben sie am Darmkanale sitzen, nicht an der Bauchhaut. Sie für Nieren zu halten, würde eine vollkommenere Entwicklung des Gefäfssystems voraussetzen, die nicht beobachtet wird. Auch bei den Räderthieren, Rolifer vulgaris und Pliilodina erythrophthalma, habe ich diese Organe bestätigt, und am gröfsten bei der Gattung Euchlanis unter den Polytrochis loricatis gefunden.

\section{IV. \\ Geschlechtssystem.}

Alle Individuen sind deutlich hermaphroditisch, und besitzen die doppelten Generationsorgane in grofser Ausbildung. Die weiblichen Genera- 
tionsorgane bestehen aus einem im unbefruchteten Zustande, rundlichen oder viereckigen, auch herzförmigen drüsenartigen Eierstocke, welcher, wenn sich eine Mehrzahl von Eiern ausbildet, zweihörnig wird. Nie fand ich bei dieser Form mehr als $\mathrm{S}$ grölsere Eier. Dieser Eierstock umgiebt, leberartig, die Mitte des Darmkanals, und endet nach hinten in einen mchr oder weniger langen Stiel, oder dünnen durchsichtigen Kanal, den Eiergang, welcher mit der Reife der Eier kürzer und dicker wird, und sich mit dem Darmkanal in die Cloake mündet. Ein Kranzmuskel, durch Färbung und Anschwellung kenntlich, umgiebt dicht hinter der Vereinigung den Eingang der Cloake. Iydatina legt Eier, und ich habe den Act des Legens beobachtet; Rotifer vulgaris bringt auch lebendige Junge. Die Eier sind keine Gemmen, sondern haben deutlich dieselben 3 Substanzen, welche Herr Rudolphi bei den Eiern der Eingeweidewürmer erkannte, und für Chorion, Allantois und Anmion hielt. Das Chorion platzt mit einem Queerrifs, und läfst das selbstständige Junge frei davon gchen. Bei Zerlegung von Individuen gelang es mir zuweilen den Eierstock unverletzt zu isoliren, und dann erkannte ich (siehe Tab.VII. fig. k.) die jungen Eier in der Substanz desselben sehr gut. Es schien mir bei einigen sogar in der Mitte noch ein dunklerer Fleck zu existiren, so dafs es noch unentschieden bleibt, ob die mittlere, in jener Figur angegebene Masse der Eyer Embryo selbst ist, oder ob sie Dottersubstanz ist, in wclcher sich dieser erst entwickelt. Die grofse Zusammensetzung ist deutlich.

Die männlichen Generationsorgane bestehen aus zwei, vom Kopfe anfangenden, den ganzen Körper auf beiden Seiten durchlaufenden geschlängelten Saamenorganen, welche vorn breiter und etwas zackig, nach hinten rundlicher und schmäler sind. Sie enden in schlangenförmigen Windungen, dicht hinter der Mündung des Eierstocks, im Halse eines blasenförmigen Muskelorgans. Dieses blasenförmige Organ, welches ganz dic Gestalt und Lage eines Uterus hat, aber beim Eierlegen gar keine Function übernimmt, zeichnet sich durch grofse Irritabilität aus, dehnt sich bald zu einer Blase aus und zieht sich rasch in einen drüsenähnlichen Körper zusammen. Seiner Lage und Eigenthümlichkeit gemäfs dürfte diescs Organ zum Einschnellen des Saamens in den Eierstock bci der Selbstbefruchtung dienen und diesen Thieren ganz eigenthümlich sein. Dic Saamenorgane sind auch bei Rotifer und Philodina deutlich, doch fehlt die irritable Blase, welche durch 
ein griffelförmiges, im Nacken befindliches Organ, das dann zur männlichen Befruchtung dienen würde, ersetzt zu werden scheint. Die Analogie dieser Bildung ist bei den Mollusken deutlich, deren bekanntlich viele das männliche Zeugungsorgan im Nacken führen.

\section{V.}

Nervensystem der Hydatina.

In der Mitte zwischen den Muskelscheiden der Räderorgane, um den Schlundkopf nach vorn liegen drüsenartige, unregelmäfsige, durch Farbe sich auszeichnende, zusammenhängende Körper. Aus einem obern, eiförmigen, gröfsern entspringt ein ziemlich dicker Strang, welcher schief im Nacken gegen das Rückengefäfs geht und sich daselbst, etwas vor dem zweiten Paare der Gefäfszweige, anhcftet, aber nicht endet, sondern, ohne sich in einen bedeutenden Knoten zu verdicken, in fast gleicher Stärke wicder zurückláuft. Zurückgekehrt nach der Gegend des Mundes und den drüsigen Körpern verliert er sich, nicht in dem gröfseren, von dem er ausgegangen, sondern zwischen, oder in den kleineren benachbarten. Diese Nackenschlinge ist bei der Seitenlage des Thieres sehr deutlich zu sehen. Sie ist kein Muskelstrang, weil sie bei ihrem Ansatzpunkte an der Haut sich nicht wie die übrigen Muskeln ausbreitet, und weil sie bei Contraction der Kopfgegend, sich nicht verkürzt, sondern schlangenförmig gebogen, also passiv erscheint. Sic ist kein Gefäfs, weil. bei der Dicke ihres Durchmessers entweder eine herzartige Pulsation, oder ein Strömen der im Innern sichtbaren trüben Substanz. bemerkbar sein müfste. Diese Gründe und die bekannte vollkommen übereinstimmende Analogie anderer niederer Thiere, berechtigen und nöthigen, diese deutlich vorliegenden Organe, für ein von kleineren umgebenes gröfseres Nervenganglion und eine Nervenschlinge des Nackens zu halten. Vom Anheftungspunkte dieser Schlinge am Rückengefäfs sah ich noch 2 sehr feine Nervenfäden nach der Stirn gehen, wo bei andern Formen dieser Familie, wie bei Rotifer vulgaris, Augen mit rothem Pigment befindlich sind. Bei vielen ist auch ein gröfseres rothes Auge an der Anheftungsstelle der Nervenschlinge im Nacken selbst (Eosphora Najas), und in diesem Falle bildet diese Schlinge einen doppelten Sehnerven. - Auf der Bauchseite entspringt überdiefs aus dem Gehirn ein einfacher dünner Nervenfaden, welcher unverästet dicht an der Bauchbedeckung herabgeht, und um die 
inneren Muskelscheiden der Schwanzzange 3 Schlingen bildet, deren zwei vorderen 2 Gefäfsschlingen des Rückengefäfses entgegenkommen. Dieser Nerv ist wegen Nähe der Muskeln schwer zu sehen, jedoch von mir öfter deutlich gesondert erkannt worden. Sein Ursprung ist noch ungewifs.

\section{II.}

\section{Anwendung der beobachteten Structur auf Systematik.}

Nach diesen Erfahrungen habe ich versucht, aus der Masse der unrichtig gekannten Thiere, welche bisher mit dem Namen Infusionsthiere bezeichnet waren, nach den allgemeinen Regeln der Naturgeschichte, und namentlich der Zoologie, 2 von einander geschiedene Klassen der Phytozoen zu bilden, in denen diese Thierformen nicht mehr nach der ganz unsicheren äufseren Form, sondern nach der festeren Gesammtstructur ihres Wesens geordnet sind. Mangel an nachzuweisenden Gefäfsen bei sonst hinlänglich klarem Bau (grofser Paramaecien und ähnlicher Formen), mögen vorläufig die Polygastrica von den verwandten Entozoen u. s. w. scheiden, deren Gefäfse ziemlich klar erkannt worden sind. Die Gattung Euglena beweist übrigens, dafs es auch bei den unvollkommneren, noch einer unmittelbaren Selbsttheilung unterworfenen Infusorien Andeutungen ron Augen, und mithin eines Nervensystems, giebt, was mit ihrem Tastsinn sich wohl vereinigt, und die Aufmerksamkeit der beobachtenden und systematisirenden Naturforscher sehr verdient. Die Klasse der Räderthierchen erscheint mehr organisirt, als die der Entozoen es ist. Thre Augen sind regelmäfsiger Charakter von bei weitem der Mehrzahl der Gattungen, und da dieselben auch bei den kleineren Formen noch erkannt werden, wo man das directe Aufsuchen des Nervensystems aufgeben mufs, so halte ich diesen Charakter für einen sehr günstigen zum Behufe systematischer Anordnung und Erkennung. Von den Mollusken und Krebsen, welche ebenfalls Gefäfse und Nerven haben, unterscheiden sich sämmtliche Infusorien, sowohl die Magenthierchen (Polygastrica), als die Räderthierchen (Rotatoria), durch den Mangel eines pulsirenden Herzens, oder eines Centralorgans für das Gefäfssystem; von niedereren Formen aber unterscheiden sich die Räderthierchen, durch ausgebildetere Structur. Zahllose microscopische Untersuchungen, welche ich durch Tage und Nächte fortsetzte, haben mich in kurzer Zeit in den Stand Phys. Abhandl. 1830. 
gebracht, sämmtliche bekannte Hauptformen, den gewonnenen Grundsätzen gemäfs, wieder zu prüfen, und das Resultat dieser Untersuchungen' sind die hier folgenden 2 Tabellen, welche gewifs durch mehrseitige Theilnahme an den Untersuchungen sich bald ansehnlich vergröfseren, und der Naturgeschichte einen ihrer wesentlichen Theile im wissenschaftlichen Gewande zufügen werden.

Rücksichtlich der Einrichtung beider Tabellen bemerke ich, dafs es meine Absicht war, auf ein Gesetz aufmerksam zu machen, welches die schaalentragenden Infusorien mit den nackten überall eng verbindet, und kaum erkannt worden ist. Man könnte nicht selten Schaalentragende Formen mit andern nackten, wegen vollständiger Übereinstimmung der äufseren und inneren Bildung, in eine und dieselbe Thiergattung stellen, ohne der Natur Gewalt an zu thun. Dennoch habe ich der leichten Erkennung des Charakters halber, denselben der Hauptabtheilung, den Ordnungen zugeschrieben. Geringer ist noch im Ganzen die Zahl der beobachteten gepanzerten Formen bei den Polygastricis, aber weniger ungleich ist sie mit der der nackten bei den Räderthierchen. Gehören die Bacillarien rücksichtlich des innern Baues wirklich zu den thierischen Formen, wofür vieles Äufsere spricht, so erwächst durch sie der gepanzerten Bildung der Magenthierchen ein ansehnliches Material. Bei den Naviculis sieht man zuweilen, aufser den bewegten Körperchen in den Spitzen und im Innern, einen vieltheiligen, freilich sehr kleinen Fufs aus der Längsspalte ragen, mit welchem sie sich fortschieben. Ein Queerschnitt theilt dieselben Thierchen nicht in 2, sondern in 4 Theile, indem dann die beiden Queertheile in der Längsspalte auseinander gehen. Ungeachtet vieler Details, welche ich über diese Gruppe gesammelt habe, gelang es aber doch noch nicht, sie zur Aufnahme von Nahrung zu bringen.

Was die systematische Behandlung der ganzen Klasse der Magen-: thierchen $\left({ }^{1}\right)$ anlangt, so ist sie vielleicht noch der Veränderung ausgesetzt. Ich habe nämlich die Zahl der Formen, vielleicht aus Unvollkommenheit meiner Beobachtung, ill 2 gröfsere Gruppen sondern müssen. In der einen habe ich sowohl die Stelle, als die Öffnung und Umgebung des

(') Magen, nicht. Blinddïrme, sind diese Anhänge des Darmes deshalb zu nennen, weil sie nicht zum Verdauungsprocels vorbereitete Stoffe aufnehmen, sondern mit ganz rohen Stoffen unnittelbar gefüllt werden, und weil das Thierchen willkührlich bald den ersten, bald den letzten nit Übergehen der andern füllt. 
Mundes, und auch das Auswerfen der unverdauten Nahrungsstoffe, ganz deutlich beobachten können, wodurch ich eine klare Ansicht der Structur und einen festen Eintheilungsgrund erhalten habe. In der andern aber habe ich zwar die Stelle des Mundes und die Magen erkannt, allein ich habe nie die Auswurfsöffnung und den Act des Auswerfens sehen können. Es schien mir daher zweckmäfsiger, die letzteren, meist ihrer Kleinheit wegen sehr schwierig zu beobachtenden Formen, in einer ersten Abtheilung der Klasse abzusondern, und ich machte mir, der vergeblichen Beobachtung zufolge, von ihrer Structur die Idee, als wäre bei ihnen Mund und Auswurfsöffnung ein und dasselbe, oder als hinge die sichtbare Mehrzahl kleiner Magen mit dem Munde radienartig zusammen. Diese nenne ich denn Anen-

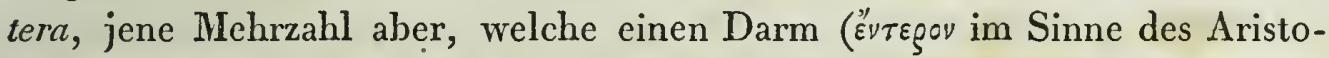
teles) deutlich führen, Enterodela. Die Anentera habe ich nach der Anwesenheit äufserer Organe in 3 Familien gesondert, und Körperform und Verhältnifs der Organe benutzte ich zu Gattungscharacteren, wo sie fest erschienen.

Die Enterodela, sowohl die nackten als gepanzerten, habe ich nach der relativenStellung der Mund- und Auswurfsöffnung in 4, wie ich glaube, sehr naturgemäfse Familien sondern können. Andere Körperverhältnisse und die Verhältnisse äufserer Organe benutzte ich zu Gattungscharacteren. Der Form allein habe ich aber bei diesen nirgends einen Einflufs gestattet.

Rücksichtlich der Klasse der Räderthierchen ist folgendes zu bemerken: Ich nenne die Klasse der Räderthierchen nicht Rotifera, dem bei französischen Naturforschern üblichen Namen Rotiféres gemäfs, sondern Rotatoria, weil der Name Rotifer schon seit dem Jahre 1803 als Gattungsname von Schrank verbraucht ist, und weil diefs der alte, durch Spallanzani und andere Italiener früher Zeit angewendete Name für die Vorticella rotatoria oder Furcularia rediviva ist. Lamarck bildete bekanntlich mit dem französischen Namen Rotiféres eine Section, und Cuvier eine Ordnung der Infusionsthierchen, aus welcher letzteren Bory de St. Vincent zwei machte: Roliféres und Crustodés. Deshalb hat auch der letztere Gelehrte den alten Gattungsnamen Rotifer des eigentlichen Räderthierchens durch den neuen Namen Esechielina ersetzen zu müssen geglaubt. Dieser Name aber, welcher vom Propheten He sekiel entlehnt ist, weil derselbe in scinen Visionen die Cherubim mit 4 radförmigen Organen sah, scheint weder pas-

E 2 
send, noch wegen des Vorrechtes des frühern zulässig. Monohyla rotatoria nannte schon Schweigger einzelne dieser Formen.

Die Klasse der Räderthierchen, welche von der Klasse der saugenden Eingeweidewürmer und jhrer Verwandten (Suctoria) sich durch die Räderorgane sehr bestimmt unterscheidet, weshalb auch die gleichfalls mit Darm u. s. w. versehenen Vibrio fluviatilis, aceti und glutinis vielleicht sogar zur Gattung Oxyuris zu ziehen sind, zerfällt zuerst wieder in die 2, mehr: künstlichen als natürlichen, aber die Bestimmung der Arten erleichternden Ordnungen, in Nackte und Gepanzerte (Nuda-Loricata. Der Name Crustodea für die letztern ist eine vox hy brida, deshalb nicht anwendbar). Jede dieser Ordnungen zerfällt in 4 Familien nach der Natur der Räderorgane, und in diesen geben die bisher ganz übersehenen (nur bei Rotifer von einigen Beobachtern angegebenen, zuletzt aber von Bory de St. Vincent in Zweifel gezogenen) meist roth gefärbten Augen sehr feste und auch nicht allzuschwierige Gattungscharaktere. Die Kauorgane habe ich nur selten zur Unterscheidung der Gattungen benutzt, obwohl sie sehr charakteristisch zu șein scheinen und namentlich die Philodina aculeata von den übrigen Formen dieser Gattung trennen würden; ihre Untersuchung ist aber schwierig und zerstört das Thier.

Es folgt nun der systematische Versuch selbst: 


\title{
PHYTOZOA.
}

\author{
Classis I. \\ POLYGASTRIGA $\left({ }^{1}\right)$.
}

Animalia evertebrata apoda, nonnulla caudata; Vasa sanguinifera et Systema nerveum nullibi conspicua. Oculorum rudimenta paucis. Os omnibus ciliis vibrantibus coronatum nudumve ventriculis pluribus appendiculatum aut canali alimentario perfecto polygastrico auctum. Pharynx non discretus, inermis. Partus. Ovipara? (vivipara) et sponte dividua. (Utrum gemmae sint, an ova vocanda interna propagula observationes olim decident.)

\section{A. ANENTERA.}

Ore ventriculis pluribus appendiculato, ano discreto nullo

(tubo intestinali nullo).

\section{Ordo I. Nuda. ORDo II. Loricata.}

\section{Famila I. GYMINICA.}

\section{Corpore non ciliato, ore ciliato nudove.}

Sectio I. MONADINA.

A) pullis internis nunquam conspicuis: cor-

pore in binas aut quaternas partes sponte.

dividuo:

a) cauda nulla:

a) pellucida:

Monas termo Müller.

atomus Müll. = M. lens M.

guttula. nov. sp.
15 species.

B) obscura $\left({ }^{2}\right)$ :

(1) Ich nehme in dieses Verzeichnifs nur solche Thierformen namentlich auf, deren Ernăhrungsorgane ich durch Farbesubstanzen -geprüft häbè. - Von dèn übrigen mir bekannten, wahrscheinlich ebènso organisirten Ạrten, füge ich nư die Zahl hinzu, und die ungeprụ̈ften, oder widerstrebenden Gattungen erwähne ich in den Anmerkungen.

(2) Hierản schliefsen sich Volvox globulus, Volvöx Morum und die einfaclien Vibrionen, de-" ren Ernährungsạpparat, ich noch nicht, oder nicht deutlich ausgemittelt habe, auf folgende Weise: 


\section{ORDo I. Nuda. ORDo II. Loricata.}

FAMULIA II. EPITRICHA.

Corpore ciliato, ore ciliato nudove.

\section{Sectio IV. PERIDINAEA.}

A) pullis internis conspicuis nullis:

a) ciliorum ordine transverso:

Peridinium cinctum. Vortic. cincta Müll. pulvisculus. nov. sp. minor.

2 species.

B) obscura:

Doxococcus globulus. Volvox glob. Müller.

3 species.

b) caudata :

Bodo. nov. Gen. Monas punctum Gleichen.

4 species.

? Urocentrum Nitzsch. Turbinella Bory. Cercaria turbo $M_{0}$ an Vorticella?

1 species.

B) pullis internis conspicuis:

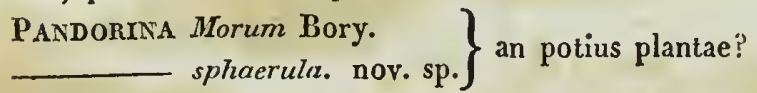

2 species.

Sectio II. VIBRIONIA. Elongata, in se nunquam contracta.

a) corpore filiformi cylindrico undatim tlexili (in multas partes transverse dividuo):

Vibrio bacillus Müller.

- lineola Müller.

rugula Müller.

4 species.

b) corpore filiformi rigido spirali :

SPIRILlUM volutans. Vibrio spirillum Müller. undula. Vibrio undula Müller.

2 species.

c) corpore oblongo, fusiformi aut filiformi (tereti aut triquetro nec quadrangulo) aperte undatim non flexili, nec spirali:

Bacterum. nov. Gen. - Haec genera, Oscillatoriis valde affinia, ore nutriri nondum vidi. 11 species.

\section{Sectio III. ASTASIAEA.}

Elongata, contractione polymorpha; (longitudinaliter dividua [Eugl. acus.])

a) oculorum rudimento nullo:

As'TASIA euchlora. nov. Gen.?

- haematodes. al. sp. $\}$ Os omnibus distinctum.

4-6 species. 


\section{ORdo I. Nuda. \\ ORDO II. Loricata.}

b) ciliorum ordine longitudinali:

?Crclidium glaucoma Müller $\left({ }^{1}\right)$.

4 species.

Famidis III. PSEUDOPODIA. Famila I:

Corpore proteo, processibus pediformibus variabili.

Sectio V. AMOEBAEA.

Amoeba diffluens. Proteus diffluens Müll. radiosa. nov. $\mathrm{sp.}$

processibus acutis radiatis.

2 species.
Sectio I. BACILLARIA. cum lorica dividua $\left({ }^{2}\right)$.

b) oculorum rudimento distincto:

EUGLENa viridis. Cercaria viridis Müller. acus. Vibrio acus Mülller. pleuronectes. Cercaria pleuronectes Müller.

6 species.

(1) Hieran schliefsen sich die Gonia und Volvoces, deren äufsere wirbelnde Behaarung deutlich ist, wie folgt:

c) ciliis ubique sparsis:

Pantotrichum volvox. nov. Gen.

1 species.

$B)$ pullis internis conspicuis.

a)_corpore compresso (quadrangulo):

Gonium pectorale Müller.

2 species.

b) corpore globoso:

Volvox globator Müller.

1 species.

(2) Da es scheint, als existirten keine den 2 ersten Familien der nackten Magenthiere entsprechende. Formen bei den gepanzerten, so bilden die Pseudopodia loricata die erste Familie dieser Ordnung, und den Anfang würden die Bacillarien geben, deren äufsere Bewegungsorgane durch veränderliche, aus einer seitlichen Längsspalte hervorgeschobene kleine Papillen gebildet werden, welche an die proteischen Veränderungen der Difflugia erinnern. Obwohl sich meine fruchtbaren Untersuchungen dieser Section bis jetzt nur auf die Gattung. Navicula beschränken, so erlaubt doch einerseits die Ähnlichkeit der Formen, andererseits fordert das von mir gegebene, sonst unverständliche geographische Verzeichnifs, die systematische Übersicht derselben hier anzuschliefsen. Offenbar sind mehr Gründe, diese Körper für unvollkommen beobachtete Thiere, als für vollkommen beobachtete Pflanzen zu halten. 
ORDo I. Nuda.
ORdo II. Loricata.

Sectio II. ARCELLINA.

lorica non dividua.

a) lorica urceolata (i):

b) lorica scutellata:

Arcella vulgaris, nov. Gen.

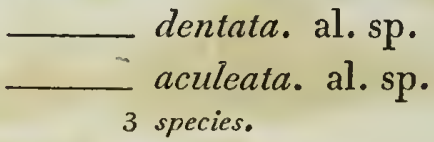

\section{BACILLARIA.}

A) lorica bivalvi quadrangula, dorso longitudinaliter dividua:

a) libera solitaria aut gregaria;

\section{Navicula;}

b) libera concatenata catenulis polymorphis :

\section{BACLlLaria;}

c) libera fasciatim concatenata, nec polymorpha, dein diffracta:

Fragilaria;

Exrlaria;

d) libera apoda radiata (flabelliformia):

e) affixa sessilia;

SYNEDRA. nov. Gen.

Gompionema;

$f)$ affixa pedicellata saepe dichotoma, apice dilatata;

g) affixa pedicellata saepe dichotoma, basi apiceque contracta:

\section{Cocconema. nov. Gen.}

\section{ECHINELLA;}

h) affixa pedicellata radiata (flabelliformia):

B) loriea univalvi tereti, transverse in duas quatuorve partes dividua:

Closterium;

In welchem Zusammenhange einige Seealgen: Girodella, Schizonema, Micromega caet. mit Navicula stehen, ist durch genauere Beobachtungen erst auszumitteln. In demselben Falle

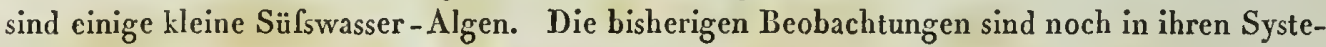
men zu befangen.

(1) An diese Formen der Bacillarien schliefst sich Difflugia, bildet aber mit einer neuen Form durch einen physiologisch wichtigen Charakter (siehe oben) eine eigene Section der Familie unter dem Namen Arcellina, wie folgt:

a) lorica ureeolata:

Difflugla proteiformis Le Clerc.

2 species.

b) siehe oben.

Von allen Formen dieser Familie ist es mir bisher nur gelungen, sämmtliche Arten der Gattung Arcella zur $\Lambda$ ufnahıne von Nahrung und ihre innern Ernährungsorgane zur Anschauung zu bringen. Vergl. Tab. $T$. 
der Infusorien und ihrer geographischen Verbreitung.

\section{B. ENTERODETA.}

tubo intestinali perfecto (ore anoque terminato) polygastrico.

ORDo I. Nuda.

$\therefore$. Familia IV. ANOPISTHIA. Famila II.
Ore anoque contiguis in eadem fovea.

Sectio VI. VORTICELLINA.

Sectio III. OPIIRYDINA.

A) corpore pedicellato, pedicello filiformi nudo (nec vaginato), saepe ramoso:

a) pedicello in spiram contractili (sit v. v.):

Vorticella convallaria Müller. citrina Müller.

5 species.

b) pedicello in spiram non contractili: Eristruis digitalis. Vort. digit. $M$. anastatica. Vort. anast. $M$.

3 species.

B) corporis pedicello nullo:

a) ciliorum corona simplici:

Trichodina grandinella. Trichoda gr. $M$.

b) ciliorum corona duplici:

Stentor polymorphus Oken.

$3-4$ species.
A) corpore nudo pedicellato, pedicello filiformi vaginato:

a) in spiram contractili:

Carchesium fasciculatum. Vorticella fascic. Müller. nebuliferum. $V$.neb. $M$. jolypinum. $V$.polyp. $\boldsymbol{M}$. 3 species.
$B)$ corpore gelatina involuto nec pedicellato: Opurydiun versatile. Vort. vers. $\boldsymbol{M}$.

1 species.

$C)$ corpore vagina membranacea incluso:

a) non pedicellato:

Vaginicola crystallina. n. sp. tincta. n. sp. decumbens. n. sp.

3-6 species.

b) pedicellato:

Tintinnes.

\section{Famila V. ENANTIOTRETA.}

Ore anoque oppositis terminalibus.

\section{Sectio VII. ENCHELIA.}

A) ore transverse truncato:

a) corpore non ciliato:

EnGhelys pupa Müller $=$ Ench . farcimen $M$. nebulosa Müller.

2 species.

Phys. Abhandl. 1830. 

ORdo I. Núda.
ORDO II. Loricata.

b) corpore ciliato:

Coleps hirtus Nitzsch. clongatus. n. sp.

3 species.

c) corpore setoso:

Actinopinys Sol. Trichoda Sol Müll.

2 species.

$\boldsymbol{B})$ ore obliquo (saepe ciliato):

a) corpore non ciliato:

a) in collum capitatum non extensili:

Trichoda carnium. E Trichoda pyro $\boldsymbol{M}$.

3 species.

?B URSARIA.

1 species.

ß) in collum capitatum extensili:

Lacrmarta olor. Vilrio olor Müller. Lacrimatoria Bory.

2 species.

b) corpore ciliato:

Leucophiss palula. Tricle. pat. $M$.

_- priformis. n. sp. ?spatluula. Ench.spatl. M.

3 specie.s.
Familia VI.
ALLOTRETA.
Famula III.
Ore anove terminali.

Sectio VIII. TRACHELINA.

A) ore inermi infero:

a) labio superiore praelongo (subaequali, colli formam referente):

Trachelius fasciola. Vibr. fasc. $M$. anas. Trichoda anas $M$. ambiguus. Trich. amb. $M$.

4 species.

b) Labio superiore brevi dilatato obliquo:

Loxodes cuculluliss. Kolpoda cucullulus $M$. rostrum. Kolp. rostrum $\boldsymbol{M}$.

4 species.

$B$ ore uncino suffulio, (infero):

Glaucoma scimlilluns. nov. G.

1 specres.
Sectio IV. ASPIDISCINA. Aspidisca Lynceus. Trich. Lync. M. 1 species. 
ORdo I. Nuda. Familia VII.
ORDo II. Loricata.

KATOTRETA. FAmila IV.
Sectio IX. KOLPODEA.

Nuda aut ciliata.

A) proboscide brevi inermi:

a) corpore partim ciliato:

Kolpoda cucullus Müller. Ren Müller.

2 species.

b) corpore ubique ciliato: turgido:

Paramaecium Chrysalis Müller.

2 species.

Aurelia Müller.

$B)$ proboscide nulla:

Amphileptus anser. Vibrio anser $M$.

Meleagris. Kolpoda Meleagr. M.

2 species.

Sectio V. EUPLOTA.

Euploea Charon. Trich. Char. M.

1 species.

Euploeat nomen apud Lepidoptera non susceperunt Latreille et Godart; Ploesconiam granmatici arcent.

Se c tio X. OXYTRICHINA. Setosa aut uncinosa.

a) uncinis stylisque nullis:

Oxxtricira pellionella Bory.

piscis. Trich. piscis $M$.

pullaster. Kerona pull. $M$.

4 species.

b) uncini; styli nulli:

Kerona pustulaia Müller.

1 species.

c) styli; uncini nulli:

Unostrla grandis. nov. Gen. Trichoda patens M.?

2 species.

d) uncini stylique:

Strlonychia Mj lilus. Ker. Myt. $M$.

2 species.

histrio. Kerona histrio $M$. 


\title{
PHYTOZOA.
}

\author{
Classis II. \\ R O T A T O R I A ( 1 .
}

Animalia evertebrata radiata apoda saepe caudata, ciliis peculiaribus rotantia. Ganglia nervea pharyngea plura (cur non cerebalia?); annulus nerveus nuchalis et nervus abdominalis in maioribus conspicua. Saepissime oculi, pigmento laete rubro. Canalis alimentarius distinclus simplex; ventriculi species nonnullis, appendices coecae apud alia. Pharynx saepius maxillis armatus, nonnunquam dentigeris. Vas dorsale immobile (reticulatum-?) ramosum. Succi corporis pellucidi. Hermaphrodita. Ovipara et vivipara, nec sponte dividua.

Ondo I. Nuda.

OnDo II. Loricata.

Familia I. MONOTROCHA.

Ciliorum corona simplici integra:

Sectio I. ICHTHYDINA.

B) coeca:

a) dorso glabro:

Ichurhyom Podura. Cercar. Pod. MT. (Furcocerca vox hy brida).

1 species.

b) dorso setoso:

Chantonotus larus. Trich. larus $M$.

2 species.
Sectio I. STEPHANOPINA. A) coeca:

a) cauda simplici:

Monura colurus. nov. Gen.

1 species.

b) cauda furcata:

Colunus uncinatus, Brachionus uncinat. M. (Colurella vox loybrida). bicuspidatus. n. sp. 2 species.

$B)$ oculis duobus:

Stepinanops lamellaris. Brachionus lamell. $M$.

1-2 species.

(1) Ich würde nicht dazu rathen, die Eingeweidewürmer, deren Structur nach diesen Beobachtungen einfacher als die der Räderthierchen erscheinen könnte, als zu einer tieferen organischen Reihe gehörig anzuschen. Herrn Rudolphi's klassische Beobachtungen haben es schon 


\section{ORDO I. Nuida. ' ORDo II. Loricata. \\ Familia II. SCHIZOTROCHA.}

Ciliorum corona simplici laciniatin constricta variabili.

Sectio II. MEGALOTROCHAEA.

A) oculo unico:

Microcodor clavus, nov. Gen.

1 species.

$B)$ oculis quatuor:

Megalotrocha alba. nov. sp.

1 species.
Sectio II. FLOSCULARIA.

A) coeca:

a) gelatina corpus involvente:

a) organo rotatorio bilobo et subquadrilobo:

Lacinolamia socialis Oken.

- 1 'species.

B) organo rot. multifido:

Floscularia ornata. Floscul. Oken.

ciliis longissimis eleganter ornata.

1 species.

b) vagina çorporis membranacea:

Melicerta ringens Schrank 1803.

Tubicolaria Lamarck $1815\left(^{1}\right)$. 1 species.

\section{Familia III. POLYTROCHA.}

Ciliorum coronulis plurịbus.

Sectio III. HYDATINA.

A) coeca:

a) simplicia:

a) maxillae dentatae:

Hrdatina senta. Vorticella senta $M$.

Sectio III. EUCHLANIDOTA.

A) coeca:

Lepadella ovalis. Brachion.oval. $M$. Lep. Bory.

1 species.

so festgestellt, dafs diese Thiere eine sehr ausgebildete Structur besitzen, dafs hierüber kein Zweifel sein kann, wahrscheinlicher hat die Beobachtung sie hie und da noch weiter zu entwickeln.

(1) Die Structur dieses ungemein niedlichen Thieres ist ganz anders, als sie durch Dutrochet angegeben ist. Was Dutrochet und Savigny für After halten, ist der Mund, seitlich am Grunde des Räderorgans, und der letztere hat vielleicht gerade zu, umgekehrt wieder, den After an der Basis des Schwanzes für den Mund gehalten. Ich habe das Thierchen mit blauer Farbe genährt, und mich so vollkommen über beide Punkte überzeugt. Was Dutrochet für 2 gestielte Augen hielt, sind 2 männliche Glieder im Nacken und auf der Bauchseite hat es vorn am Anfange der Mundspalte 2 harte Spitzen, wie etwa Salpina (Brachionus mucronalus. M.̈̈ll e r) und ähnliche. Das Räderorgan.ist einfach, vierlappig mit ciner doppelten Reihe von Wimpern besetzt, in deren Zwischenraume die Speise zum Munde fortbewegt wird. Der Schlunłkopf hat 2 Kiefer, - deren jeder 3 Zähne trägt. Darm und Eierstock sind wie bei:Itydutina. Der lange Schwanz ist ohne Zange, was die ganze Familie der Schizotrocha charakterisirt.' 


\section{OnDo I. Nuda.}

ORDO II. Loricata.

Hídatina gibla.

2 species.

B) maxillae inermes:

t) ore recto terminali:

Enteroplea lacustris. nov. Gen.

1 species.

t) ore obliquo infero:

Pleurotrocha petromyzon. nov. Gen.

1 species.

b) composita:

Zоовотитол pellucidus. nov. Gen.

1 species.

B) oculo unico:

a) frontali:

Furcularia giblia. n. sp.

2 species.

b) dorsali:

a) cauda setacea nec furcata:

Monocenca Rattus. Trich, Rat. M. Monocerca Bory.

2 species. bicornis. n. sp.

B) cauda simpliciter furcata:

†) ciliis rotatoriis aequalibus :

Notomata lacinulata. Vortic. lacinul. $M$.

longiseta. Vort. longis. $M$.

aequalis. $\mathrm{n}$. sp.

aurila. Vortuc. aurita $M$.

sacrigera. n. sp.

decipiens. n. sp.

forcipata. n. sp.

felis. Vort. felis $M$.

$B)$ oculo unico:

a) lorica depressa:

a) cauda simplici:

Monostyea cornuta. Trich. corn. $M$.

2 species. quadidentata. n. sp.

ß) cauda furcata:

Eucillanis macrura. nov. Gen.

2 species. dilatata. al. sp.

b) lorica turgida aut angulosa:

a) cauda simplici:

Mastigocerca carinata, nov. Gen. 1 species.

ß) cauda furcata:

Salpina mucronala. Brachionus mucronatus $M .\left(^{1}\right)$ spinigera. n. $\mathrm{sp}$. ventralis. n. $\mathrm{sp}$. redunca. n. sp. brevispina. n. sp.

8 species.

(1) Der Kamm auf dem Riicken dieser und ähnlicher Formen veranlafste die irrige Meinung bei Müller und Bory de St. Vincent, dafs es zweischaalige Räderthiere gebe. 
der Infusorien und ihrer geographischen Verbreitung.

\section{ORDo I. Nuda.}

ORDo II. Loricata.

$t+$ ) ciliis rotatoriis inaequa-

libus, partim Iongiori-

bus, setaceis tentaculi-

formibus:

Scaridium longicaudum. Trichoda longicauda $M$.

1 species.

\%) cauda bis furcata:

Dinocharis pocillum. Trich. pocil. $M$.

tetraclis.

paupera.

3 species.

c) oculis binis aut bis acervatis:

a) frontalibus simplicibus:

Diglena calellina. Cerc. catell. $M$. - capilata. n. sp.

C) oculis quatuor:

Squamella bractea. Brach. bract. M.

Squanella limulina Bory. 1 species.

3 species.

b) dorsalibus simplicibus:

a) cauda simplici:

Ratrulus lunaris Bory. Trich. lunaris Bory.

1 species.

B) cauda furcata:

Distemana forcipalum. Cerc. forc. $\boldsymbol{M}$.

_. forficula. n. sp.

3 species. seligerum. n. sp.

c) dorsalibus acervatis:

Theonus vernalis. nov. Gen.

1 species.

D) oculis tribus:

a) uno dorsali, duobus frontalibus:

Eosphora Najas. nov. Gen.

1 species.

b) tribus dorsalibus:

Norops dorsalis. nov. Gen.

1 species. 


\section{Ordo I. Nuda.}

ORDo II. Loricata.

E) oculis pluribus in circulum dispositis:

Crcloglena lupus. Cerc. lupus $M$.

1 species.

\section{Familia IV. ZYGOTROCHA.}

Ciliorum coronulis binis.

Sectio IV. PHILODINAEA.

A) coeca:

Callidina elegans, nov. Gen.

1 spccies.

$B)$ oculis duobus:

a) frontalibus (ante organa rotatoria):

a) cauda ter furcata:

Rotifer vulgaris Schrank. tardigradus. n. sp. macrurus Schrank.

3 species.

P) caudae quinque apicibus:

Actrnunus meplunius, n. G. (Schiebel, Oken.)

1 species.

b) dorsalibus (pone org. rot.):

(c) cauda simpliciter furcata:

Monolabis conica. nov. Gen.

1 species.

B) cauda ter furcata:

Pinlodina erjethroplutínalma. n. G. $\left({ }^{1}\right)$
Sectio IV. BRACHIONAEA.

A) coeca:

?Noteus Bakeri. Brachion. Bak. M. 1 species.

B) oculo unico:

a) cauda nulla:

Anuraed palea Bory. (Anurella vox hybrida).

1 species.

b) cauda furcata:

Brachionus urceolaris Müller.

Bakeri. n. sp.

3 species. palea. n. sp.

C) oculis duobus:

Pterodina palina. Brach. patin. $M$. Proboskidia Bory. (Proboscidea et Proboscidia plantis et insectis sacra, Probnskidia nefas).

1 species.

(1) Zu den Infusorien hat man bisher auch immer noch die Gattungen Cercaria Nitzsch, Spermatozoon (Baer) und die Wasser- und Essig-Älchen gerechnet, weiche ich mit dem eigenen Gattungsnamen Anguillula, schon nach Müller's Andeutung, bezeichnet habe. All diesen Thierformen fehlen aber das Wirbelvermögen und dessen Organe, während sie deutlich nicht zu den Polygastricis gehören, auch nicht durch Theilung sich zu vervielfältigen scheinen. Ich finde den schicklichsten Platz für dieselben bei den Enıozoen, obwohl ich die Structur der Saamenthierchen mit vollkommener Klarheit noch nicht erkannt habe. Bei Cercaria ephemera sah ich, dafs die 2 seitlichen der 3 von Nitzsch erkannten Augenpunkte keine Augenspuren, sondern die spiralrörmigen Anfänge der 2 Eierstöcke sind. Bei Anguillula fluviatilis bin ich. in Zweifel geblicben, ob das Geschlechtsorgan des Männchens in einer Scheide befindlich ist, 


\section{ORDo I. Nuda.}

ORDo II. Loricata.

Philodiva aculeata. al. sp. citrina. al sp.

3 species.

wie bei Oxyuris, deren ganzer Bau sich bei ihnen wiederholt. Sehr stark unterscheiden sich von den übrigen Vibrionen Vibrio serpentulus und Vibrio gordius durch eine Saugwarze an der verdickten Schwanzspitze und Fühlfäden am Munde, die aber nicht wirbeln; daher bildete ich aus ihnen dic Gattung Amblyura. Blutkügelchen sind keine Thiere.

Ferner sind mehrere von Hern Bory de St. Vincent und andern Systematikern gegebene Gattungsnamen, welche ich nicht angeführt habe, nicht als ausgeschlossen anzusehen, sondern gehören Formen vorzugsweise an, deren bisherige Beobachtung noch nicht erlauble, ihnen eine Stelle anzuweisen. Wer aber, anstatt Gattungen zu vermissen, die Artenzahl anf Kosten der Gattungen mehren wollte, kann das sehr leicht, wenn das Trennen der Formen nach physiologischen Principien bis zu seiner natïrlichen Grenze miihsam ausgeführt sein wird. 


\section{III.}

Geographische Verbreitung der Infusorien, besonders in Sibirien, mit Rücksicht auf die verschiedenen Weltheile.

Nachdem ich die Infusorien mit bestimmteren Charakteren versehen und ihre Gattungen und Arten auf festere Regeln gebracht habe, ist es mehr als früher möglich, über die Verbreitung ihrer Formen auf der Erdoberfläche einige sicherere Resultate mitzuthcilen. Ich hatte die Ehre der Akademie in einem früheren Vortrage anzuzeigen, dafs ich auf mcinen Reisen in Afrika und Arabien mit Dr. Hemprich diese organischen Lebensformen nicht unbeachtet gelassen, und dafs unter den beobachteten 57 aufsereuropäisehen, subtropischen und tropischen Infusorienarten nur ein Drittheil ganz denen ähnlich sei, welche ich vorher bei Bcrlin, und mit demselben Microseop ebenda wieder nachher beobachtet habe. Zwei Drittheile der Zahl hielt ich aber für von den europäischen verschicdene Thiere. Zu diesem Resultate gesellte sich seit jener Zeit eine noch weit gröfsere Anzahl von mir meist im nördlichen Asien beobachteter Thierformen derselben Klassen. Herrn Alexander von Humboldt's Sommerreise durch Rufsland bis in den Norden des Uralgebirges, zu den Hochgebirgen des Altai und bis zum caspisehen Meere, an welcher Theil zu nehmen ich das Glück hatte, war nicht so eilig, dafs es nicht möglich gewesen wäre, mit Ernst jene aus Erfahrungen entsprossene Ideen übcr Infusorien, dercn Verfolgung mir als eine Pflicht vorschwebte, auf demselben einzig sichern Wege der'Erfahrung weiter zu entwickeln. Durch glücklichen Zufall hatte ich mich schon seit längerer Zeit vor Antritt der letzten Reise an das bercits im Eingang erwähnte Cheval liersehe noch vorzüglichere Microseop, als jene waren, die ich in Afrika benutzte, gewöhnt. Ick hatte sehr feine Micrometer im Pistorschen Institute zu Berlin anfertigen lassen, und hatte durch die Gefälligkeit des jungen sehr wissenschaftichen Herrn Doctor Dickson aus London, ein Glasmierometer von Dollond erhalten, welches, worüber man erstaunt, auf noch nicht einer halben Linie Raum, 400 nebeneinander auf Glas eingeschnittene gleiche Theile eines in 10000 Theile zerlegten Zolles angiebt, wodureh es möglich wird, Infusoricn, die $\frac{1}{10000}$ Zoll Gröfse haben, sieher direet zu mes- 
sen, und noch weit kleinere richtig zu schätzen. Mit Hülfe der Pis tor schen Micrometerschraube konnte ich todte und still liegende Infusorien bis auf $\frac{1}{45000}$ Zoll oder $\frac{1}{4000}$ Linie direct messen, eine Gröfse der Feinheit, deren ich bei der Messung nie bedurfte. Diefs alles kam glücklich zu statten. Ich habe mich nun bemüht, aus diesen mechanischen Kunstwerken auf jener Reise für dic Naturgeschichte, in Bezichung auf Infusorien, den inöglichsten Nutzen zu ziehen. Nach meiner Rückkehr habe ich mit demselben Instrumente und denselben Hülfsmitteln die Infusorien bei Berlin von neuem sehr genau geprüft, und mit den auf meinen beiden Reisen gefertigten Zeichnungen, Messungen und Bemerkungen verglichen. Das Resultat dieser Arbeit ist es, welches ich hiermit vorlege. Zuerst aber spreche ich von den in Rufsland allein beobachteten Infusorien-Formen und ihrem Verhältnifs. Auf 22 verschiedenen Punkten bis zu den weit ausgedchnten südöstlichen Grenzen des grofsen rufsischen Reichs, war es mir wieder vergönnt, die Natur über ihre verborgensten Organismen zu befragen, möge es mir gelungen sein, als Dolmetscher derselben, ihre Antwort richtig verstanden und richtig übertragen zu haben.

Dic Gesammtzahl der von mir beobachteten rufsischen Infusorien beträgt nach systematischer Reduction. der sämmtlichen Formen 113 selbstständige Arten. Die beobachtete Formenzahl verhält sich wie folgt:

a) Europäische Beobachtungspunkte:

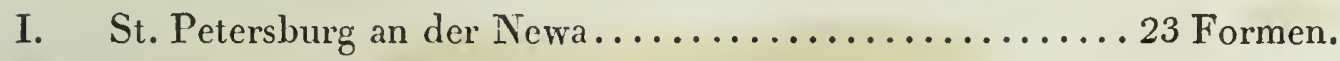

II. Saratof an der Wolga ...................... 6 -

III. Kurotschkinskischer See bei Astrachan (in Salzwasser von daher, welches in Astrachan in Flaschen aufbewahrt war, beobachtet)....................... 1 Form.

IV. Sakmara Flufs westlich von Orenburg (Conferven von daher in Uralsk untersucht) $\ldots \ldots \ldots \ldots \ldots \ldots \ldots \ldots \ldots \frac{1}{31 \text { Formen. }}$

b) Asiatische Beobachtungspunkte:

V. Uralsk am Uralflusse ..................... 7 Formen.

VI. Orenburg am Uralflusse $\ldots \ldots \ldots \ldots \ldots \ldots \ldots \ldots \ldots . \ldots \ldots$

VII. Ilezkaja Saschtschita bei Orenburg (aus Salzwasser der Steppe; in Orenburg beobachtet).............6 6

G 2 
VIII. Soimonofskoi im Uralgebirge ( ${ }^{1}$ ) in der Kupfergrube... 3 Formen.

IX. Kyschtym im Uralgebirge (mit Conferven des Sumpf-

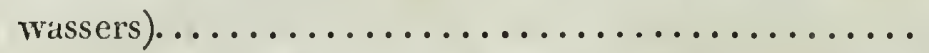

X. Catharinenburg im Uralgebirge an der Iset (aus dem

Flusse, aus Sümpfen und aus dem See Schartasch)...26

XI. Nishne Tagil im Uralgebirge am 'Flufse Tagil........ 1 Form.

XII. Bogoslofsk im nördlichen Uralgebirge am Flufse Turja . 6 Formen.

XIII. Petropawlofsk östlich vom Ural in der sibirischen Steppe

(aus Conferven des Salzwassers eines Steppensees).. 3

XIV. Troizk östlich vom Ural in der sibirischen Steppe (aus

Conferven einer salzigen Lache)............ 1 Form.

XV. Tobolsk am Irtysch und Tobol in der sibirisehen Ebene 21 Formen.

XVI. Barnaul in Sibirien am Obi............... 8

XVII. Platofskische Steppe zwischen Barnaul und dem Koliwaner See ....................... 1 Form.

XVIII. Smeïnogorsk im Altaigebirge .............. 12 Formen.

XIX. Koliwan am Flüfschen Belaja (mit Conferven beobach-

tet in Smeïnogorsk)................. 1 Form.

XX. Buchtarma im Altaigebirge am Irtysch...........6 Formen.

XXI. Prochodnoi-Alpe des Altai bei Riddersk (mit Confer-

ven, die ich voin Kamme der Alpe mitgenommen

hatte, in Riddersk beobachtet) $\ldots \ldots \ldots \ldots \ldots \ldots \ldots 2$

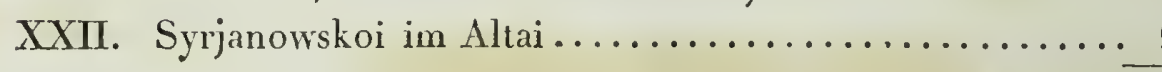

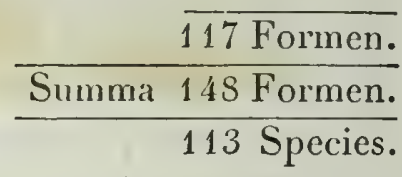

Nimmt man die Bergkette des Uralgebirges und an deren südlichem Ende den Uralflufs als natürliche Grenzen von Asien und Europa an, und rechnet man dic umnittelbaren Grenzbewohner schon zu $\Lambda$ sien, so gehören von diesen 113 Infusorienarten 31 nach Europa, während 82,zu Asien zu rechnen sind. Ton allen wurden, mit Wiederholung einzelner Formen, in St. Petersburg 23 Arten; in der astrachanischen Steppe mit dem Bett der

(1) An den Punkten, wo nicht Salzwasser ausdrïcklich genannt wird, ist allemal Süfswasser zu verstehen. 
Wolga und des Uralflufses 24 Arten; auf der Bergkette des Ural 37 Arten; auf der Fläche von Sibirien 33 Arten und im Altaigebirge, nicht fern von den Grenzen des chinesischen Gebiets, 22 Arten beobachtet.

Systematisch betrachtet, gehören die 113 russischen Infusorienarten 51 Gattungen an. Es sind unter ihnen aus der ersten Phytozoenklasse (den Polygastricis) 95 Arten, welche zu 39 Gattungen gehören, aus der zweiten Phytozoenklasse, oder den Räderthierchen, sind unter ihnen 18 Arten, welche zu 12 Gattungen gehören. Ich habe dabei noch die Gattung Anguillula, von der ich in Rufsland 3 Arten beobachtete, mit hinzu gerechnet, weil - viele gerade diese allein als Infusionsthierchen kennen, obwohl ich sie im System zu den Entozoen gewiesen habe. Bei den systematischen Vergleichungen werde ich Anguillula weiter mit rechnen, aber da sie weder zu den Polygastricis noch zu den Räderthierchen gehören, immer auszeichnen.

Übereinstimmend in Maafs und Körperform und mithin ganz, oder sehr wahrscheinlich ganz gleich mit in Berlin vorkommenden, oder von MüJler abgebildeten und sonst bekannten mitteleuropäischen Infusorien, sind folgende Formen Rufslands :

\section{POLYGASTRICA, 55 Arten:}

Actinophris Sol.

Амовва diffluens.

Arcella vulgaris.

Aspidisga Lynceuls.

Bacterium tremulans. Monas?

Carciresium fasciculatum.

Cilosterium cornu. lunula. trabecula.

Cocconena cistula?

Coleps hirtus.

Cyclidium glaucoma.

Difflugia proteiformis.

Doxococcus globulus. pulvisculus.
Exilaria panduriformis. Jabellum.

Euglena acus?

Fragilaria pectinalis.

Glaucona scintillans.

Gomphonema discolor.

Kerona pustulata.

Kolpoda cucullus. Ren.

Loxodes cucullulus. cucullio.

Leucopirnys ?fluida.

Moxas atomus. suttula. Enchelys? termo. 
Monas mica. nova.

Navicula fulva.

gracilis. ulna.

Oxxtricina lepus. pullaster.

Pandorina Morum.

Paramalcium Aurelia. Chrysalis.

SpImLlum volutans. Trachelius fasciola. anas.
Trachelius fal $x$. lamella. trichophorus?

Tricioda paramaecium. Tricisodina grandinella. Vibrio rugula. lineola.

Vorticella convallaria. a) campanulata. B) pyriformis. microstoma.

Urocentrum turbo.

ROTATORIA, 11 Arten:

Anuraea paler.

Brachiones urceolaris.

Colurus uncinatus.

Diglena catellina? capitata?
Lepadella? triptera. Monostrua cornuta? Monura colurus. Rotiren vulgaris. Salpina bicarinata?

Eospiora Najas?

Zu diesen würden sonst 3 Anguillula-Arten gehört haben, welche ich gleichzeitig beobachtete, und die sämmtlich auch in Berlin vorkommen.

Die Summe der mit den mitteleuropäischen übereinstimmenden russischen Infusorien beträgt demnach 66, mit den Älchen (Anguillula) 69, was von der Gesammtzahl mehr als $\frac{3}{5}$, oder fast $\frac{2}{3}$ ist. Die übrigen 44 in Mitteleuropa noch nicht verzeichneten gehören ebenfalls, wie die afrikanischen, gröfstentheils bekannten, oder von mir aufgefundenen europäischen Gattungen an. Neue Gattungen ganz unbekannter Formen, als Frucht dieser Reise waren folgende 5 :

\section{ARCELLA, ASTASIA, $\mathrm{BODO}$,}

Seitdem ich aber diese Gattungen characterisirt habe, sind mir auch bei Berlin, theils dieselben Formen vorgekommen, theils habe ich doch
EOSPHORA, TRICHODISCUS. 
andere Arten derselben Gattungen hier aufgefunden. Das erstere ist'der Fall bei den sehr ausgezeichneten Formen Eosphora und Arcella, von denen ich letztere zuerst in Tobolsk sah, jetzt aber in 3 Arten hier gefunden habe. (Herr Doctor Leo in Berlin hat, wie er mir sagt, auch mehrere dieser Formen und vor mị bei Berlin beobachtet, sie unter dem Gattungsnamen Difflugia beschrieben und der naturforschenden Gesellschaft übergeben, welcher Aufsatz noch nicht gedruckt ist.) Bei den drei übrigen ișt das letztere der Fall, so dafs von allen Gattungen keine jenen Ländern ganz eigenthümliche übrig geblieben ist.

Die Zahl der beobachteten Arten verhält sich zu der Zahl der Gattungen, wie folgt:

Von 27 Gattungen wurde 1 Art beobachtet.

\begin{tabular}{|c|c|c|c|c|}
\hline & 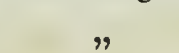 & wurden & 2 & Arte \\
\hline " & , & $"$ & 3 & $"$ \\
\hline & $"$ & $"$ & 4 & $"$ \\
\hline & Gattung & $"$ & 6 & $"$ \\
\hline & $"$ & $"$ & 7 & $"$ \\
\hline & $"$ & $"$ & 8 & $"$ \\
\hline & $"$ & $"$ & 13 & $"$ \\
\hline
\end{tabular}

Die 4 sich durch Formenmenge auszeichnenden Gattungen sind sämmtlich aus den Poljgastricis, nämlich:

TRACHELIUS mit 6 Arten.

$\begin{array}{lrrr}\text { NAVICULA } & " & 7 & \\ \text { BACTERIUII } & " & 8 & " \\ \text { MONAS } & " & 13\end{array}$

Von der letztern Gattung wurden 10 Arten in Asien, 3 in Petersburg beobachtet.

Unter den Räderthierchen scheint sich die Gattung Hjodatina in Sibirien am meisten zu entwiickeln. "Ich zählte 3, sämmtlich neue Arten. Doch beobachtete ich damals das Auge noch nicht aufmerksam, worein ich jetzt die Gattungscharaktere lege, und mein Urtheil gründet sich daher auf die durch meine Zeichnung festgestellte, ganz mit jener Gattung übereinstimmende Form und Structur. Die Gattung Diglena gab 2 Arten, bei denen derselbe Zweifel bleibt, die aber selbst mit unsern Arten übercinzustimmen scheinen. Bei Berlin ist die Gattung Notommata am reichsten an Arten. 
Rücksichtlich der östlichen Längenverbreitung zeichnen sich folgende in Berlin und am Altai beobachtete Formen besonders aus:

Magenthierchen, 16:

Cuostenium lunula.

Coleps hirtus.

Kolpoda cucullus.

Levicopinys? fluida.

Loxodes cucullulus. cucullio.

Monas atomus.

- mica.

terino.

Navicula fusiformis.

- gracilis.

Oxitricha lepus.

Paramaegium Aurelia.

Triciodina grandinella.

Trichodiscus sul.

Vibrio rugula.
Räderthierchen, 6:

(Anguillula fuviatilis.)

Anuraea palea.

Diglena catellina? capitata?

Monostrua cornula?

Rotifer vulgaris.

Infusorienformen, die 1) St. Petersburg und Bogoslofsk fast im $60^{\text {sten }}$ Breitengrade, und 2) den Sinai im $28^{\text {sten }}$, mit Dongala bis zum $19^{\text {ren }}$ Breitengrade gemeinsam bevölkern, sind:

Nagenthierchen, 4:

Räderthierchen, keine.

Crclidiuar glaucoma.

Kolpoda cucullus.

Paramaecium Chrysalis.

Trachelius lamella.

Infusorienformen, welche Berlin, der Altai und die Breite des Sinai bis Dongala gemein haben, sind:

Magenthierchen, 4:

Closteniuni lunula.

KoLPODa cucullus.

Monas termo.

Navicula fusiformis.
Räderthierchen, 3:

(Anguillula fluviatilis.)

Diglena catellina?

Rotifer vulgaris. 
Von Formen, welche an allen geographischen Extremen meiner Beobachtung, nämlich 1) am Sinai bis Dongala, 2) in Berlin, 3) in St. Petersburg und Bogoslofsk und 4) am Altai gleichzeitig waren, und die mithin die Frage lösen könnten, ob es ganz allgemein verbreitete Infusorien, gleichsam Weltbürger unter ihnen giebt, ist bis jetzt erfahrungsgemäfs allerdings eine, aber nur eine zu nennen:

\section{KoLPODA cucullus.}

Diese hiermit vorgetragenen Zahlenresultate sind, schon wegen ungleicher, oft sehr geringer Beobachtungsmengen an den verschiedenen Orten, keineswegs als feste Principien aufzunehmen, sie sollen nur dazu dienen, zu klarem Bewufstsein über das zu gelangen, was wir wirklich über die Verbreitung der Infusorien durch Erfahrung wissen, und einen Maafsstab abgeben, zu erkennen, wie weit poëtische Hypothesen diefs erweitert haben, oder später erweitern.

An diese Beobachtungen, welche auf einer grofsen Ausdehnung der Erdoberfläche mit möglicher Sorgfalt angestellt wurden, schliefse ich noch eine kleine Zahl anderer, die zwar in den genannten Zahlen mit begriffen waren, die aber ein besonderes Interesse gewähren dürften. Es sind Beobachtungen über das Vorkommen der kleinsten Thierkörper in finstern Schachten unter der Erde.

Da auf der Reise im Ural und Altai Herr v. Humboldt alle wichtigeren Erzgruben befuhr, so benutzte ich in seiner Begleitung diese Gelegenheit, aus den tieferu Punkten derselben stehendes Wasser, nasse Schimmelmassen und schleimige Überzüge der Zimmerung in gereinigten stark ausgetrockneten Glasfläschchen zur Beobachtung von Infusorien mitzunehmen, die ich dann sogleich zu Tage mit dem Microscop untersuchte. Mehrere Male waren meine Bemühungen umsonst. Ich fand in den aus der Tiefe mit solcher Vorsicht genommenen Feuchtigkeiten, dafs sie nicht am. Gestänge und in den Schachten unmittelbar von ohen herab gelaufen sein konnten, mehrmals keine Infusorien, zweimal aber fand ich deren in ziemlicher Zahl, und davon einmal unter Verhältnissen, die bei völligem Abschlufs des Tageslichts in 56 Saschenen (Lachter) Tiefe mir die Üherzeugung liefsen, als wären sie nicht vielleicht am selben Tage mit dem Wasser von oben hinab gedrungen, sondern als wären sie am Orte selbst wohnhaft und erzeugt worden. Diese beiden fruchtbaren Beobachtungspunkte waren: die Silbergrube von SmeïPhys. Abhandl. 1830. 
nogorsk im Altai, und dic Kupfergrube von Soimonofskoi im Ural. Die erstere licferte mir in der angegebenen gröfsern Tiefe 4 Infusorienarten, welche sämmtlich bekannte Formen waren, die ich aber an denselben Punkte über der Erde nicht beobachtet habe, nämlich:

\section{(Avguillula fluviatilis). \\ KOLPODa cucullus. \\ Loxodes cucullulus. cucullio.}

Dic letztere Grube gab mir, bei geringerer Tiefe von nur 6 Saschenen (Lachter), drei andere, nämlich:

Monas atomus.

- Enchelys.

termo.

Es ist zu bemerken, dafs unter diesen Formen wieder Kolpoda cucullus angetroffen wird, und dafs sämmtliche Formen sehr verbreitet sind.

Das Gesammtresultat meiner bisherigen Beobachtungen über Infusorien möchte ich schliefslich in Folgendem übersichtlich zusammenfassen:

1. Alle Infusorien sind organisirte, und zum Theil, wahrscheinlich alle, hoch organisirte Thiere.

2. Die Infusorien bilden 2 ganz natürliche Thierklassen nach ihrer-Structur, lassen sich nach der Structur wissenschaftlich abtheilen, und erlauben keine Vereinigung ihrer Formen mit gröfseren Thicren, so ähnlich sie auch oft erscheinen.

3. Die Existenz von Infusorien ist in 4 Welttheilen und im Meere nachgewiesen, und sie bilden die Hauptzahl, viclleicht die Hauptmasse der thierisch belebten Organismen auf der Erde.

4. Einzelne Arten sind in den entferntesten Erdgegenden dieselben.

5. Die geographische Verbreitung der Infusorien auf der Erde folgt den schon bei anderı Naturkörpern erkannten Gesetzen. Nach Süden hin giebt es in andern Weltgegenden stellvertretende abweichende Formen mehr, als nach Westen und Osten, aber sie fehlen nirgends, auch betrifft die climatische Verschiedenheit der Form nicht blofs die gröfseren.

6. Das Salzwasser der sibirischen Steppenseen zcigt keine auffallend ab-weichenden eigenthümlichen Infusorienformen. 
7. Das Meerwasser nährt andere und gröfsere Formen als das Flufswasser, viele aber sind dieselben; bei keiner übersteigt die Körpergröfse eine Linie.

8. Im Wasserdunst der Atmosphäre, der sich als Regen und Thau niederschlägt, beobachtete ich nie, auch wohl sonst nie jemand mit Sicherheit lebende Infusorien.

9. In den Tiefen der Erde, wo atmosphärische Luft, aber wohl kaum ein Minimum von reflectirtem Licht Zutritt hat, finden sich Familien derselben Infusorien, wie auf dẹr Oberfläche.

10. Die directen Beobachtungen für die generalio primiliva mangeln, wie es nun scheint, sämmtlich der nöthigen Schärfe. Diesclben Beobachter, welche das plötzliche Entstehen der kleinsten Organismen aus Urstoffen gesehen zu haben meinen, haben die sehr zusammengesetzte Structur dieser Organismen ganz übersehen. Ein arges Mifsverhältnifs ist hier nicht zu verkennen, und die Täuschung liegt am Tage. Das Mifsverhältnifs mag weniger der Übereilung der Beobachter zur Last fallen, als der Unzulänglichkeit der benutzten Instrumente, oder dem Mangel an Übung in deren Gebrauch. Beobachtungen über das Entstehen krebsartiger Thicre und Insecten aus Urstoffen, sind die Nachklänge einer veralteten Zeit, wo die Raupen aus den Blättern wuchsen.

11. Die Idee, als hinge der Mensch, wenn auch nur zum Theil rom Willen ihn zusammensetzender Infusorien ab, wird durch die Beobachtung bescitigt, dafs die Infusorien sich ihre Nahrung suchen müssen, Eier legen, und sich nie bleibend und wachsend verbinden.

12. Dic Entwicklung aller von mir hinlänglich beobachteten Infusorienformen ist cyclisch, ganz bestimmt, nur zuweilen sehr formenreich, daher täuschend und genau zu beachten.

13. Die Resultate meiner Beobachtungen erinnern lebliaft an den alten physiologischen Satz: Omne vivum ex ovo. Nie sah ich nämlich bei 12 jähriger angestrengter Beobachtung das plötzliche Entstehen eines ausgebildeten Infusoriums aus Schleim oder Pflanzenzellen, wohl aber unzählige Male das Gebähren der Eier und das Ausschlüpfen der Jungen aus den gröfseren von diesen. Auf solche Erfahrungen gestützt bin ich der Meinung, dafs diese Thiere durch Generatio primitiva 
nicht gebildet werden, sondern aus Eiern entstehen. $\mathrm{Ob}$ nun die freien Eier nur zum Theil das Product des Gebährens, zum Theil aber das Product einer Generatio primitiva sind, ist noch nicht reif zur Entscheidung.

14. Die activen Bewegungen und Contractionen bei Pflanzen und ihren Theilen, besonders bei Algen, sollten, wenn'sie auch infusorielle, oder thierische Bewegungen genannt würden, nicht die Idee von Thierheit erwecken. Innere Ernährungsorgane und nachzuwieisende bestimmte Mundöffnung, zur Aufnahme selbst fester Stoffe, scheiden die scheinbar einfachsten Thiere von den Pflanzen. Nie, auf vielfache Versuche, habe ich einen beweglichen Algensaamen die geringste feste Nahrung zu sich nehmen gesehen, und so unterscheidet sich die fruchtstreuende Alge von der sie umschwärmenden Monade, wie der Baum vom Vogel.

15. Endlich lenke ich darauf die Aufmerksamkeit, dafs die Erfahrung eine Unergründlichkeit der organischen Schöpfungen dem kleinsten Raume zugewendet zeigt, wie die Sternenwelt dem gröfsten, deren nicht naturgemäfse Grenzen die optischen Hülfsmittel ziehen. Bis an das Walten der Urstoffe mögen sich Hypothesen wagen, der Erfahrung kannes nochnicht vorliegen. Die Milchstrafse der kleinsten Organisation geht durch die Gattungen Monas, $V i$ brio, Baclerium, Bodo. 


\section{Tabelle I.}

\section{Verzeichnifs der in Rufsland im Jahre 1829 auf Herrn}

A. v. Humboldt's Reise beobachteten Infusorien.

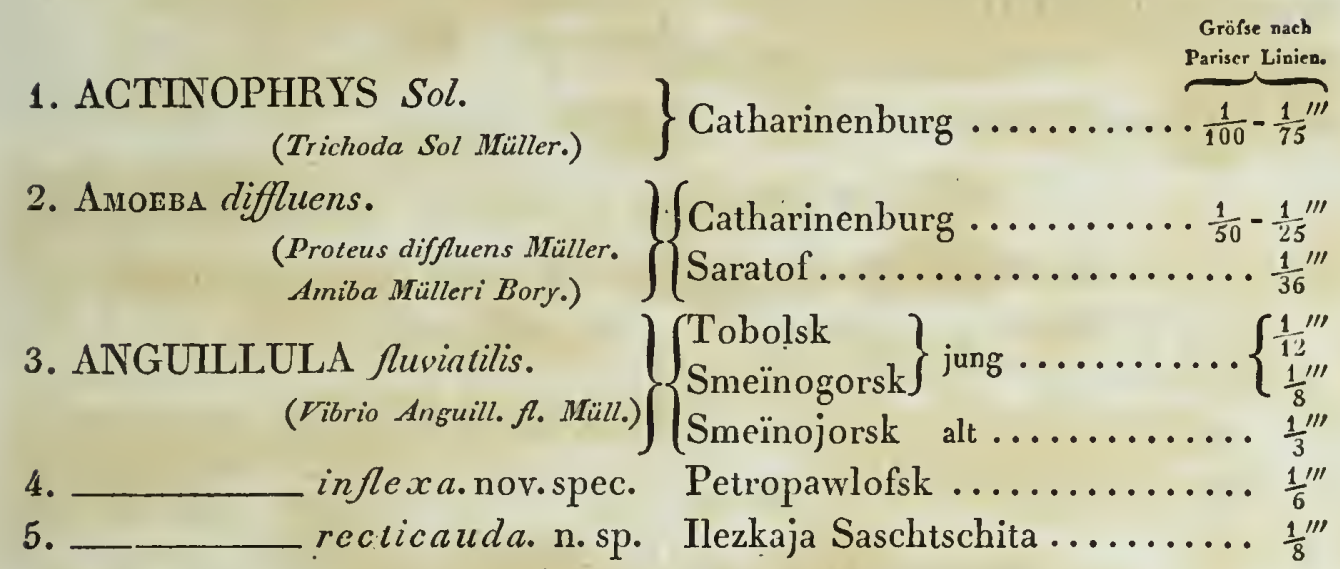

6. Anuraea palea.

(Brachionus Müller.

Anurella Bory.)

\} Smeïnogorsk............... $\frac{1^{\prime \prime \prime}}{8}$

7. ARCELLA vulgaris. nov. Gen. $\left\{\begin{array}{l}\text { Catharinenburg } \ldots \ldots \ldots \ldots \ldots \frac{1}{100}-\frac{1}{40}{ }^{\prime \prime \prime} \\ \text { Tobolsk } \ldots \ldots \ldots \ldots \ldots \ldots \ldots \ldots \ldots \ldots \ldots \ldots \\ \frac{1}{100}-\frac{1}{20}\end{array}\right.$

8. ASPIDISCA Lynceus. $\quad$ Catharinenburg $\ldots \ldots \ldots \ldots \frac{1}{100}-\frac{1}{75}{ }^{\prime \prime \prime}$

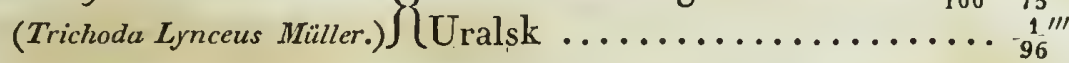

9. ASTASIA haematodes. n. G. Platofskische Steppe......... $\frac{1}{33}$

10 viridis. al. sp. Syrjanofskoi............ $\frac{1}{100}-\frac{1}{75}{ }^{\prime \prime \prime}$

11. BACTERIUM cylindric. n. G. Ilezkaja Saschtschita......... $\frac{1}{96}$

12. deses. (Enchelys deses Müller.)

\} Syrjanofskoi ................ $\frac{1}{100}$

13. Enchelys. al. sp. Petersburg ................ $\frac{1}{240}{ }^{\prime \prime}$

14. fuscum. al. sp. Catharinenburg $\ldots \ldots \ldots \ldots \ldots \frac{1}{1<5}$

15. — Monas. al. sp. Ilezkaja Saschtschita......... $\frac{1}{336}$

16. Punctum. al. sp. Petersburg.............. $\frac{1}{336}-\frac{1}{333}{ }^{\prime \prime}$

17. — termo. al. sp. $\quad\left\{\begin{array}{l}\text { Tobolsk } \ldots \ldots \ldots \ldots \ldots \ldots \ldots \ldots \ldots \frac{1}{500^{\prime \prime \prime}} \\ \text { Petersburg } \ldots \ldots \ldots \ldots \ldots \ldots \ldots \frac{1}{500}{ }^{\prime \prime \prime}\end{array}\right.$ 
18. BACTERIUM tremulans. al.sp. Petersburg................

19. Bacillaria elongata. n. sp.

Tobolsk .................. $\frac{1}{40}{ }^{\prime \prime \prime}$

20. BODO didymus. n. G.

21. viridis. al. sp.

Catharinenburg. ......... $\frac{1}{800}-\frac{5}{600}{ }^{\prime \prime \prime}$

22. vorlicellaris. al. sp.

23. Brachionus urceólaris Müller.

Smeïnogorsk $\ldots \ldots \ldots \ldots \ldots \ldots \ldots \frac{1}{500}{ }^{\prime \prime \prime}$

Catharinenburg $\ldots \ldots \ldots \ldots \ldots \cdot \frac{1}{100}{ }^{\prime \prime \prime}$

24. CARCHESIUM fasciculatum.

(Vorticella fascic. Müller.) $\}$

25. Closterium cornu. n. $\mathrm{sp}$.

Tobolsk................ $\frac{1}{20}-\frac{1}{10}{ }^{\prime \prime \prime}$

26.

lunula Nitzsch.

27. trabecula. n. sp.

28. COCCONEMA cistula. n. G. 29. Coleps liritus Nitzsch.

(Diceralella hirta Bory.)

30. Colurus uncinalus.

(Brachionus Müller.

Colurella Bory.)

31. Cychidium glaucoma Müller. 32.

margaritaceum. n.sp.

33. Difflugra proteiformis. Le Clerc.

34. DIGLENA capitata. n. G. 35 .

catellina? n. G. (Cercaria catellina Müller.)

36. DOXOCOCCUS globulus.

(Volvox globulus Müller.)

37. inaequalis. n. sp.

38. pulvisculus. n. sp.

39. Exilaria flabellum. n. sp.

40. … panduriformis. n.sp. 41. EOSPHORA Najas? n. G. 42. EUGLENA acus.

(Vibrio acus Müller.)

43. Fragilaria angusta. n. sp.

Sakmara, Flufs bei Orenburg... $\frac{1}{36}{ }^{\prime \prime \prime}$

Catharinenburg $\ldots \ldots \ldots \ldots \ldots \frac{1}{200}{ }^{\prime \prime \prime}$

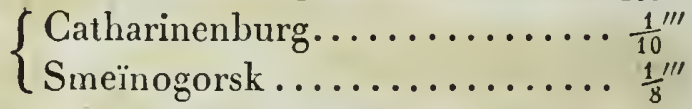

Tobolsk ............... $\frac{1^{\prime \prime \prime}}{8}$

Catharinenburg........... $\frac{1}{125}-\frac{1}{50}{ }^{\prime \prime \prime}$

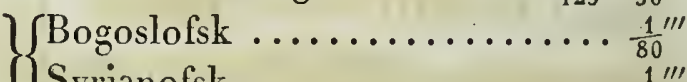

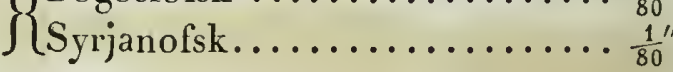

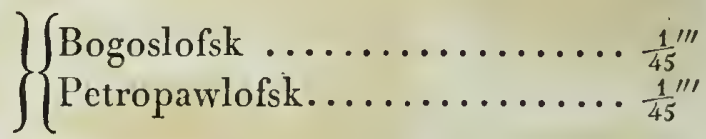

Petersburg.............. $\frac{1}{144}-\frac{1}{120}{ }^{\prime \prime \prime}$

Catharinenburg .......... $\frac{1}{125}-\frac{1}{100^{\prime \prime \prime}}$

Tobolsk.................... $\frac{1}{50}$

Buchtarma............... $\frac{1}{36}$

Smeïnogorsk.............. $\frac{1}{20}$

\}Ilezkaja Saschtschita .......... $\frac{1}{72}^{\prime \prime \prime}$

Catharinenburg $\ldots \ldots \ldots \ldots \ldots \frac{1}{200}{ }^{\prime \prime \prime}$

Catharinenburg ............................

Saratof................. $\frac{1}{80}$

Catharinenburg $\ldots \ldots \ldots \ldots \ldots . \frac{1}{36}{ }^{11 \prime}$

Tobolsk................ $\frac{1 \text {." }}{8}$

\} Catharinenburg $\ldots \ldots \ldots \ldots \ldots \cdot \frac{1}{40} 0^{\prime \prime \prime}$

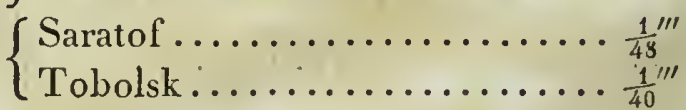


44. Fragilaria bipunctata. n. sp. 45. pectinalis Lyngbye.

46. scalaris. n. sp.

47. GLAUCOMA scintillans. n. G. 48. Gompitonema discolor. n. sp. 49. rotundatum. n. sp.

50. ?clavatum. n. sp. 51. ?constrictum. n. sp. 52. Gonium hyalinum. n. sp. 53. HYDATINA ?laticauda. n. sp. 54. ?leptocerca. n. sp. 55 . ?ternitnalis. n. sp.

56. Kenova pustulata Müller.

57. Kolpoda cucullus Müller.

58. Ren Müller.

59. Lepadella ?triptera. n. sp. 60. Leucophrys ? fuida Müller.

61. Loxodes cucullulus. (Kolpoda cucullul. Müller.)

62.

63. Monss atomus Müll. = M. lens M. 64. - enchelys. n. sp. 65. erubescens. n. sp.

66. guttula. n. sp.

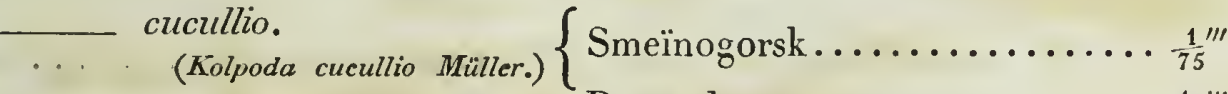
$\ldots \quad \begin{aligned} & \text { cucullio. } \\ & \text { (Kolpoda cucullio Müller.) }\end{aligned}\left\{\right.$ Smeïnogorsk............. $\frac{1}{75}{ }^{\prime \prime \prime}$

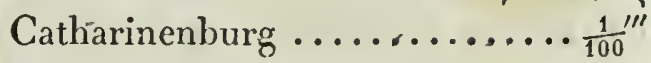

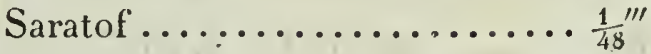

\{ Catharinenburg $\ldots \ldots \ldots \ldots \ldots \frac{1}{75}^{\prime \prime \prime}$

S Saratof ................ $\frac{1}{48}$

Petersburg............. $\frac{1}{60}-\frac{1}{40}{ }^{\prime \prime \prime}$

Troizk ................. $\frac{1}{50}$

Saratof.............. $\frac{1}{24}-\frac{1}{20}{ }^{\prime \prime \prime}$

Orenburg $\ldots \ldots \ldots \ldots \ldots \ldots \ldots \frac{1}{64}^{\prime \prime \prime}$

Catharinenburg $\ldots \ldots \ldots \ldots \ldots . \cdots \cdots \frac{1}{75}{ }^{\prime \prime \prime}$

Smeïnogorsk (1 einzelne Kugel $\frac{1}{860}$ ) $\frac{1}{172}{ }^{\prime \prime \prime}$

Tobolsk.................. $\frac{1}{24}$

Tobolsk................. $\frac{1}{24}$

Bogoslofsk................ $\frac{1}{30}{ }^{\prime \prime \prime}$

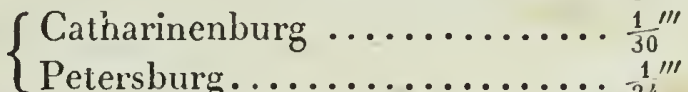

Tobol Smeïngorsk $\ldots \ldots \ldots \ldots \ldots \ldots \ldots \cdot \frac{1}{100}-\frac{1}{75}{ }^{\prime \prime \prime}$

Uralsk ................. $\frac{1}{100}{ }^{\prime \prime}$

Petersburg $\ldots \ldots$......... $\frac{1}{144}-\frac{1}{75}{ }^{\prime \prime \prime}$

Petersburg $\ldots \ldots \ldots \ldots \ldots \ldots \ldots \frac{1}{24}^{\prime \prime \prime}$

Bogoslofsk............... $\frac{1}{25}{ }^{\prime \prime \prime}$

Barnaul ................... $\frac{1}{3 \prime \prime}^{\prime \prime}$

Syrjanofskoi ................ ${ }^{\prime \prime \prime \prime}$ $\left\{\right.$ Smeinogorsk .............. $\frac{1}{60}$

Illezkaja Saschtschita ......... $\frac{1}{80}{ }^{\prime \prime}$ Barnaul ................ $\frac{1}{500}{ }^{\prime \prime \prime}$

Soimonofskoi ............ $\frac{1}{500}{ }^{\prime \prime \prime}$

Ilezkaja Saschtschita ......... $\frac{1}{288}$

Soimonofskoi ............. $\frac{1}{100}{ }^{\prime \prime}$

Kurotschkinskischer See bei As$\operatorname{trachan} \ldots \ldots \ldots \ldots \ldots \ldots \frac{1}{144}$

Petersburg $\ldots \ldots \ldots \ldots \ldots \frac{1}{250}-\frac{1}{192}{ }^{\prime \prime \prime}$ 
67. Monas ligalina. n. sp.

68.

69.

70.

71 .

72. termo Müller.

73. 74. 75. Kolpoda. n. sp.

76. Monostyua cornuta?

(Trichoda cornuta Miiller.) $\}$

77. umbra. n. sp. uva Müller.

78. MONURA colurus. n. G. 79. Navicula a) laeves: fulva.
(Bacillaria fulva
gracilis. n. sp.

80.

81. $u \ln a$. (Bacillaria ulna Nitzsch.) B) striatae:

82. fusiformis. n. sp.

83. gibba. n. sp.

84. turgida. n. sp. var. subaequalis.
Grörse nach Pariser Linien. $\{$ Petershurg. ........ $\frac{1}{500}-\overbrace{\frac{1}{384}-\frac{1}{240}}^{\prime \prime \prime}$ $\left\{\right.$ Tobolsk ............. $\frac{1}{500}{ }^{\prime \prime}$ Smeïnogorsk........... $\frac{1}{860}{ }^{\prime \prime \prime}$ Buchtarma............ $\frac{1}{120}{ }^{\prime \prime \prime}$

Barnaul ............... $\frac{1}{800}{ }^{\prime \prime \prime}$

Petersburg............. $\frac{1}{96}$

$\left\{\begin{array}{l}\text { Koliwan } \ldots \ldots \ldots \ldots \ldots \ldots \ldots \frac{1}{800}{ }^{\prime \prime \prime} \\ \text { Catharinenburg } \ldots \ldots \ldots \cdot \frac{1}{2000}-\frac{1}{1800}{ }^{\prime \prime \prime} \\ \text { Soimonofskoi } \ldots \ldots \ldots \ldots . \frac{1}{1000}{ }^{\prime \prime \prime} \\ \text { Petersburg } \ldots \ldots \ldots \ldots \ldots . \frac{1}{1000}{ }^{\prime \prime \prime}\end{array}\right.$

Syrjanofskoi $\ldots \ldots \ldots \ldots \ldots \frac{1}{200}{ }^{{ }^{\prime \prime}}$

Smeïnogorsk ............ $\frac{1}{860}{ }^{\prime \prime \prime}$

Petersburg .......... $\frac{1}{288}-\frac{1}{144}$

Smeinogork ...............

Tobolsk ............. $\frac{1}{24}$

Tobolsk .............. $\frac{1}{36}{ }^{\prime \prime \prime}$

\}Catharinenburg ......... $\frac{1}{36}$ Nitzsch. $)\}$ Buchtarma............ $\frac{1}{60}{ }^{\prime \prime \prime}$

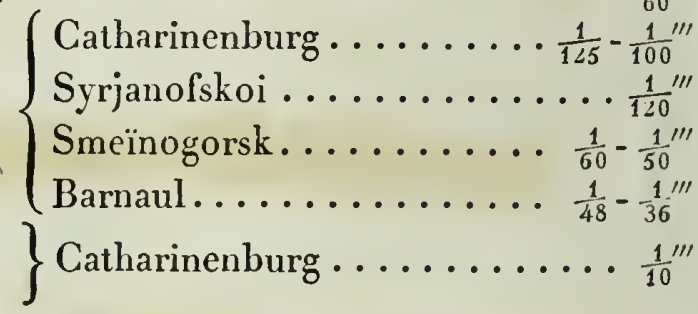

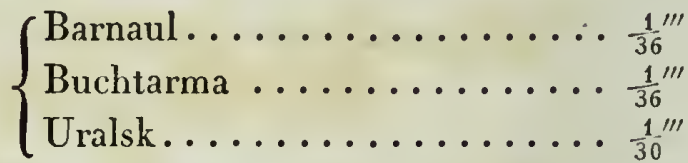
Orenburg........... $\frac{1}{12}-\frac{1}{10}{ }^{\prime \prime \prime}$ Catharinenburg ........ $\frac{1}{50}-\frac{1}{10}{ }^{\prime \prime \prime}$ $\left\{\right.$ Tobolsk .............. $\frac{1}{36}$ Orenburg. ........... $\frac{1}{36}-\frac{1}{24}{ }^{\prime \prime \prime}$ Orenburg........... $\frac{1}{36}-\frac{1}{24}$ 
85. Navicula uncinata. n. sp. 86. Oxxтricha Lepus Bory.

87. pullaster. (Kerona pullaster Müller.)
A Mon'un Bory?

Orenburg $\ldots \ldots \ldots \ldots \ldots \frac{1}{20}^{\prime \prime \prime}$

Syrjanofskoi ............ $\frac{1}{45}$

Uralsk

Kyschtym ......... $\frac{1}{24}-\frac{1}{10}{ }^{\prime \prime \prime}$

88. Pandorina Mortum Bory?

$\left\{\right.$ Syrjanofskoi $\ldots \ldots \ldots \ldots \ldots \ldots \frac{1}{20}{ }^{\prime \prime \prime}$

89. Paramaecium Aurelia Müller.

$\left\{\right.$ Petersburg.............. $\frac{1}{18}{ }^{\prime \prime \prime}$

90. Chrysalis Müller.

91. compressum. n.sp.

92. ovatum. n. sp.

93. Rotifer vulgaris Schrank.

94. SALPINA bicarinata. n. G. 95. SPIRILLUM volutans. (Vibrio spirillum Müller.)

96. SPIRODISCUS fulvus. n. G. 97. Trachelius anas.

(Vibrio anas Müller.)

98. falx Schrank.

99. jasciola. (Vibrio Müller.)

$\left\{\begin{array}{l}\text { Petersburg } \ldots \ldots \ldots \ldots \ldots \ldots \frac{1}{12}-\frac{1}{8}{ }^{\prime \prime \prime} \\ \text { Bogoslofsk } \ldots \ldots \ldots \ldots \ldots \ldots \frac{1}{25}{ }^{\prime \prime \prime}\end{array}\right.$

Uralsk.............. $\frac{1}{18}$

Petersburg............. $\frac{1}{24}$

Riddersk. . . . . . . . . $\frac{1}{8}-\frac{1}{7}{ }^{\prime \prime \prime}$

Tobolsk ............. $\frac{1}{10}{ }^{\prime \prime \prime}$

\} Petersburg........... $\frac{1}{192}-\frac{1}{96}$

Syrjanofskoi $\ldots \ldots \ldots \ldots \ldots \frac{1}{100}{ }^{\prime \prime}$ \} Petersburg............. $\frac{1}{24}$ Petersburg............. $\frac{1}{36}$

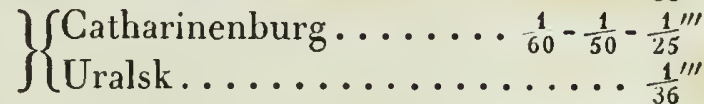
100. ? ? _lobuliferus.n.sp. 101. lamella. (Kolpoda lamella Müller.) \} Petersburg........... $\frac{1}{75}-\frac{1}{48}$ 102. trichophorus.n.sp. Tobolsk .................... $\frac{1}{100}{ }^{\prime \prime \prime}$ 103. Trichoda ? Paramaecium. n. sp. $\left\{\right.$ Petersburg........... $\frac{1}{96}-\frac{1}{88}$." ( $f r$. Enchel. seminulum M. $)\}\left\{\right.$ Catharinenburg . . . . . . $\frac{1}{100}$

104. Trichodina grandinella. (Trichodagrandin. Müller.)

105. com os a. n. $\mathrm{sp}$. \} Riddersk ................. $\frac{1}{96}$ 106. - stellina. (Vorlicel. slellina Müller.) $\}$ Petersburg $. \ldots \ldots \ldots \ldots . . . \frac{1}{46}^{\prime \prime \prime}$ 107. TRICHODISCUS Sol. n. G. Phys. Abliandl. 1830.

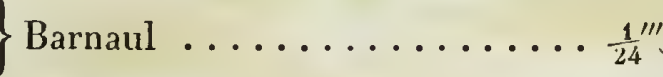
$\left\{\begin{array}{l}\text { Kyschtym . . . . . . . . . . } \frac{1}{36 \prime \prime} \\ \text { Barnaul . . }\end{array}\right.$ Barnaul.............. $\frac{1}{30}$ 
108. Virrio amblyoxys. n. sp. 109. lineola Müller.

110. rugula Müller.

111. Vorticelua Convallaria Müll.

a) campanulata.

B) pyriformis.

112. microstoma. n. sp.

113. Urocentrum turbo Nitzsch. (Turbinella Bory.)
Gröfse nach Pariser Linien. Tobolsk .............. $\overbrace{}^{\frac{1}{50}}$ Petropawlofsk ............ $\frac{1}{300}{ }^{\prime \prime \prime}$ CBarnaul............... $\frac{1}{48}{ }^{\prime \prime}$ $\left\{\right.$ Uralsk................ $\frac{1}{96}{ }^{\prime \prime}$ Petersburg........... $\frac{1}{96}-\frac{1}{48}{ }^{\prime \prime \prime}$

Nishne Tagil ...... Körper ... $\frac{1}{80}{ }^{\prime \prime}$ $\left\{\begin{array}{l}\text { Catharinenburg } \ldots \ldots \text { " } \ldots . \frac{1^{\prime \prime \prime}}{80} \\ \text { Petersburg. . . . } \\ \text { B. }\end{array}\right.$ Bogoslofsk ...... " ... $\frac{1}{96}{ }^{\prime \prime \prime}$ \} Tobolsk ............. $\frac{1}{45}$ 


\section{Tabelle II.}

Verzeichnifs der russischen Infusorien nach den

XXII Beobachtungspunkten.

(Geordnet nach der geographischen Breite der Orte von Süden nach Norden.)

$\mathrm{I}$.

Kurotsclikinskischer See bei Astrachan. $46^{\circ}$ N.B. $66^{\circ}$ Ö.L.? .

(Es wurde Salzwasser dieses Sees beobachtet, welches in Astrachan längere Zeit in Flaschen aufbewahrt worden war.)

Monas erubescens. n. sp.

II.

Buchtarma ain Altai und Irtysch. $49^{\circ}$ N.B. $101^{\circ}$ Ö.L.

Bacillaria elongata. n. sp.

DIGLENA capitata. n. sp.?

Monas mica Müller.

Navicula fulva. gracilis. n. sp. fusiformis. n. sp. ventricosa. n. sp.

$\cdot$

III.

Syrjanofskoi im Altaigebirge.

Astasia viridis. n. sp.

BACTERIUM deses.

Coleps hirlus Nitzsch.

LOXODES cucullulus.

Monas umbra. n. sp.

Navicula gracilis. n. sp.
Oxytricha lepus Bory.

Paramancium Aurelia Müller.

SPIRODISCUS fulvus. n. sp.

$$
\text { IV. }
$$

Prochodnoi-Alpe bei Riddersk im Altai. (Aus Conferven von der Alpe; beobachtet in Riddersk.

Rotrfer vulgaris Schrank. TRICHODINA grandinella.

$$
\text { V. }
$$

Smeïnogorsk (Schlangenberg) im AltaiGebirge.

(Die mit * bezeichneten sind aus der Tiefe des Bergwerks.)

*ANGUILLULA fuviatilis.

Anuraea palea Bory.

BODO viridis. nov. Gen.

DIGLENA catellina.

Gonium hyalinum. n. sp.

* Kolyoda cucullus Müller.

*LOXODES cucullulus.

* _._. cucullio.

Monas Kolpoda. n. sp. uva Müller.

MONOSTYLA cornuta.

Navicula gracilis. n. sp. 
VI.

Koliwanski Sabod im Altai.

(Steinschleiferei am Flüfschen Belaja reka. Aus Conferven.)

Closterium linula Nitzsch. Monas termo Müller.

VII. Uralsk an Uralflusse.

Aspidisca Lynceus.

(Trichoda Müller.)

Kolpoda cucullulus Müller.

Navicula fusiformis. n. sp.

Oxytricha pullaster.

(Kerona Müller.)

Paramaecium compressum. n. sp.

Tracielius fasciola.

(Vibrio Müller.)

Visnio rugula Müller.

VIII.

Saratof an der Wolga.

Amoena diffluens.

(Proteus Müller.)

Exilaria flabellum. n. sp.

Fragilaria angusta. n. sp.

- pectinalis Lyngbye.

- scalaris. n. sp.

GonpHonema rotundatum. n. sp.

IX.

Ilezkaja Saschtschita bei Orenburg.

(Im Salzwasser.)

Anguillula recticauda. n. sp.

BACTERIUM monas. n. G. cylindricum. al.sp.
DOXOCOCCUS globulus.

(Volvox Müller.)

LOXODES cucullulus.

(Kolpoda Müller.

Monas atomus Müller.

$\mathrm{X}$.

Orenburg am Uralflusse.

Navicula gilbla. n. sp. uncinata. n. sp. - turgida. n. sp. var.

XI.

Sakmaraflufs bei Orenburg.

(An Conferven.)

Carchesium fasciculatum.

(Vorticella Müller.)

XII.

Platofskische Steppe zwischen Barnaul und Koliwan im östlichen Sibirien.

ASTASIA haematodes. n. G.

XIII.

Kyschtym im südlichen Uralgebirge.

Pandonixa Morum Bory. TRICHODISCUS Sol. n. G.

XIV.

Soimıonofskoi im südlichen Uralgebirge.

(Aus einer 6 Saschenen tiefen Kupfergrube.)

* Monas a tomus Müller.

* ___ encholys. n. sp.

*__ terno Müller. 
der Infusorien und ihrer geographischen Verbreitung.

XV.

Troizk im südwestlichen Sibirien am Ui,

(Aus salzigem Wasser der Steppe.)

Gomphonena discolor. n. sp.

XVI.

Barnaul im östlichen Sibirien am Obi.

Leucophrys ? fluida Müller.

Monas atomus Müller.

$$
\text { ovalis. n. sp. }
$$

Navicula gracilis. n. sp.

- fusiformis. n. sp.

Trichodina stellina.

(Vorticella Müller.)

TRICHODISCUS Sol. n. G.

Vibrio rugula Müller.

XVII.

Petropawlofsk im westlicleen Sibirien am Ischim.

(Aus salzigem Wasser der Steppe.)

Anguillula inflexa. n. sp.

Colurus uncinatus.

(Brachionus Müller.)

Vibrio lineola Müller.

\section{XVIII.}

Catharinenburg a. d. Iset im Uralgebirge.

(Aus der Iset, dem See Schartasch und aus Sumplwasser.)

ACTINOPHRYS Sol.

(Trichoda Müller.)

Amoeba difluens.

(Proteus Müller.)

ARCELLA vulgaris. n. G.

ASPIDISCA Lynceus.

(Trichoda Müller.)
BACTERIUM ?fuscum. n. G.

BODO didymus. n. G. vorticellaris. al. sp.

Closterium lınula Nitzsch.

COCCONEMA vernale.

Cychidium? margaritaceum. n. sp. DOXOCOCCUS pulvisculus. n. G. inaequalis. al. sp.

Exilaria panduriformis. n. sp.

Fragilaria bipunctata. n. sp. scalaris. n. sp.

Gomphonema constrictum. n. sp.

Kenova pustulata Müller.

Monas termo Müller.

Navicula fulva.

(Bucillaria Nitzsch.)

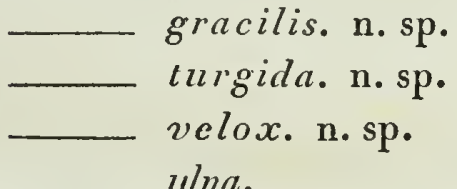

(Bacillaria Nitzsch.)

Trachelius fasciola.

(Vibrio Müller.)

Trichoda ? Paramaecium. n. sp.

Vorticelda Convallaria Müller.

\section{XIX.}

Nislne Tagil im nördlichen Uralgebirge am Trigil.

Vorticelua Convallaria Müller.

XX.

Tobolsk im nordwestlichen Sibirien am Irtysch und Tobol.

Anguillula fluvialilis.

(IVibrio Müller.) 
ARCELLA vulgaris. n. G. BACTERIUM Monas. n. G. Brachionus urceolaris Müller. Closterium trabecula. n. sp.

Colurus uncinatus.

Diffiugra proteiformis Le Clerc. EOSPHORA Najas? n. G.

Fragilaria angusta. n. sp. HYDATINA ?leptocerca. n. sp. ?laticanda. n. sp.

Kolpoda cucullus Müller.

Monas hyaliua. n. sp.

MONOSTYLA ?lunaris. n. G. MONURA Colurus. n. G.

Navicula turgida. n. sp. SalPina ?bicarinata. n. sp.
Trachenius globuliferus. n. sp. trichopliorus. n. sp. Vibrio amblyoxys. n. sp. Urocentrum turbo Nitzsch.
XXI. Bogoslofsk im nördlichen Uralgebirge an der Turia.

Nahe am $60^{\text {sten }}$ Breitengrade.

Coleps liirtus Nitzsch.

Colurus uncinatus.

(Brachionus Mïller.)

HYDATINA ?terminalis. n.sp.

Lepadella ?triptera. n. sp.

Paramaecium Chrysalis Müller.

Vorticella microstoma. n. sp.

\section{XXII.}

Petersburg.

$60^{\circ}$ N. B. $48^{\circ}$ Ö. L.

(Die verzeichneten Thierchen fanden sich theils im Newa-Wasser, theils zwischen Conferven des Sumptwassers, theils in Aufgïssen, welche ich mit verschiedenen Vegetabilien bereitete; eine andeı Anzahl erhielt ich durch die Güte des bekannten Physiologen Hrn. Dr. Pander und des Hrn. Dr. Weifse, welche mit wichtigen wissenschaftlichen Untersuchungen über das Verhalten der Infusorien in den Infusionen beschäfligt waren und mir die Ansicht derselben freundlich überliefsen.)

BACTERIUM enchelys. n. G. Monas hyalina. n. sp.

putuctume. al. sp.

termo. al. sp.

trenculans. al. sp.

Cxcuidum glauconıa Müller.

GLAUCOMA scintillans. n. G.

Kerova pustulata Müller.

Kolpoda cucullus Müller.

$$
\text { Ren Müller }
$$

Monas guttula. n. sp. umbra. n. sp. volvox. n. sp.

Paramaecium Aurelia Müller. Chrysalis Müller.

SPIRILLUM volutans. (Vibrio spirillum Müller.)

Trachelius anas.

(Trichoda Müller.) 
Tracielius falx Schrank. lamella.

(Kolpoda Müller.)

Trichoda? Paramaecium. n. sp.
TRICHODINA comosa. n. G. Vibrio rugula Müller.

Vorticella Convallaria Müller.

B) pyriformis.

Anmerkung: Ich habe in diese Verzeichnisse alle solche Körper aufgenommen, welche die microscopisch beobachtenden Zoologen bisher für Infusorien hielten, obwohl eine Anzahl Gattungen noch nicht in den von mir beigefiigten Versuch eines Systems der Infusorien aufgenommen werden konnte. Hoffentlich wird diese Arbeit noch andere Beobachter anregen, auf gleichem Wege fortzubauen, wodurch die noch vorhandenen Fragzeichen und Zweifel bald verschwinden werden.

Die Gattungen Trichodiscus und Spirodiscus, von denen in den systematischen Tabellen nicht die Rede ist, sind rücksichtlich ilırer Structur noch dunkel, doch gehört die erstere, welche auch bei Berlin vorkömmt, wahrscheinlich in die Nähe von Actinophrys, und die letztere in die Nähe von Spirillum. Beide werde ich in einem weiteren Beitrage zur Naturgeschichte Rufslands, den ich mitzutheilen gedenke, nebst den übrigen neuen Formen speciell charakterisiren; eine kurze vorläufige Diagnose liegt in den Namen.

Im Übrigen liefern vorläufig dieselben 2 systematischen Tabellen im kleinsten Raume die bündigste Erliuterung der neuen und alten Gattungsnamen. Die Gattungen Asıasia und Euglena sind bereits in Poggendorf's Annalen der Physik und Chemie, X VIII. Band, $4^{\text {tes }}$ Stück 1830. von mir umständlicher angezeigt worden.

Na c h t r a g.

Während des Druckes der Abhandlung haben die fortgesetzten Beobachtungen noch fölgendes ergeben:

1. Die Lücke, welche in System der Rotatoria Polytrocha loricala zwischen den Formen mit 1 Auge (Salpina) und denen mit 4 Augen (Squamella) fühlbar war, wenn man sie mit den Polytrochis nuclis verglich, hat angefangen sich zu füllen. Ich habe nämlich das als Lrpadella? triptera fraglich verzeichnete Thierchen von Neuem beobachten 
können und bei ihm 2 kleine Stirnaugen entdeckt, welche es aus der augenlosen Gattung Lepadella entfernen. Ich nenne es daher künftig: Metopidia triptera, und stelle es zwischen Salpina und Squamella.

2. Ich hatte Gelegenheit, eine sonderbare neue Form der Gattung Vaginicola zu beobachten. welche aus mehreren sehr kleinen Individuen zusammengesetzt ist und frei im Wasser schwimmt. Ich nenne sie vorläufig $V$ aginicola socialis. Grülse eines Individuums $\frac{1}{72}$ ".

3. Ich bemerke, dafs ich Cyclidium nuargarilaceum, aus Catharinenburg im Ural, nun auch bei Berlin gesehen, und mich sowohl von seinen Wimpern, als Ernährungsorganen überzeugt . habe. Das Fragzeichen ist daher nicht weiter beizubehalten. 


\section{Erläuterung der Kupfertafeln.}

Diese Abbildungen sollen besonders zur anschaulichen vergleichenden Darstellung des organischen Ernährungssystenı der verschiedenen polygastrischen Infusorienformen dienen. Nur als Anhang wurde die Organisation der Räderthierchen betrachtet, und die $8^{\text {te }}$ Tafel wurde später zıgefügt, weil die cinflufsreichen Beobachtungen später vollendet wurden. Alle Thiere sind in dem Zustande dargestellt, in welchem sie erscheinen, wenn man ihnen Farbesubstanzen als Nahrung gegeben, daher das Blau Indigo-, das Roth Karmin-, das Grün Saftgrüngenufs anzeigt. Im natürlichen Zustande sind sie sämmtlich fast farblos. Die rothen einzelnen Punkte bei den Thieren rer $7^{\text {ten }}$ Tafel zeigen aber nicht Ernährungsorgane, sondern die natürliche Färbung ihrer Augen an, welche durch den Genufs verschiedenfarbiger Speisen nicht verändert, und nach Tub.VIJ. Fig. 1. $c$. bei den Jungen im Mutterleibe schon erkannt wird. Überall ist auf die verschiedenen Entwicklungsstufen der Thiere, so weit der Raum, welcher besonders die Übersicht befördern sollte, es gestattete, Rücksicht genommen, aber die $3^{\text {te }}, 5^{\text {te }}$ und $\eta^{\text {te }}$ Tafel sind besonders auch der cyclischen Entwicklung einzelner Thiere gewidmet.

Sämmtliche Figuren sind von mir selbst gezeichnet, und nicht willkührlich oder planlos vergröfsert dargestellt, sondern gerade in der Gröfse abgemessen, welche das Microscop gab. Nur auf der $1^{\text {sten }}$ Tafel sind einige selır kleine Thierchen nach 800 maliger Vergröfserung des Durchmessers gezeichnet, und das findet sich angezeigt, alle übrigen sind es nach 350 maliger Vergrölserung desselben olne weitere Bemerkung. Demgemäls sollte das Bild der IIydatina senta der $8^{\text {ten }} \mathrm{Tafel}$, welche $\frac{1}{8}$ Linie grofs und $350 \mathrm{mal}$ vergrölsert ist, noch nicht völlig 4 Zoll grofs sein.

Das menschliche Auge sieht nicht immer dieselben Gegenstände in derśelben Grö Ise. Manche Personen sehen sie immer etwas gröfser als andere, selbst beide $\Lambda$ ugen einer und derselben Person zeigen Unterschiede, und auch ein und dasselbe Auge sieht etwas anders zu andern Zeiten. Dieser Unstand bringt bei microscopischen Gegenständen Verwirrung, wo er nicht berücksichtigt wird. Daher ist es nötlig, obwohl es bisher in sehr wenigen Fällen geschah, die Gegenstände selbst nit einem (am besten einem Glas-) Micrometer, dessen Verhältnifs ein für allemal bekannt ist, zu messen. Diefs Maafs, da es durch das Auge gleichzeitig gesehen und verglichen wird, schneidet den durch jene Veränderlichkeit entspringenden Zweifel und Irrthum fïr die Gröfsen vollständig ab, aber es bessert nicht das Sehen desselben Gegenstandes in verschiedener Gröfse. Um mithin sämmtliche Figuren in relativ richtiger Gröfse nebeneinander zu haben, sollte man sich des Mittels bedienen, dieselben auf einen und denselben Maafsstab zu reduciren. Da mein Auge nicht allzugrofse Variationen zeigt, so habe ich diese Reduction unterlassen und die Figuren gerade so gegeben, wie ich sie sah, nur lábe ich ihr wirkliches Maals, nämlich immer ihre höchste, nit dem Mịcrometer gemessene Grölse dabei angezeigt, welche Angabe dennach wichtig und als Regulaţor zu betrachten ist.

Phys. Alliandl. 1830. 


\section{Tafel 1 .}

I ${ }^{\text {ste }}$ Gruppe. Die Schlufs-Monade, Munas termo Müller mit blauem Farbcstoff gefüllt, bei 800 maliger Vergröforung des Ihurclımessers gesehen. Wäre das Thierchen $\frac{1}{1000}$ Linie grofs und $1000 \mathrm{mal}$ vergröfsert, so wiirlc es cine Linie grofs erscheinen. Die Messung dieser Thicrchen ergab $\frac{1}{1500}-\frac{1}{2000}$ Linie. Deutlich erkennt inan noch im Hittertheile des Leibes 1 bis 4 und bis 6 Punkte von blauer Farbe, welche sich, vergleicht man die ïbrigen gröfseren und deutlicheren Infusorien, ohne alle Gefahr des Irrthums für Magen crkenuen lassen. Dabei sielıt man den Vordertheil des Thierchens noch leer. Es giebt noch eine andere $\Lambda \mathrm{rt}$ von Monaden, welche dieselbe Gröfse hat, die ich aber nie zur Aufnahme von Nahrung bringen konnte. Jene lebt in vegetabilischen, diese in thierischen odcr Pilzaufgüssen gewöhnlicher. Vielleicht gehen sie nicht gern von einer Nahrung zur andern sehr verschiedenen über. Ich trenne die andere Form einstweilen als Monas crepusculum, Dämmerungs-Monade, deren Thierlieit ich nicht beweiscn kann. Von beiden leben oft ungefähr 500 Millionen in einten Tropfen.

II ${ }^{\text {te }}$ Gruppe. Die Atomen-Monade, Monas atomus Mülle r, deren Gröfse nur $\frac{1}{288}{ }^{\prime \prime \prime}$ beträgt und die, wie die folgende, nur 380 nal vergröfsert ist. Bci dieser sieht man schon deutlich die scharf umgrenzten mit (1.) blauer und (2.) rother Farbe gefüllten Behälter. Einige sind in der Mitte mehr oder weniger zusammengesclinürt und im Begriff sich durch Theilung zu vervielfältigen. Einige Individuen sind leer und diese gehö̈ten sonst nach $M$ üller eincr andern Art, dfr Monas lens, an. Die Jungen der Kolpoda cucullus lassen sich von dieser Form durch kein mir bekanntes Nittel unterscheiden. Sie gehört zu den Monaden die in ciner ihrer Entwicklungsstufen sich aneinander längen und traubenförmig erscheinen, sich aber allenal wieder auflösen. Monzas uoa $\mathrm{M}$ ïll e $\mathrm{r}$ unterscheide ich durch andre Charactere.

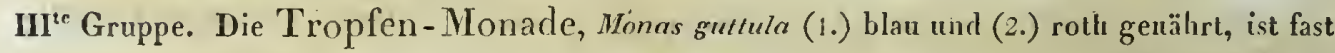
noch einmal so grofs als vorige und kugelrund. Wegen ilırer Gröfse und Durchsichtigkeit wird sie viel deutlichcr. Sie dreht sich un ihre Längsaxe und lat inmer den von den farbigen Punkteı abgewendeten Theil im Schwimmen vorn. Da sieht man auch kleine Virbel im Wasser, da ist also cin wahrer Mund mit Winpern zu suchen, den ich jedoch nicht so deutlich an sich erkannte, dafs ich ihn hätte in der Zeichnung angeben können. Bei der Staub-Monade Monas pulvisculus ist ein bewimperter Mund dentlich zu erkennen. Die Wirkung zeigt, dafs er bei den kleineren Formen ebenfalls da sein mufs. Ich sah sie nie traubenförmig.

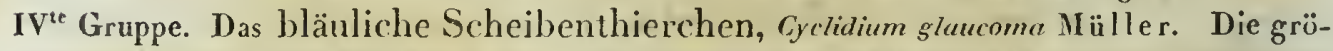
fseren Individuen A. sind 800 mal vergrö $\{$ sert, die kleineren B. 380 mal, einige sind blau, andere sind roth genährt. Einige a. sind im Begriff sich zu theilen. Die breiteren schwimmen aıf dem Rücken, oder dem Bauche, die schmäleren sieht nan von der Seite, einige halb gewendet. Man unterscheidet bei der Seitenlage und wenn das Wasser mit Farbestoff erfülltt ist, den sie bewegen, deutlick einen Kranz von Wimpern (vergl. $c$. und $d$. der Blanen). Der Strudel und die Mundöffnung ist vorn und unten, aber letztere nicht selbst zn erkennen, nur in der Wirkung. 
Wie Fig. A.d. bei den Rothen und B. * bei den Blauen erscheinen sie beim Eintrocknen des Wassers im Toule.

V' Gruppe. Das schmelzende Wechselthierchen, Amoeba diffluens, ist schon sehr grofs im Verhälınifs zu jenem. Sie haben keine bestimute Gestalt, sondern ändern dieselbe willkührlich. In seiner gröf,ten Zusammenziehung bildet es eine gallerlige Kugel (Fï.V. 1.). Fig.V.2. ist dasselbe Thier und V. 5. wieder dasselbe, ausgedehnt. Bei V.2.* sielı man einen hellen Fleck, den Mund ohne Wimpern, der sich bald erweitert bald zusammenzieht. Zu Fig. 3. und 4. wällte ich benbachtete Formen welche durch genofsne Nuvicula ulna und gracilis dentlich zeigen, dafs sie auch grofse Körper überwältigen und verzehren. Beide Figuren sind nach demselben Thiere genommen; bei 4.* ist die Munlöffunng deullich. 1. 2. und 5. haben Indigo verzelırt und zeigen ihre polygastrische Structur, die in 3. und 4. durch unverhältnif,mä[sige Erweiterung einzelner Magen nicht deutlich werden konnte.

VI $^{\text {te }}$ Gruppe. Das gewöhnliche Kapselthierchen, Arcella vulgaris. Der strahlenartig feingeriefte Schild und der willkiihrlich bald in 2 bald in 7 Fortsätze verlängerte veränderliche crystallhelle Leib ist in Fig. 1. sichıbar und * halte ich für die durchscheinende Mundöffnung; 2. ist ein Junges; 3. ist die Seitenlage. Die blauen Flecke zeigen die Mehrzahl der Mlagen an. Ich habe viel gröfsere Individuen beobachtet und bis 20 Magen gezählt. Seil dem Drucke der systematischen Tabelle fantl ich auch eine zweite Art der eigentlichen Gattung Difflugia bei Berlin, welche sich durch eine hintere Spitze an ihrer Hülse und bedeutendere Gröfse auszeichnet, ich nenne sie: das spitzige Schmelzthierchen, Diffugia acuminata. Farbige Nahrung verschmäht sie auch.

VII ${ }^{\text {te }}$ Gruppe. Das thierische Haarthierchen, Trichoda carnium, eine neue Art; eíne der verschicdenen Thieıformen, welche Müller Kolpoda pyrum nannte. Deutlich sielıt man bei A.* den gewimperten seillichen Mund, welcher durch die Wasserwirbel Farbetheitchen einzieht, und ihm entgegengesetzt bei * die Auswurfsöfrnung. Die helle Queerlinie derselben Figur deutet auf bevorstehende QueerTheilıng hin, die bei $a$. und $b$. schon weiter vorgerückt und daneben vollendet ist. Die kleineren sind Junge, welche man zwischen den Alten sieht. Manchmal zeigen sie Längsfalten wie bei $B$., besonders wenn das Wasser zu nuangeln anfängt und man neues hinzuthut. Nach der 11 üllerschen Methodle würde man diese danu für Paramaecien halten müssen. Die Figur B.* zeigt ein vertrocknetes Thierchen in Tode, wo die Wimpern sehr deutlich werden.

\section{Tafel II.}

I $^{\text {se }}$ Gruppe Das puppenförmige Flaschenthierchen, Enchelys pupa und zugleich Enchelys farcimen von $M$ ïlle r, je nachlem es jung oder alt, hungrig oder genährt ist. Die Figuren 4. 6. 7. 8. 9. sind offenbar die letztere $\Lambda \mathrm{rt}$, während 1. 2. 3. und 5. zur ersteren gehören. In den Figuren 9. 10. - 14. habe ich die Beobachtung des Verschlingens eines Loxodes cucullulus mitgetheilt, welches das langgestreckte Thier plötzlich in ein eiförmiges umwandelt. Die gewimperte grofse ganz 
vordere Mundöffnung ist bei allen siclıtbar. Das Auswerfen verdauter Nahrung zeigt Fig. 3., und in Fig. 15. ist der Darmkanal dargestellt, wie man sich ihn durch mühsame Beobachtıng der gröfseren Formen allmälig deutlich machen kann. Der gewimperten Mundöffnnng ist die nackte Analöffnung entgegengesetzt, vor welcher eine Cloaken-ähnliche Erweiterung des Darmes gesehen wird. Die Magen bilden mit dem Darme eiue Traube. Die übrigen ungewissen Dunkelheiten des Körpers sinłl, der Analogie nach, die den Darm umliüllende Eierstockmasse.

II ${ }^{\text {te }}$ Gruppe. Das weite Wimperthierchen, Leucophrys palula. Diese ziemlich grofse Infusorienform ist sehr dazu geeignet, eine deutliche Ansicht des Darmkanals dieser Thierehen zu geben, nur darf sie nicht, wie man es oft findet, sich schon mit grünem Schleim oder andern halb durchsichtigen Dingen unregelmäfsig gefüllt haben. Fig. 1. ist nach der Natur gezeichnet, und beim Drehen des Thieres erschienen allmälig die übrigen Tleile des Darmkanals, wie sie in Fig. 6. gezeichnet sind; bei * ist die Analöffnung. Ein unregelmäfsig natürlich bunt genährtes Thier ist Fig. 2., welehes noch nicht viel Indigo verzehrt hatte. Ein ganz nit Indigo gesättigtes Thier ist Fig. 3. Es hat 51 gefüllte Magen und die Ansleerung zeigt die Analstelle. Fig. 4. ist dasselbe Thier in der Theilung, welche Queertheilung ist. Fig. 5. ein solcher frei schwimmender Theil, worlurch die Veränderliehkeit der Körpergestalt wieder anschaulich wird. - Da rler Name Leucophra unrichtig gebildet ist, und deshalb von einigen ( Gold $\int_{11} \mathrm{~s}$ ) Leucophora geschrieben wird, was gegen die Absicht des Gründers seheint, so habe ich für gut gehalten, obige Endung anzuwenden.

III ${ }^{t e}$ Gruppe. Das birnförmige Wimperthierchen, Eeucophrys pyriformis, eine neue Art, die wahrscheinlieh auch unter Kolpoda pyrum Müller gehört hat. Die Körperbehaarung ist in Längs - Reihen gestellt, wie auch bei der vorigen. Oft ziehen die Thierchen sie ein, oder legen sie an den Körper an (2.3.9.10.) und erscheinen dann glatt wie Trichoda carnium, giebt man ihnen aber etwas Indigo in den Tropfen, so erscheinen sie sogleich alle wie Fig. 7. In 5. und 6. ist die Theilung dargestellt. Fig. 3. zeigt die Ausleerungsstelle. Die kleinen Pfeile welche hier und da bei den Figuren stehen, zeigen die durch das Wirbeln der Thierchen erzeugten Wasserströmungen und ihre Richtung an. Die seitliche Mundöffnung hat gröfsere Wimpern.

IV te Gruppe. Das gewöhnliche Sonnenthierchen, Actinophrys Sol; Trichoda Sol Müller. Auf die grofse Mundöffnung dieses Thierchens hat schon Eichhorn aufmerksam gemacht, und sein Verschlingen gröfserer Thiere zu umständlich bewundert. Es hat einen deutlichen fleischigen Rïssel, den es bald mehr bald weniger vorschiebt, wie in Fig. 1. 8. 4. angegeben ist, oft sieht man nur seine Stelle (wie in Fig. 3. und 5.) deutlich, und diese zieht sich zuweilen rasch zusammen (Fig. 7.) bis zu einer kleinen Queerspalte. Kehrt das Thierchen seinen Rüssel vom Auge weg oder ihm zı, so täusclıt man sich leicht. Die Theilung ist Queertheilıng (Fig. 6.). Ich zählte bis 20 Magen bei ihm. Oft sah ich es an Kerona pustujala geheftet, die es am Schwimmen hinderte, bis sie still stand und starb. Sie sehien dieselbe mit dem Rüssel auszusaugen. 


\section{Tafel III.}

Dieses Blatt ist ganz der Darstellung der Entwicklung des gewöhnlichen Busenthierchens, der Kolpoda cucullus gewidmet. Fig. 1. ist ein ansgeschiedener Eierstock, wie ich ihn nach dem beobachteten Acte des Ausscheidens frei im Wasser liegen sah. Das Mutterthier, welches im Gebähract begriffen ist, findet sich darübcr als Fig. 14.a. Die weitere Entwicklung der Eiermasse lıbe ich noch nicht beobachten können, aber die kleiısten Formen der Kolpoda cucullus, deren Entwicklung zu gröfsern ich beobachtet habe, finden sich unter den Figurengruppen 2. 3. 4. Fast möchte ich glauben, dafs ich auch die frühesten Stulen schon oft gesehen habe, und sie nur für Arten der Gattung Monas halten mufste, weil ich sie nicht ungczwungen in Zusammenhang mit den Formen der Kolpoda bringen konnte. Jene kleinsten bei denen kein Zweifel ïbrig bleibt waren von der Gröfse einer $\frac{1}{144}$ Linie. Bei mehreren von ihnen sieht man Winpern in der Mitte des Körpers an seiner etwas concaven Seite, die sogleich ganz deutlich werdcn, wenn das Wasser durch Farbe getrübt wird und ihr Nahrungstrieb Stoff crhält. Die mit * bezeichneten Figuren derselien obern Gruppen sind nach auf das Glas angetrockneten Thierchen gezeichnet. Bei 4.* ist eins laufend oder tastend dargestellt. Die übrigen theils blau, theils roth, theils grün genährten Gruppen zeigen den mehr erwachsenen Zustand in seiner allmäligen Entwicklung an. Die breitern Formen liegen auf der Seite, die schmäleren kehren dem Auge, mehr oder weniger gewendet, den Rücken oder den Bauch zu. Das Individuum, welches in der Mitte der Tafel mit * bezeichnet ist, zeigt den ausgebildeten ganz unverletzten Zustand des Thieres an. Im Grunde scines busenförmigen Ausschnitts erkennt man eine längliche hellere Stelle, welche den Mund bezeichnet, und die das Thierchen bald öffnen bald schliefsen kann. Diese ganze Gegend ist mit Wimpern besetzt, welche dem Rücken fehlen. Das Individuum der $7^{\text {ten }}$ Gruppe, welches der Zahl am nächsten steht, zeigt mit dem untersten der $6^{\text {ten }}$ Gruppe und dem obersten der $5^{\text {ten }}$ so wie mit Fig. 11. $a$. und $b$. die Afterspalte unterhalb der Mundöffnung in verschiedenen Graden der Bestimmtheit. Der zungenförmige Theil in der Mitte ist die Scheidewand der beiden Öffnungen. Der helle Fleck im Grunde der ersten ist iiberall der Mund. Die zweite Spalte ist bei vielen nicht sichtbar, wegen ihrer Zusammenziehung. In der mittleren Figur der $7^{\text {sen }}$ Gruppe ist der Act des Auswerfens dargestellt. Figur * der $7^{\text {ten }}$ Gruppe ist dasselbe Thier, dessen Gebähren oben angegeben ist, kurz vor dem Gebähren. Fig. 14. $a$. zeigt dasselbe Individuum in Act des Gebährens und Fig. 14.6. nach vollendetem Acte, wo es wieder so munter mit den andern schwamm und im Wasser wirbelte, wie vorher. Die Figuren 9. 10. und 13. stellen andere durch wiederholten Gebähract vcränderte lebendige Individuen derselben Thierart vor, welche zeigen, wie wenig die Körperform geeignet ist, zur Unterscheidung dieser Thierchen zu dienen. Fig. 12. ist noch jung, und vorn scharf abgestutzt, wohl eine Mifsbildung. Der Durchmesser der einzclnen körnigen Fibern des ausgeschiedenen Eierstocks betrug $\frac{1}{1000}$ Linie, folglich verhält sich dersclbe zum Mutterthier, welches $\frac{1}{14}$ Linie lang war, wie $40 \mathrm{zu} 1$. Somit wäre denn der Cyclus einer Art-Entwicklung eines Infusoriums fast vollständig beobachtet und festgestellt. Etwas Geduld und Zeit wird die Beobachtung bald vollenden. 


\section{Tafel IV.}

$I^{\text {ste }}$ Gruppe. Das flimmernde Perlenthierchen, Glaucoma scintillans. Eine neue Thiergattung, vielleicht dieselbe, an wclcher Gleichen seine Versuche machte. Es ist crystallhell und wahrscheinlich oft für Cyclidium glaucona gehaiten, welches viel kleiner ist, vielleicht selbst von $M$ ülle $\mathrm{r}$ damit verwechselt worden. In stehenden. Wasser ist es sehr häufig. Eine bewegliche Borste unter der fast mitten am Bauche befindliche Nlundöffnung, welche oscillirt, giebt ganz die Erscheinung eines Herzschlags. Die ziemlicls grofsen Magen bringen ein interessautes Ansehn hervor. Es hat einen kleinen Rüssel und pflanzt sich auch (Fig. 4. und 5.) durch Queertheilung fort. Ein Junges aus dem Ei schcint Fig. 9. zu sein, weil es zu klein ist, um aus Theilıng entstanden zu sein. Fig.10. drängt sich zwischen 2 härteren Körpern durch. Die Afteröffnung ist am Ende des Körpers.

II $^{\text {te }}$ Gruppe. Das nymphenartige Längenthierchen, Paramaecium chrysalis Müller. Dies hat mir die gröfstc Zahl von Magen sehen lassen, indem ich bis 120 gezählt habe, und doch noch Raum genug für andere sah. Im klaren Wasser sieht man die Behaarung, welche in regelmäfsigen Reihen steht, nicht, aber bei Zuthun von Farbe wird sie augenblicklich sichtlar. Daher hat man unrecht gethan, die haarigen Formen von den glatten abzusondern. Der Rüssel bildet eine längliche Halbkugel, die in Fig. 2. deutlich ist. Dic Auswurfstelle ist bei Fig. 6. zu sehen.

III ${ }^{\text {te }}$ Gruppe. Das haubenförmige Lippenthierchen, Loxodes cucullulus, Kolpoda cucull. Müller. Loxodes bezeichnet eigentlich das Schiefe des durch die gewimperte Lippe gebildeten Vorderrandes. Das Thierchen ist übrigens unbehaart. Es ist eins der gemeinsten, und besonders durch seine Längstheilung, wie in dęn Figuren 6. 7. 10. 11. dargestellt ist, auffallend und leicht zu erkennen. Die ganze obere Reihe der Figuren zeigt einfache Thierchen in verschiedenen Bewegungen und Lagen. Die schmalen sind von der Seite gesehen, die breiten von oben oder unten. Die ganze untere Reihe ist der vierfachen Theilung derselben gewidmet. Fig. 5. 6. 7. 10. 11. 12. zeigen verschiedene Perioden der Längstheilung von hinten nach vorn. Fig. 8. und 9. sinıl zwei ganz gesonderte Theile. Fig. 14. stellt ein in der Längstheilung von vorn nach hinten begriffenes Individuum vor. Fig. 13. zeigt eine von vorn und von hinten gleichzeitig eintretende Theilung, und Fig. 15. eine bevorstehende Queertheilung. Fig. 16. ist Fig. 17. von der Seite gesehen. Fig. 17. zeigt oben bei* den MIund, unten bei * die Stelle der Analöffnung. Im Innern erkennt man eine verschluckte Navicula. Fig. 21. suclit sich Nahrung dnrch Wirbeln.

[Y ${ }^{\text {te }}$ Gruppe. Das bindenförmige Halsthierchen, Trackelius fasciola. Die Stelle der Mundöffnung ist eine Längsspalte, wohin bei Fig. 9. der Stern zeigt. Fig. 2. 3. 5. 6. sind Scitenansichten. Es vermehrt sich durch Queertheilung und Längsthcilung. Fig. 7 . ist das Ilinterstiick eines durch Queertheilung gespaltenen Individuuns. Fig. S. ist ein in der Queerthcilung von hinten nach vorn begriffenes Individuum. Dieses Thierchen gehört vielleicht richtiger noch zur Gattung Amplizleptus, da der After nicht ganz an Ende ist. Trachelius lamella ist viel- 
leicht das Junge aus dem Ei von dieser Form. In getrübten Wasser sieht man es behaart.

$V^{\text {te }}$ Gruppe. Das gansförmige Halsthierchen, die Wassergans, Trachelius anas, Trichoda anas II üller. Der ganze Kürper ist behaart, die Ilärchen stehen in Längsreihen. Die cylindrische Körperform unterscheidet es leiclıt voın vorigen, welches unten flach ist. Wenn es den Ilals so bewegt, wie Fig. 2. der vorigen Gruppe, so hat es, wie Mïller annahn, einige Ähnlichkeit mit der Figur einer Gans. Bei Fig. 6. und 7. ist Mund und After deutlich zu selıen, bei den übrigen erkennt man die Cloake als helleren Raum. Der halsförmige Vordertheil, welcher an seiner Basis, bei Fig. 7.*, die Mundsjalte trägt, ist eigentlich eine Oberlippe. Der Körper zeigt, aufser den mit Farbe gefüllten, noch viele mit blofsem Wasser gefüllte, blasenähnliche Magen.

\section{Tafel $V$.}

Diese ganze Tafel ist besonders der Darstellung der Structur und Entwicklung des glockenartigen Wirbelthierchens, Vorticella Convallaria M ̈̈ller gewidmet, welches cins von denen ist, deren unbekannte Entwicklungsgeschichte am meisten Irrthüıner veranlafst hat, indem man aus seinen verschiedenen Lebensformen 6 eigene Gattungen gebildet hat, deren einige sogar in anderen Naturreichen, als die andern, untergebracht wurden. Die 3 obersten Gruppen der Tafel zeigen den Kreislauf der Art und Entwicklung von einem dem Eistande nicht sehr entfernten Punkte bis zur Vollendung an. Die Gruppe $\alpha_{\text {. }}$. zeigt Pünktchen von $\frac{1}{1000}$ Linie Gröfse, die um einige alte Individuen und deren Wurzeln versammelt sind und zittern, aber nicht fortgehen, daher wahrscheinlich schon an viel feineren unsichtbaren Stielchen sitzen. Dieselben Thierchen erscheinen nach einiger Zeit wie Fig. $a .2$., und zeigen da schon deutliche Stiele und Köpfchen, sogar erkennt man bei den letztern einen Wirbel im Wasser. Schrank führte diese jungen sclion etwas deutlichen Thierchen als Vorticella monadica und eigene Thierart auf. Iclı sah sie nie spiralförmig zusammenschnellen, wie die Alten. Etwas später erscheinen sie wie die 3 kleinen Vorticellen bei ${ }^{*}$ in Fig. $a .3$. , und dann schnellen sie schon ihren Spiralfadeu. Die gröfseren Individuen sind alte, hängen aber dabei doch mit einer Art von Wurzelı zusammen. Hätte ich noch den Act des Ausstofsens des Eierstockes der Erwachsenen beobachten können, so wäre der Cyclus beinah geschlossen. Aus Wurzelfasern der Alten sah ich nie keulenförmige Junge oder Knospen treiben. Die Wurzeln scheinen der mit dem Thiere lıeranwachsende netzförmige Eierstock zu sein, wie ich ihn bei Kolpoda beobachtet habe. Die Stiele der Wirbelthierchen könnten also fortwachsende Stiele gestielter Eier sein. Die Wurzelfasern der zusammengesetzten kleinen $\Lambda$ scidien, Botryllen uni dergl. scheinen mir ganz andrer Natur zu sein. Da sieht man keulenförmige Knospen und vollkommne Thiere an derselben Wuzel sitzen.

Aufser dieser eigentlichen Fortpflanzung, in deren Kreis vielleicht einige Formen der Gattung Bodo, als freigewordene gestielte Junge gehören könnten, haben die Wirbelthierchen eine dreifache Vermehrungsweise, deren jede andere, eigenthümliche, Formen bedingt. Die erste ist die Längstheilung. Sie wird in den Figuren a. 4. bis a. 12. anschaulich, welche das Fortrïcken der Theilung zeigen. Fig. 9. ist doppelt, einmal im ausgereckten Zustande, einmal 
im spiralförmig zusanınenschnellenden. Ist die Theilung schon ganz vollendet, wie in Fig. 10., so entsteht am Ilintertheil des Körpers eine Falte, aus welcher, vorher nicht bemerkbare, neue Wimpern treten, die gekrümmt und stärker, als die vorderen sind. Von ihnen bis zum Stiel erstreckt sich ein conischer Hintertheil. In rliesem Zustande tritt die völlige Trennung ein. Eins der Thierchen dreht sich dann plölzlich sehr schnell um seine Längsaxe, wodurch es vom Sticle abreilst und nun als Lamarcks neue Gattung Urceolaria (siehe Fig. 12.) frei davon schwimmt. Haben beide sich tosgedreht, so bleibt der Stiel allein zurück, der keine Contractionen mehr zeigt, und den ich nie wieder neue Thiere treiben sah (Fig. 13.). Die weitere Form-Entwicklung der Urcenlaria ist in den Figuren 14. bis 31. dargestellt. Gewölnnlich schwimmt das frei gewordene Thierchen mit dem Ende, welches früher Hintertheil war, nach vorn gerichtet. Hatte es nun die vordere bei der Bewegung nach hinten gewendete, Mundgegend etwas mehr zusammengezogen, und deren Wimpern eingezogen, während es sich mit dem hinteren Theile fortbewegt, so nannte Schrank die Form, als eigene Gattung, Ecclissa (siehe $a .15 . a .16 . a .17$.). War dieselbe Form nach linten (was eigentlich vorn ist) nicht verengert, halle sie aber die conische Basis vorgetrieben, so nannte Bory de St. Vincent dieses Wärzchen (welches beim Schwimmen vorn war, eigentlich aber den den Stiele früher zunächst gestandenen Ilintertheil bezeichnet) eine Nase und das Thierchen als eigene Gattung: Rinella (siehe $a .1$ 1.). Hatte das Thierchen seine vorderen Wimpern eingezogen, eine glockenförmige Gestalt angenommen, und hinten oder vorn wirklich nur 2 oder scheinbar nur 2 Wimpern aus gestreckt, so nannte Bory de St. Vincent es wieder als eine neue Gattung: Kerobalana (19. -20.). Halte es alle Wimpern und auch den spitzen Hintertheil eingezogen, so nannte derselbe das Thierchen als eigene Gattung: Craterima (21.-22.). War es hinten abgerundet, ohne Wimpern, und wisbelte es'vorn mit seinen Wimpern, so bildeten diese Formen die Gattung Urceolaria (23. - 25.).

Aufser diesen und vielen andern Veränderungen des $\ddot{A} u$ fseren, streckt sich nun dieselbe Form noch in die Länge und wird walzenförmig, so dafs sie leicht für eine Art der Gallung Enclielys gehalten werden kann (Fig. 26. -31.). In diesem gestreckten Zustande pflegt sie sich noch einmal der Queere nach zn theilen, dessen Streben in Fig. 27. dargestellt ist. Fig. 28. schwimmt um einen harten Körper.

Die dritte Art der individuellen Vermehrung ist in den Figuren 32. - 4\% dargestellt. Es ist eine wahre Knospenbildung wie bei den Armpolypen, Mydra. In Fig. 35. ist die Knospe zum Ablösen reif, wie in der Gruppe a.3. Fig. *, und ist nun, sobald sie frei ist, eine Form der Gattung Oplirydia von Bory de St. Vincent, welche sich sehr rasch im Wasser herumschnellt und allmälig in die Formen 40. 43. 41. 41. und 42. übergeht, die sich der UrceolarienBildung immer mehr nähern. Fig. 15. zeigt ein Thierchen im Tode durch Erhitzung, wo die vordere Scheibe blasenartig ausgetrieben ist.

In all den andern genannten Zuständen ist das Thierchen von gleicher Munterkeit.

Das Glockenthierchen hat ïberdies neuerlich wieder zu der wunderlichen Meinung geführt, als besitze es wohl eine Zauberkraft, wie die, welche man der Klapperschlange zuschreibt (*), davon ist aber keine Spur zu finden. Geringe Vergröfserungen, bei denen man den Leib des Thierchens selır klar, die Wimperorgane aber gar nicht sieht, laben die sonder-

(*) A g a r d b über die Zauberkraft der lnfusorien Nov. Act. Acad. Caes. Leop. Carl. X. 1920. p. 127. 
bare Täuschung verursacht; ein Beweis dafs Klarheit der Microscope die Wirkung der Vergröfserung nicht ersetzt. Das Thierchen macht mit einem doppelten Kreise von Wimpern, welcher am Rande der vordern abgestutzten Fläche befindlich ist, einen beständigen Wirbel im Wasser, der, sobald fremde Körperchen im Wasser schwimmen, die mit bewegt werden, höchst interessant zı sehen ist. Besonders deutlich wird er bei farbigen Trübungen des Wassers. Dieser Wirbel dient offenbar zunächst, um Nahrungsstoffe anzuziehen. Undeutliche Vergröfserung haben die Idee festgestellt, als besitze das Glockenthierchen meist nur 2 oder 4 entgegengesetzte Wimpern. Diese Täuschung kommt daher, weil die sehr feinen Wimpern einzeln schwer zu sehen sind, zumal wenn sie bewegt werlen; dagegen sieht man, wenn das Thierchen horizontal liegt, milhin beide Wimpern-Kreise vertikal stehen, und dem Auge als eine Queerlinie erscheinen, mehr solcher Wimpern in den Enden dieser Queerlinie, wo die Krümmung der Kreise liegt, und diese scheinbare Annäherung gröfserer Mengen von Wimpern giebt jenes Bild von 1 oder 2 Winpern bei kleiner Vergröfserıng. Wo man 2 zu sehen glaubte, gehört gewöhnlich eine dem innern Kreise, die andere den äufsern an; wo ınan eine einfache sah, deckten sich die beiden Kreise. An Fig. b. l. wird man sich diefs deutlicher machen können.

Die Mundöffnung der Glockenthierchen liegt nicht vorn in der Mitte der Wirbelkreise, wie in einem Trichter, sondern an der Seite zwischen den beiden Wimperkreisen, und die Mitte ist geschlossen. Von dieser seitlichen Mundöffnung geht ein mit vielen gestielten Magen versehener Darmkanal, mehr oder weniger cirkelförmig, durch den Körper und endet sich dicht nelen dem Munde in derselben Grube. Dafs beide Öffnungen nebencinander, aber geschieden liegen, erkannte ich daraus, dafs das Thierchen beim Auswerfen oft nicht aufhört zu wirbeln und Nahrung einzunehmen. Um die Ernährungsorgane anschaulicher zu machen, wählte ich die Darstellung der gröfsern Vorticella citrina. Die Mundöffnung ist in $\mathbf{6 . 4}$. mit bezeichnet, in 6.5. ist der Act des Auswerfens und der Verlauf des Darmes zu sehen. In b.6. ist die Kerobalanen-Form dieser Art, wie in 6.5. die Urceolarien-Form dargestellt. Dasselbe wiederholt sich bei allen Arten der Gattung. Nährung durch Farbe ist bei diesen, fast in allen mit einer Haut iiberzogenen vegetabilischen Aufgüssen häufigen, Thierchen am leichtesten und am genugthuendsten zu erreichen.

\section{Tafel VI.}

Ite Gruppe. Das blasige Krallenthierchen, Kerona pustulata Müller. Es ist in verschiedeneu Lebenszuständen und bewegungen dargestellt. Fig. 7. ist ein Junges welches nicht aus Theilung, vielleicht aber noch aus Gemmenbildung stammen konnte. Fig. 3. und 12. sind in der Queertheilung begriffen. Fig. 5. bildet eine Gemme. Fig. 2. tasten und klettern, Fig. 10. excernirt. Fig.4. zerfliefit zum Theil, ohne seine Munterkeit zu verlieren und zeigt wie verschiedenartige Körper-Formen dadurch entstehen können, deren ich auch eine grofse Anzahl beobachtet habe. Ich halte dies Zerlliefsen für ein Absondern des kierstocks samt dem Körpertheil. Fig. 13. ist ein einzelner selbstständiger Theil nach der Queertheilung. Sie scliwiminen oft auf dem Rücken, dann kehren sie den Mund, als eine vordere und untere grofse Längsspalte dem beobachtenden Auge zu, und man sieht deutlich an der linken Mundseite 5 krallenartige Haken. Kehren sie den Rücken nach oben, so sieht 
man diese undeutlicher, oder erkennt sie nicht; in ihrem Mangel oder Dasein liegt das Unterscheidungszeichen der Gattungen Oxytricha und Kerona. Fig. 1. nimmt Nahrung durch Wirbeln ein, und giebt die Normalform des Thieres. - Ist Oxytricha pellionella, das häutige Hechelthierchen, vielleicht das Junge aus dem Ei von diesem?

II ${ }^{\text {te }}$ ruppe. Das Nachenthierchen: der Charon, Euploea Charon, Trichoda Charon M üller, Ploesconia Charon Bory. Das Thierchen ist auf dem Rücken mit einem crystallhellen Schilde hedeckt und schwimmt gewöhulich auf dem Rücken. Unten hat es eine doppelte Reihe von Haken, die es als Fïfse oder Krallen braucht. Hinten hat es 5 etwas stärkere und längere Borsten, vorn auch einige, die aber feiner sind. Der Mund wird durch eine sehr grofe seitliche gewimperte Längsspalte gebildet, die auf der rechten Seite liegt und in deren Mitte die kleinere eigentliche Schlundöffnung ist, dicht an ihrem Ende nach hinten ist die Afteröffnung ebenfalls seitlich. Fig.10. ist ein auf dem Bauche und Fig.11. und 12. sind 2 auf dem Rücken liegende wirbelnde Thiere. Neben einer, noch nicht beobachteten, Eierstock - Ausscheidung, pflanzt es sich durch Längstheilung Fig. 7. 9. 18. und durch Queertheilung Fig. 11. 13. fort. Die Figuren 3. 4. 5. 6. und 15. 17. 19. stellen die kleinsten von nir beobachteten Jugendzustände dar, die nur aus Eiern kommen konnten. Fig. 20. macht die $\Lambda$ uswurfsstelle bemerklich. Fig. 2. 3. und 16. klettern. Rücksichtlich des Namens bemerke ich noch: Ploesconia ist unrichtig gebildet und Euploea isl, obwohl die französisclıen Entomologen den F abriciusschen Gattungsnamen nicht fortfïhrten, doch, da ihn $\mathrm{O}$ ch se $\mathrm{n}$ h e imer anerkennt, unsicher und daher von nir nicht glücklich gewählt worden. Man könnte ihn in Euplotes umwandeln.

III ${ }^{\text {te }}$ Gruppe. Das grüne Augenthierchen, Euglena viridis. Cercaria viridis Müller. Es ist das Thierchen, welches am hïufigsten im Frühjahr die Oberfläche des stehenden Wassers schön grün färbt, wobei es in Berlin gewöhnlich von der grünen Staubmonade Monas pulvisculus und dem grünen Spindelthierchen Astasia euchlora begleitet wird. Nach Mïller und mehreren andern Bcobachtern soll es einen gespaltenen Ilintertheil haben, das ist aber eine optische Täusclung durch Schwingen des Scliwanzes vom Thierchen veranlafst. Es ist sehr biegsam, und erscheint in den verschiedensten Fornen. Wenn es stehen bleibt und stirbt sieht man es gewöhnlich als Kugel, wenn es schwimmt als spindelförmiges Fischchen, sonst in den Figuren 7. 12. 16. und vielen andern. Vorn hat es eine Mundstelle mit Wimpern, die einen Wiıbel erregen Fig. 5. 7. S. 11. 13. Das Auge ist immer sehr deutlich und schön roth. Ich labe es, wie alle stark grün gefärbten Thierchen, nie deutlich zur Aufnahme von Nahrung bringen können. Zuweilen erscheinen bei blauer Nahrung sehr kleine blaue Piinktchen im Innern, aber nie ganz deutlich. Einmal sab ich bei rother Fütterung einen zienlich grofsen roth gefültten Magen Fig. 12. Die Versuche sind mir aber nie sehr zur Überzeugung gelungen. Ich habe auch nie eine Thcilung, oder Fortpflanzung anderer Art, beobachtet, wohl aber sehr kleine Individuen Fig. 1. - 4., welche Eier verrathen. Eine Längsthei- 
lung sah ich erst vor Kurzem wiederholt bei dem nadelförmigen Augenthicrchen, Euglena acus, Vibrio acus $\mathrm{M}$ üll er.

IV ${ }^{\text {te }}$ Gruppe. Das gewundene Augenthierchen, Euglena spirogyra, eine hisher ganz unbekannte Form. Es ist cylinılrisch, kann sich aber bandförmig machen. Vorn ist an der Mundstelle ein deutlicher Einschuitt. Im Innern sind spiralförmige gewundene Reihen kleiner Körnchen und gröfiere Fingeweide. Es wirbelt im Wasser, hat zuweilen sehr kleine zweifelhafte Magen gefüllt, aber bedarf noch einer weitern Prïfung.

$V^{\text {te }}$ Gruppe. Das schollenartige Augenthierchen, Euglena pleuronectes, Cercaria pleuronectes $M$ iiller. Das Auge war bei dieser Form noch nicht erkannt worden, ist aber sehr bestimmt. Fig, 2. und 5. sinl von der Seite gesehen, Fig. 4. ist ein Junges. Die weifsen Blasen in Innern nögen Magen sein, denn sie sind veränderlich. Die Ernährungsorgane, welche durch Farbestoff sichtbar wurden, sind aber viel kleinere Behälter. Vielleicht liebt es diese Farben nicht. Zuweilen erscheint es gestreift: Fig. 1. und 3. Der Einschnitt am Vordertheil ist ein Mund, welcher Wirbel macht. Fig. 4. ist ein Junges, das wohl nur aus Eiern stammen kann. Ich fand vor Knrzem bei Berlin zwischen Conferven noch eine dieser sehr ähnliche viel gröfsere neue Art, das langschwänzige Augenthierchen, Eugrlena longicauda, dessen fädenförmiger Hintertheil so lang, als der Leib ist, mit welchem es $\frac{1}{15}$ Linie grofs ist. Die Augen und der Mangel beobachteter Theilung bestimmten mich früher bei diesen Thierchen eine noch gröfsere Entwicklung anzunehmen, als ich jetzt es möchte. Ich sah sie daher in früheren Mlttheilungen fraglich für die kleinste Stufe der Rälerthierchen an, allein seit ich bei Euglena acus die Theilung beobachtete, bin ich nicht mehr geneigt jener Ansicht zu folgen, sondern rechne sie zu den darmlosen Magenthierchen (Polygastrica anentera).

\section{Tafel VII.}

Auf dieser Tafel sollte die Structur der Klasse der Räderthierehen durch die Hauptformen derselben, besonılers und ausschliefslich rücksichtlich der Ernährungsorgane dargestellt werden. Zu den Symbolis plysicis hatte ich schon vor mehr als 2 Jahren die Entwicklung und Structur einiger Räderthierchen (Negalntrocha, Lacinularia und andre) in Kupfer stechen lassen, noch eh ich die Farbenversuche anstellte, und diese habe ich nicht wiederholen wollen. Ich habe deshalb hier andere Thiere gewählt, aber solche vorgezogen, welche gewöhnlicher vorkommen und leichter zu prüfen sind. Die erste und zweite Gruppe enthalten doppelräderige Thiere $\left(\boldsymbol{Z}_{y g \text { gotrocha }}\right)$ die dritte und vierte vielräderige (Polytrocha), woran sich das Wasserälchen schlieIst.

$I^{\text {te }}$ Gruppe. Das eigentliehe, gewöhnliche Räderthierchen, Rotifer vulgaris von $\mathrm{Schrank}$, Vorticella rolatoria von Müller, Furcularia rediviva von $\mathrm{Lamarck}$ genannt. Auf diefs Thierchen beziehen sich die wunderbaren Wiederbelebungsversuche nach vieljährigem Tode, von denen viele Handbücher erzählen, die sich aber niclt bestätigen. Wer mit mir den Organismus dieser Thierchen verfolgt, wird auch den Grund des Mangels an Bestätigung leichter einsehen, als an ihm 
zweifeln. Fig. 1.a. ist ein auf dem Rücken liegendes kriechendes Thierchen. Bei * ist sein gewimperter Mund mit einem hakenförmigen Fortsatze, den es bald mehr nach oben, bald mehr nach unten kehrt. Das zweite Sternchen bezeichnet das äufsere männliche Organ im Nacken. Die 2 rothen Punkte sind 2 auf dem Rücken des rüsselartigen Stirntheils befindliche durchscheinende Augen mit rothem Pigment. Die Streifung des Körpers wird durch die durchscheinenden Muskellagen veranlafst. Über dem nännlichen Organe auf der Bauchfläche sieht man die Spuren der beiden eingezogenen Räderorgane, weiter nach hiuten den Schlundkopf, dessen beide Zähne man sogar unterscheidet, dann folgt ein bandförmiger, wenig ausgezeichneter Darm, welcher über 9 grofsen Eiern hingeht und in der Mitte einen fadenförmigen mit blauer Nahrung ausgefüllten Kanal zeigt, der sich hinten in eine blasenförmige Cloake erweitert. Der Körper endet mit einem aus-und einschiebbaren Schwanztheile, welcher 3 Paar gabelförmige Spitzen hat, von denen aber gewöhnlich nur 2 Paar zum Vorschein kommen, während das dritte Paar zum Ansaugen und Festhalten dient. Fig. 1.b. ist dasselbe Thierchen im zusammengezogenen Zustande und indem es durch Ausleerung die Ausgangsöffnung des Darmkanals bemerklich macht. Fig. 1.c. ist ein auf denı Rücken schwimmendes Räderthierchen mit entwickelten Räderorganen. In seinem Leibe erkennt man 2 den Auskriechen nahe, vollständig ausgebildete Junge, welche sogar schon das rothe Pigment der Augen haben, und deren beweglicher Schlundkopf sehr deutlich ist. Das Thierchen hat seinen Darmkanal mit Carmin gefüllt. Fig. 1. d. ist eine öfter zu beobachtende Stellung dieser Thierchen, welche der Selbstbefruchtung halber angenommen zu werden scheint. Eine Verbindung von 2 Thierchen sah ich nie. Fig. 1.e. ist ein reifes ausgeschiedenes $\mathbf{E}$, worin man den Schlundkopf des Embryo ebenfalls deutlich erkennt.

II ${ }^{\text {te }}$ Gruppe. Das klare Rückenauge, Philodina erythrophthalma, eine bisher mit den Räderthierchen verwechselte, ganz eigene neue Thiergattung, welche die Augen nicht vorn, auf dem rüsselförmigen Stirntheil, sondern auf dem Rücken, hinter dem männlichen Organe, trägt. Es giebt melırere Arten dieser Gattung bei Berlin, deren eine grofse weiche Stacheln hat und eine andere schön gelb gefärbt ist. Sie leben sämmtlich zwischen Conferven im Thiergarten ziemlich häufig und lassen sich sehr lange in Gläsern erhatten. Fig. 2. $a$. ist ein auf dem Bauche schwimmendes Thierchen, 2.b. schwimmt auf dem Rücken, 2. $c$. liegt auf dem Rücken und wirbelt, wobei die Mundstelle deutlich wird. Die Augen scheinen durch. Bei Fig. 2. a. und 2.c. ist das männliche Organ zu sehen, bei 2. $d$. ist eine Eigruppe gezeichnet, wie man sie gewöhnlich findet, und ein Junges verläfst eben die Eischaale, wobei es schon die Iiälfte der Länge der Mlutter hat. Diefs ist also der Entwicklungscyclus. Im Übrigen sind die Organe wie beim Rädeuthierchen. Die Möglichkeit der wiederholten Prüfung dieser Form zu einer Zeit, wo sie schwierig zu haben waren, verdanke ich der wissenschaftlichen Theilnahme und der gütigen Mittheilung des Herrn Regierungsraths von Bärensprung.

III' Gruppe. Nackte vielräderige Räderthierchen, Rotuioria polytrocha nuda. Das durchsichtige Dreiauge, Eosphora Najas. Diefs ist wieder eine noch ganz 
unbekannte Form, welche bei Berlin im Thiergarten nicht selten unter Conferven lebt und leicht mit dem hellen Krystallthierchen, Hydatina senta, verwechselt wird, aber einen längeren verdünnten Hintertheil und 3 rothe Augen hat. Ich habe dasselbe Thierchen in Tobolsk in Sibirien beobachtet und habe schon da das Rückenauge deutlich erkannt. Die beiden Stirnaugen habe ich erst hier entdeckt. Die zusammengesetzte Structur dieses Thierchens erklärt sich am besten durch die folgende $8^{\text {te }}$ Tafel, und ich bemerke nur, dafs die Ansatzpunkte der 8 Muskeln bei dieser Art viel länger ausgedehnt sind. Die mehrfachen Räderorgane der Stirn, die drüsigen Ohren des Darmkanals, die geschlängelten Saamenorgane mit der Muskelblase und die Gehirnınasse, sind mit dem Eierstock leicht zu erkennen. Fig.3.b. ist ein jüngeres mit Karmin genährtes Thierchen. Fig. 3. a. läfst die Auswurfsstelle erkennen.

IV Gruppe. Gepanzerte viclräderige Räderthierchen, Rotatoria polytrocha loricata. Das ciförmige Schüppchen, Lepadella ovalis, Brachionus ovalis von Mülle r, Mytilina lepidura von Bory de St. Vincent. Das Thierchen befindet sich in einer sehr durchsichtigen, festeren Schaale wie die Schildkröte, und kann Kopf und Schwanz in dieselbe zurückziehen. Die Öfnungen der Schaale sind auf der Bauchseite tief ausgeschweift, auf der Rückenseite glatt abgestutzt, und die vordere Seite ist breiter als die hintere. Die Form des Thierchens ist zusammengedrückt, und es ist, von der Seite gesehen, sehr dünn, während alle früher verzeichneten Formen rund waren. Ich mache noch auf das mehrtheilige Räderorgan, den sichtbaren gelblichen Schlundkopf, die zum Theil sehr grofsen Eier und auf den durch Farbestoff gefüllten Darmkanal aufmerksam. In Fig. 4. $a$. und 4.b. sind die beiden Theile, in welche sich der Darm scheidet, gesondert zu erkennen, in Fig.4. $c$. entleert sich eben der Magen in den Dickdarm, und in Fig.4. . entleert sich der Dickdarm nach aufsen.

Vie Gruppe. Das Flufs- ̈̈lchen, Anguillula fuviatilis, Vibrio fluviatilis Müll e r. Völliger Mangel eines Räderorgans bei deutlicher vorderer Mundöffnung und doch den Räderthieren glcich ausgebildeter einfacher Darmkanal scheiden diefs Thierchen von den beiden hier abgehandclten Thierklassen. Darm und Eierstock beim Weibchen (5.a.) und Saamenorgan, Darm und Penis beim Männchen (5. b.) sind deutlich zu erkennen. Ich hatte es mit Karmin genährt. Seine Structur ist ganz der der Gattung Oxyuris bei den Entozoen ähnlich, nur freilich lcbt es nicht in der Regel im Leibe der Thiere. Ich habe auch sein Häuten beobachtet, wie ich dasselbe bei Ascaris in Egypten gesehen. Das männliche Organ ist bei Fig. 5. b. * am hintern Körpertheil zu sehen, ob es aber in einer Scheide eingeschlossen ist, wie bei O.ryuris, liefs sich nicht entscheiden. Daher habe ich vorläufig die von Müller schon angedeutete Gattung Anguillula gebildet, in welcher es mit den übrigen übereinstimmenden frei lebenden Formen sich abgesondert in der Nähe von Oxyuris und Ascaris aufhalten mag. Ob man die Eingeweidewürmer immerfort a potiori Entozoa (Ëngeweidewürmer) nennen will, wenn auch frei lebende Thiere darunter stehen, oder Saugwürmer (Suctoria) oder anders, ist, da kein Name je vollständig passen wird, von keiner wissenschaftlichen Wichtigkeit und wahr- 
scheinlich läfst uns der hoch verdiente Gründer der Entozoen-Klasse, Herr Rudolphi, seinen alten geläufigen Namen mit seiner erneverten Autorität.

\section{Tafel VIII. \\ Zergliederung des hellen Krystallthicrchens, Hydatina senta, (Vorticella senta Mïller.)}

a. bedeutet apertura analis, die Auswurfsöfnung;

ann. n. " annulus nerveus, Nervenschlinge im Nacken;

b. oes. " "bulbus oesophagi, der Schlundkopf;

c.

" cauda, die Schwanzzange;

cilia rot. " die Wimpern der Wirbelorgane, deren jedes 6 enthält;

cl. $\quad$ "

dentes " cloaca, Darmstelle hinter der Vereinigung des Darmkanals und Eierleiters;

g. n. ein Kiefer mit den 6 scheinbar zweispitzigen Zähnen;

g. n. "
ganglion nerveurn, Nervenknötchen; ganglio oesuphagea, grofse Schlund-Nervenknoten;

i. ganglion principale, Haupt-Nervenknoten;

i. "

lig. rot. "

m. c. $\quad$ "

mand. "

m. dors. a. "

m. dors. p. "

m. lat. d. a." " glandulae digeslivae, die ohrenförmigen Darmdrüsen (Pancreas?');

intestinum, der Darmkanal;

m. lal. d. p. "

m. lat. s. a." "

m. lat.s.p. "

m. vent. $a$." "

m. vent.p. "

m. $e j$.

ligamenta organorum rotatoriorum, Vereinigungsstelle der Anheftungsbänder der Räderorgane;

musculus caudae, Schwanzmuskel;

mandibulae, die Kauorgane;

musculus dorsalis anterior, der vordere Rückenmuskel;

" $"$ posterior, der hintere "
musculus lateralis dexter anterior, vorderer rechter Seitenmuskel ;

" " $"$ postertor, hinterer "

musculus lateralis sinister anterior, vorderer linker Seitenmuskel ;

" " " posterior, hinterer " "

musculus ventralis anterior, vorderer Bauchmuskel;

m. rot. "

n. r. «

n. v. "

o. $\}$ "

ovd.

org. rot. "

oes. " "

sph. "

t. $\quad$ u

musculus ejaculatorius, Saamen-Schnellmuskel;

musculi rolatorii, Muskel der Räderorgane;

nervi recurrenles, rücklaufende Nerven;

nervus ventralis, Bauch-Nervenfaden;

ovarium, Eierstock;

oviductus, Eierleiter;

organa rotatoria, Räderorgane;

oesophagus, Schlund;

sphincter, Kranzmuskel der Cloake;

« testes, männliche Saamenorgane; 
tun. ext. bedeutet tunica externa, äufsere häutige Körperbedeckung;

tun. int. " tunica interna, innere häutige Körperbedeckung;

vas d. " vas dorsale, Rückengefäfs;"

* * locus inserendorum vasorum spermaticorum, Einmündungsstelle der männlichen Samengefäfse in die Muskelblase;

$\left.\begin{array}{l}+ \\ +\end{array}\right\} \quad$ * $\begin{gathered}\text { musculorum longitudinalium insertorum limites, Anheftungsgrenze der Längs- } \\ \text { muskeln; }\end{gathered}$

1-9 * rami vasis dorsalis transversi, Queerzweige des Rückengefälses.

Fig. I. und II. sind von der Seite gesehen, Fig. III. vom Rücken, wobei die dem Rückengefäls parallel laufenden Falten oder Gefälsverzweigungen angegeben sind. Eine grofse Ähnlichkeit des Gefälsverlaufs mit dem der Ascidien macht sehr geneigt, auch diese Gefälsspuren wirklich für Gefälse zu erkennen, obschon bei starker Spannung der Haut sie ganz zu verschwinden sclıcinen. Fig. II. ist mit ideal weggelassenem Darme und Eierstocke gezeichnet, um den Verlauf der Muskeln und übrigen Organe deutlicher werden zu lassen. Die fremden Körper im Darmkanale der Fig. I. und III. sind verschluckte Navicula fulva und $N$. gracilis, die zuweilen den ganzen Darm füllen. Fig. A. $B . E . F$. sind in der ruhigen günstigen Körperlage des durchsichtigen Thieres gezeichnet und dann auf anatomischem W'ege frei gesehen und bestätigt worden, $C$. und $D$. sind nach Präparaten gezeichnet, welche ich mir mit Druck des Thierchens durch ein Glimmerblättchen zur Ansicht brachte, wodurch man die Kauorgane sehr leicht erkennt, doch bleibt das Erlangen ihrer günstigsten Lage dem Zufall überlassen, welcher durch öftere Wiederholung sich erzwingen läfst. Fig. $C$. ist ein natürlich zusammengezogenes Thierchen. Fig. $\boldsymbol{H}$. ist ein mit dem Messer abgelöster noch wirbelnder Kopf. Fig. $\boldsymbol{K}$. ist ein Thierchen mit abgeschnittenem Hintertheil, wobei der Eierstock und ein Theil des Darmes sichtbar wurden. Ich brachte etwas Indigofarbe an dicsen Darmtheil und sah dann ihn ganz mit Wimpern besetzt, die einen Wirbel erregten. Fig. $L$. ist ein Thierchen mit abgeschnittenem Vordertheil, wobei der Schlundkop $\int$ nicht verletzt war, was die Freiheit der Organe im Innern des Körpers anschaulich macht.

In Allgemeineı bemerke ich noch, dafs ich abweichende Meinungen sachverständiger Forscher über die Deutung der Organe, welche ich zur Anschauung brachte, nicht nur nicht scheue, sondern sofern sie sich auf nüchterne Gründe stiitzen, angelegentlich wünsche. Meine eigenen Gründe für meine Ansichten habe ich mitgetheilt und vor Übereilung habe ich mich soviel als möglich gehütet, so zart auch die Gegenstände waren. Ein unbetretener Pfad wird nicht mit, e in em Gange glalt getreten. Ich selbst finde, zu bessern, zu glätten und zu mehren noch unübersehbaren Stoff und immer neue Mittel, und was ich gab ist nur ein Auszug weit zahlreicherer Beobachtungen, die meine Freunde kennen. Noch vor Kurzem gelang es mir die Kauorgane der IIydatina senta, welche ich möglichst deutlich beobachtet zu haben glaubte, noch weit klarer darzustellen. Der scheinbar geringfügige Umstand, dafs ich anstatt eines gröIseren Glimmerblättchens ein kleineres anwendete, welches sich noch enger anschlofs zeigte mir, dafs ich bis dahin den Zahnfleisch-artigen Überzug der Zähne mit als zur Substanz der Zähne gehörig angesehen hatte. Iurch Entfernung desselben auf die angegebene Weise lärst sich deutlich erkennen, dafs die Zähne einfache, harte, vorn nicht ausgerandete, sondern stumplspitzige Körperchen sind, welche in ihrer Vereinigung jederseits wie die Finger einer 
Hand erscheinen. Seit Anwendung dieser Methode sehe ich auch nicht mehr 6, sondern 5 Zähne in jedem Kiefer. In der Abbildung ist das Zahnfleisch mit gezeichnet und mithin sind die Zähne nicht so deutlich gezeichnet, als ich sie jetzt kenne.

So schliefse ich denn diese Mittheilung, nicht ohne das Gefühl, dafs ich die erkannten Tiefen der organischen Schöpfungen noch lange nicht ergründen konnte. Sie aufgeschlossen zu haben sei mir Entschuldigung für verwendete Kraft und Zeit. Mögen frische seelenvolle Blicke sich weiter in sie vertiefen und eifrig sammeln was die Natur, nicht zwecklos, in Dunkel und Kleinheit verbirgt. 


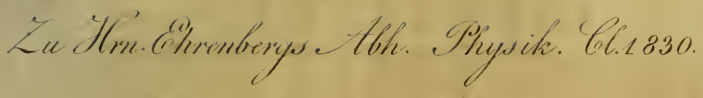

I 


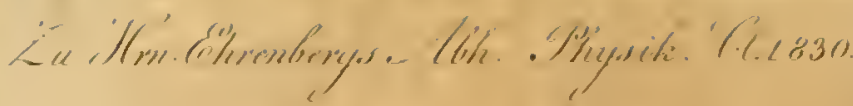
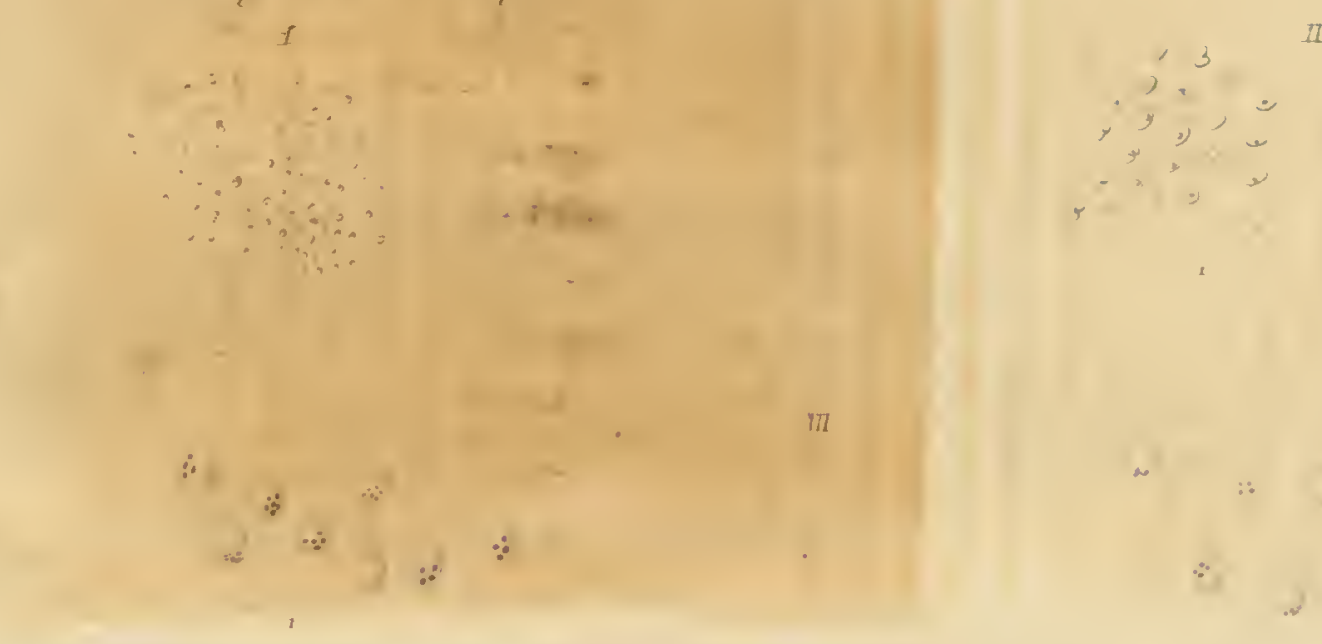

IT
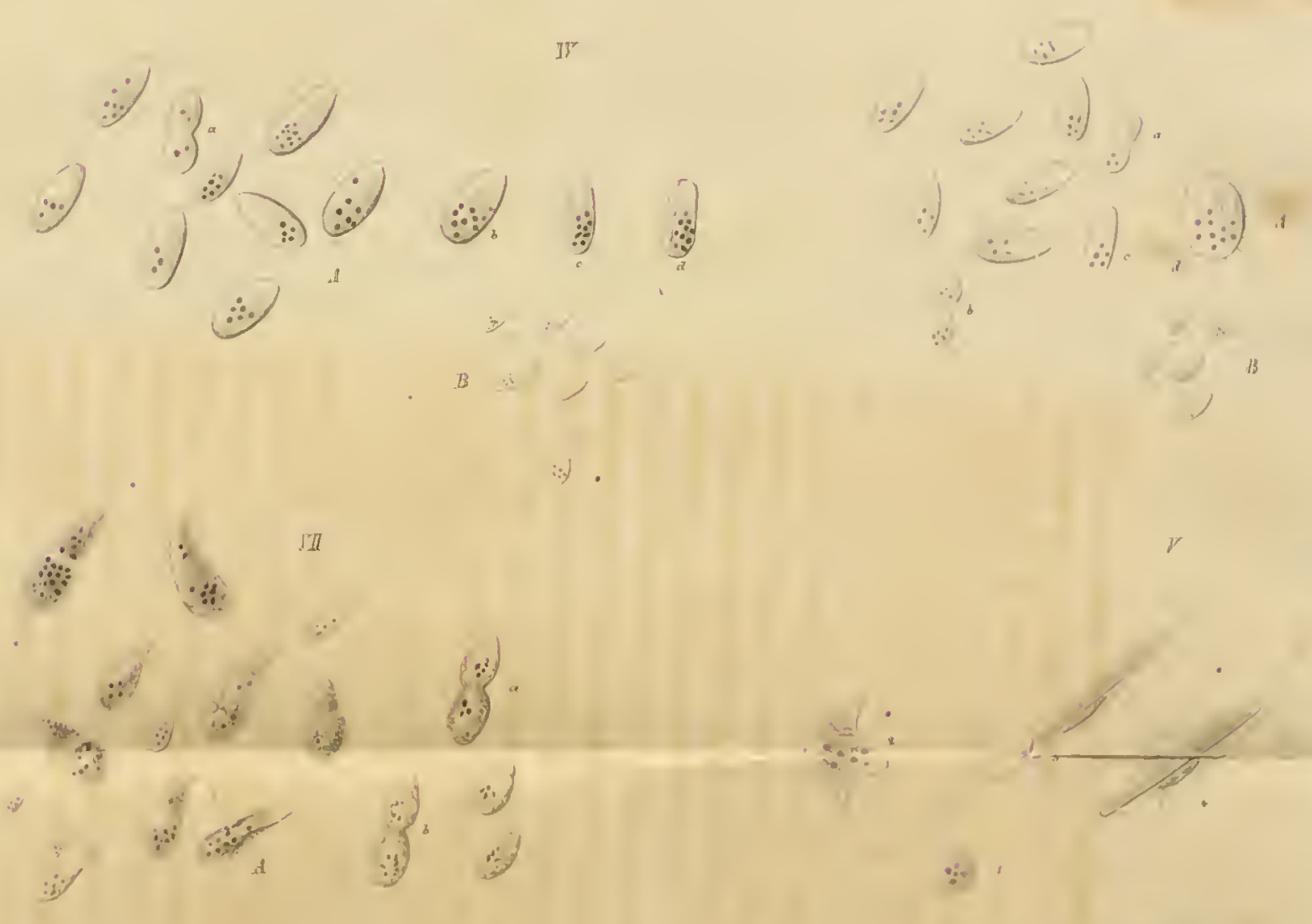

$\therefore$ af $\quad \therefore$.

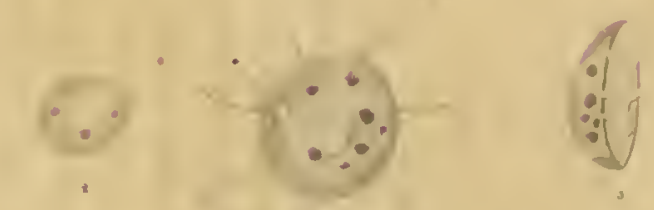

$\because$

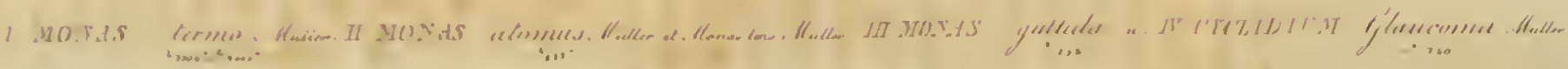

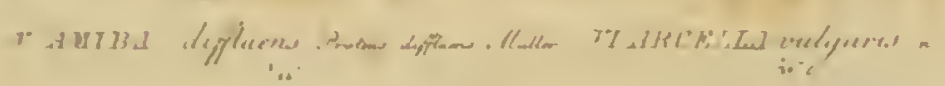
I"II I"RIIIII) III

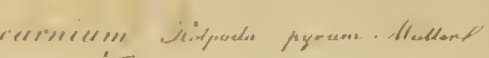




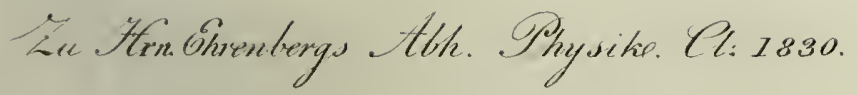



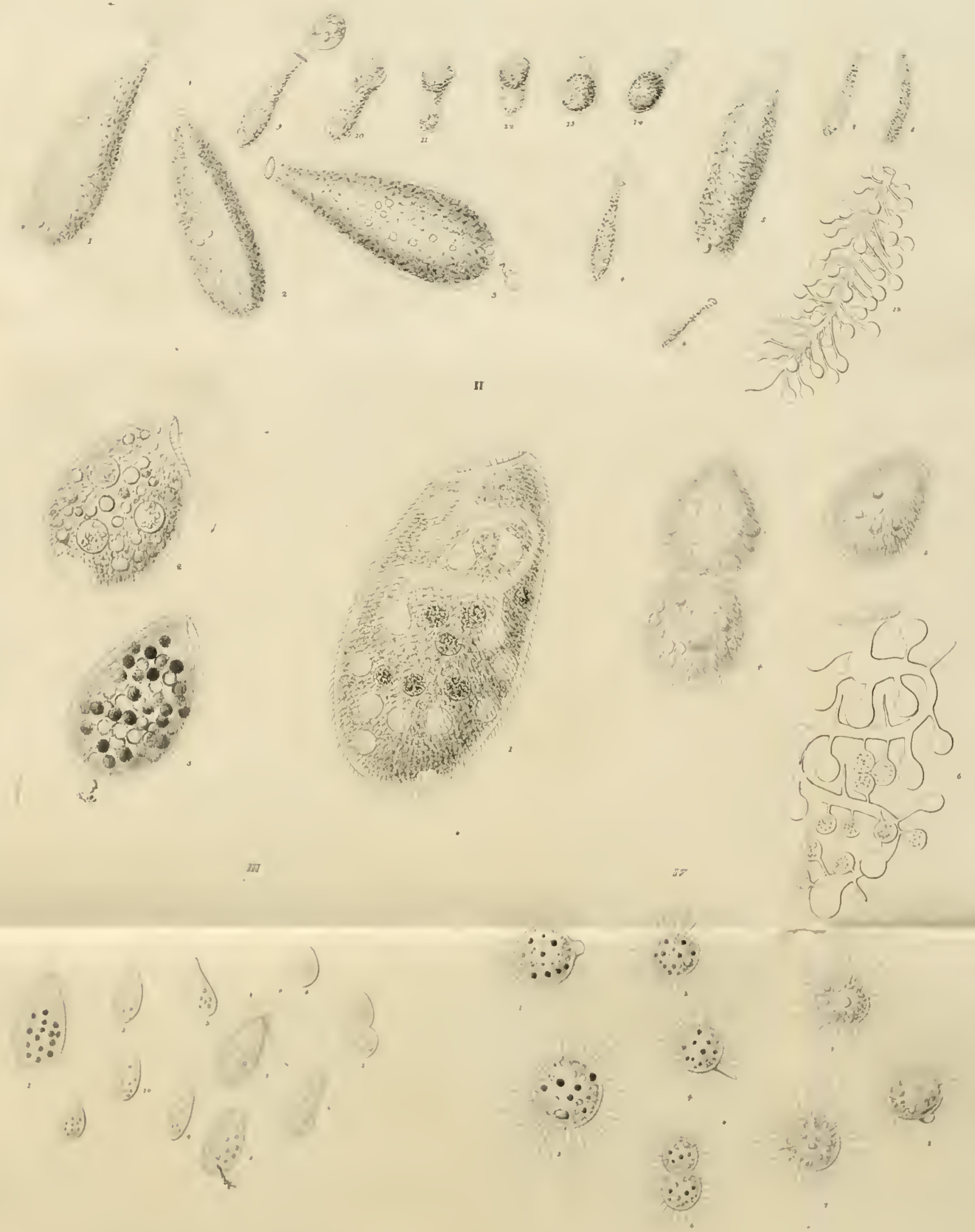

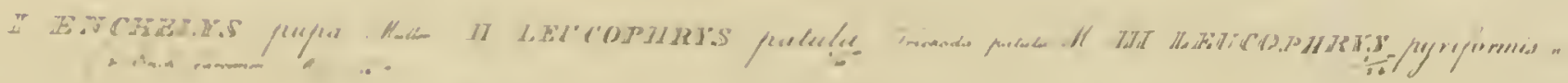

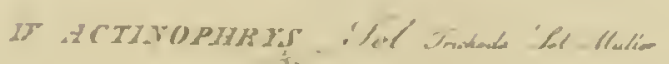




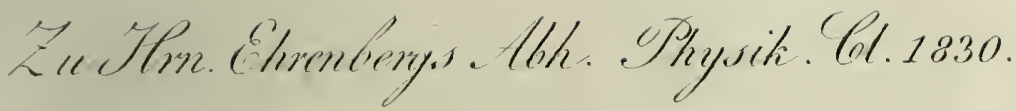
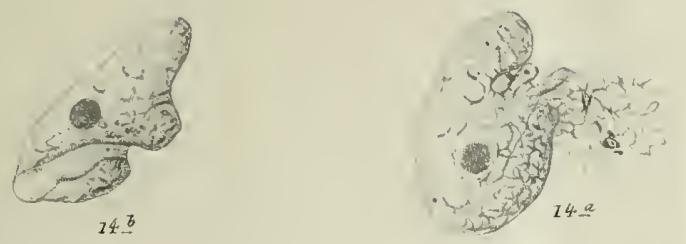

2
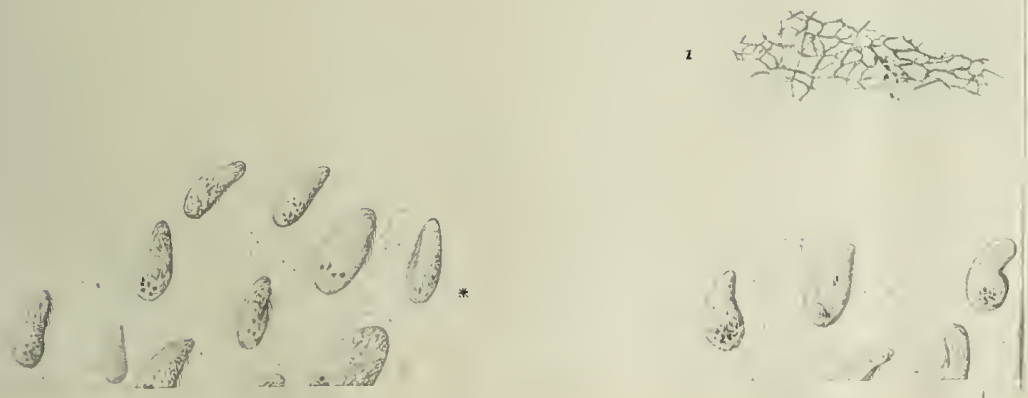


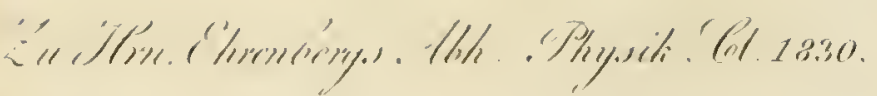
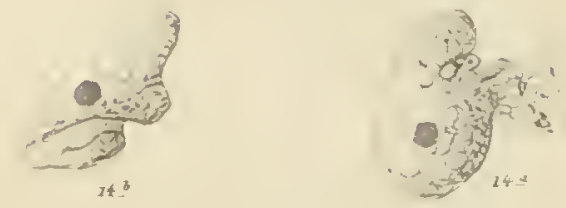

$$
\text { aterex }
$$
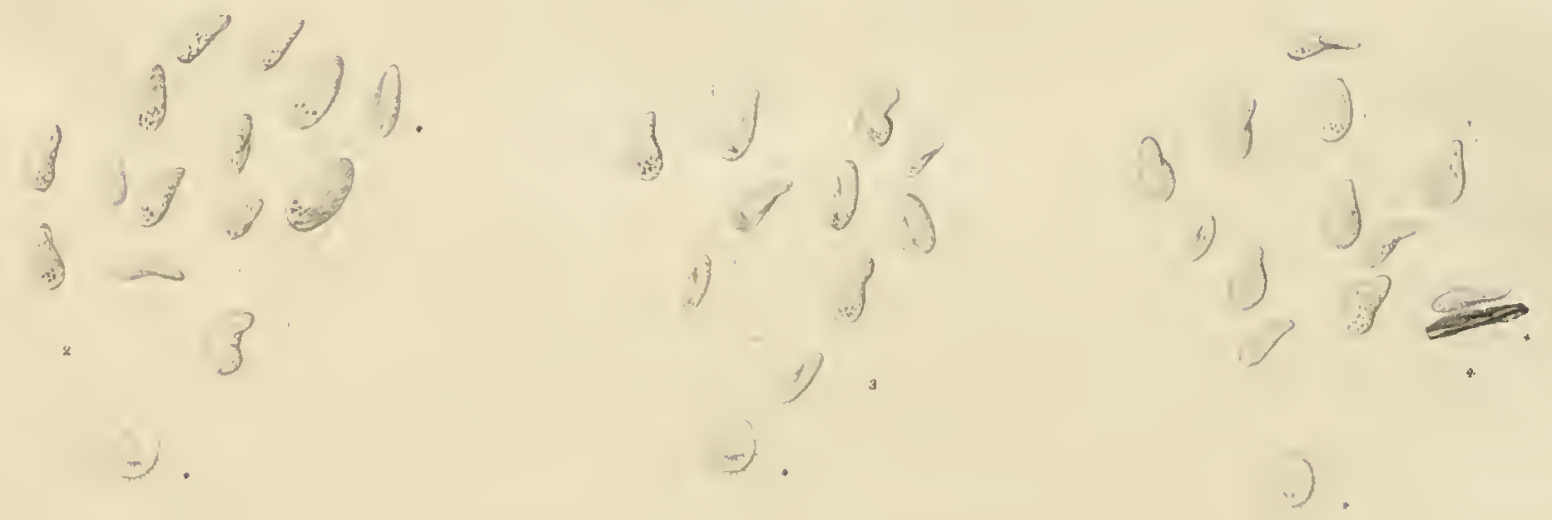

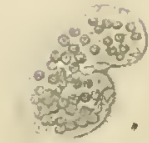
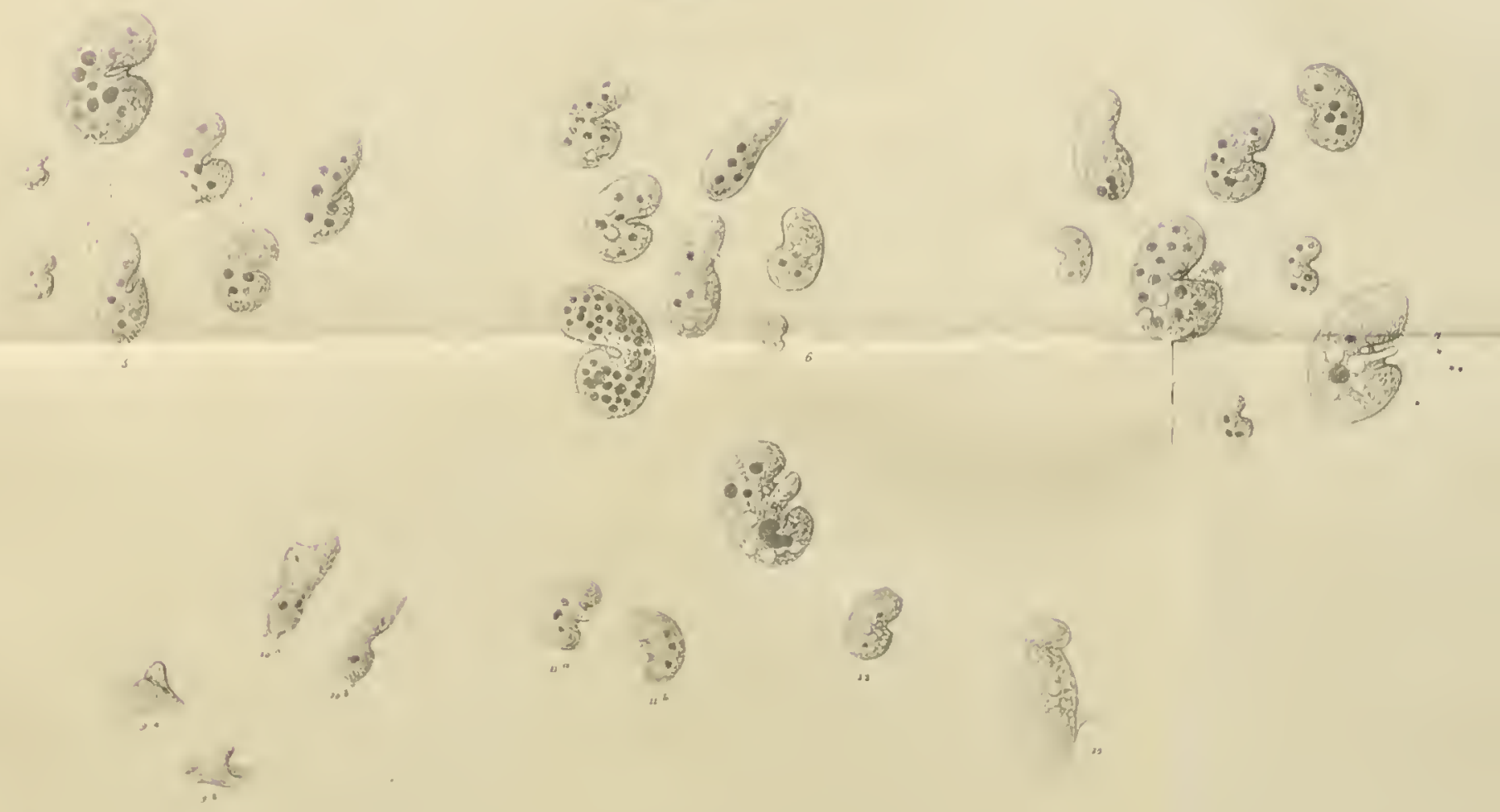

13

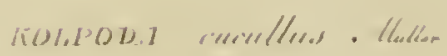

i... if 


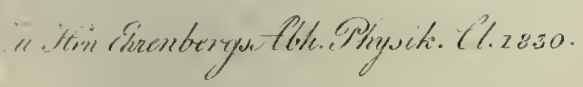

II
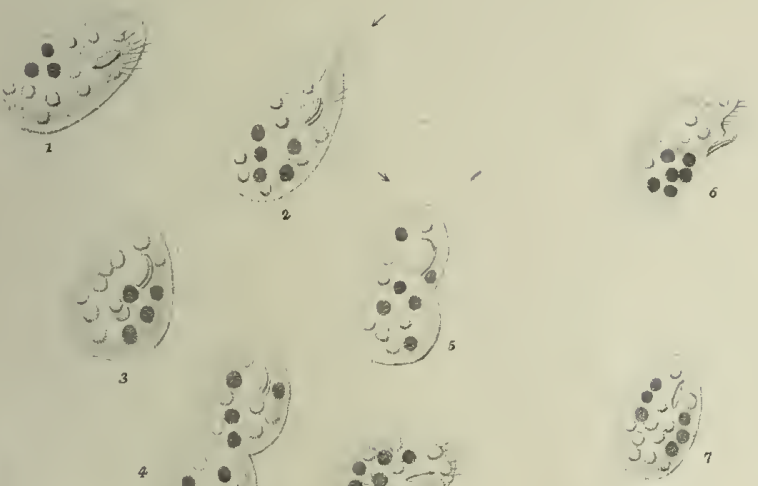

10 

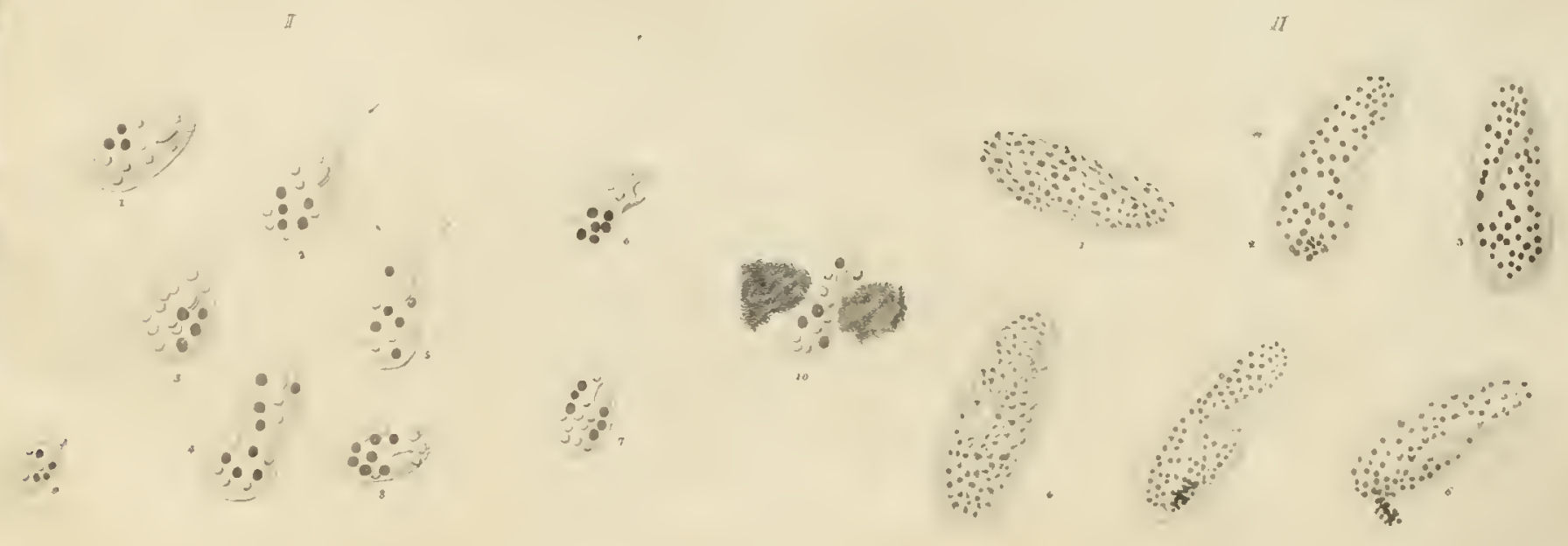

$\therefore \quad \therefore \quad \therefore$

IIII
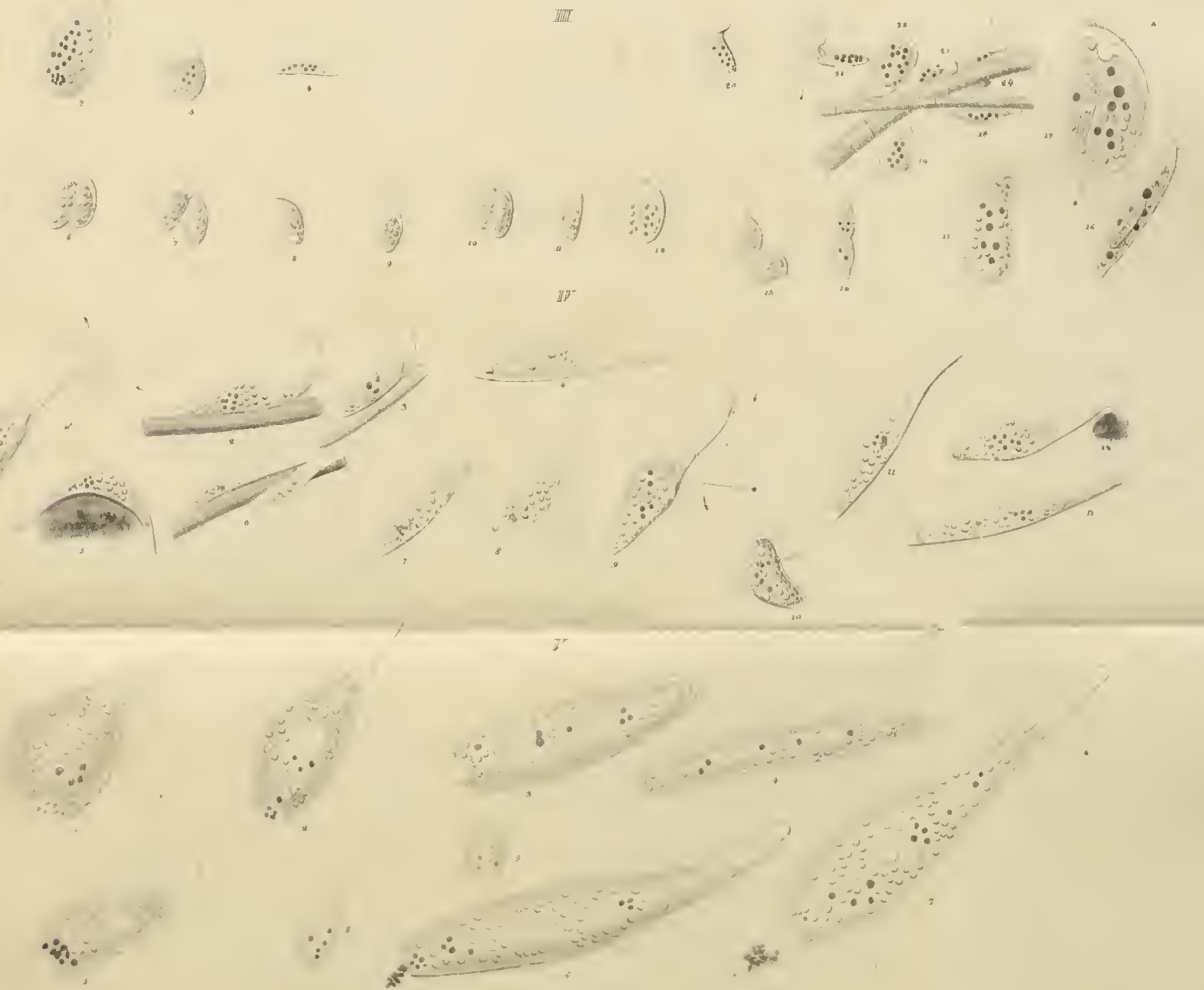

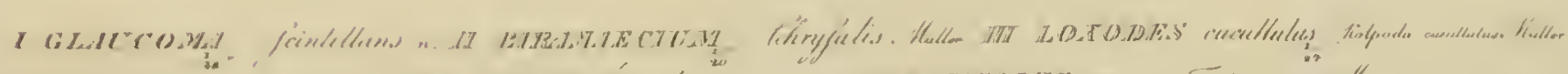

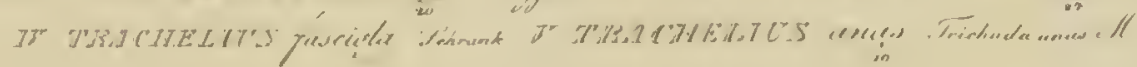


iv. Hin. Ekrenberys tbe. Shysik. Gl 1830

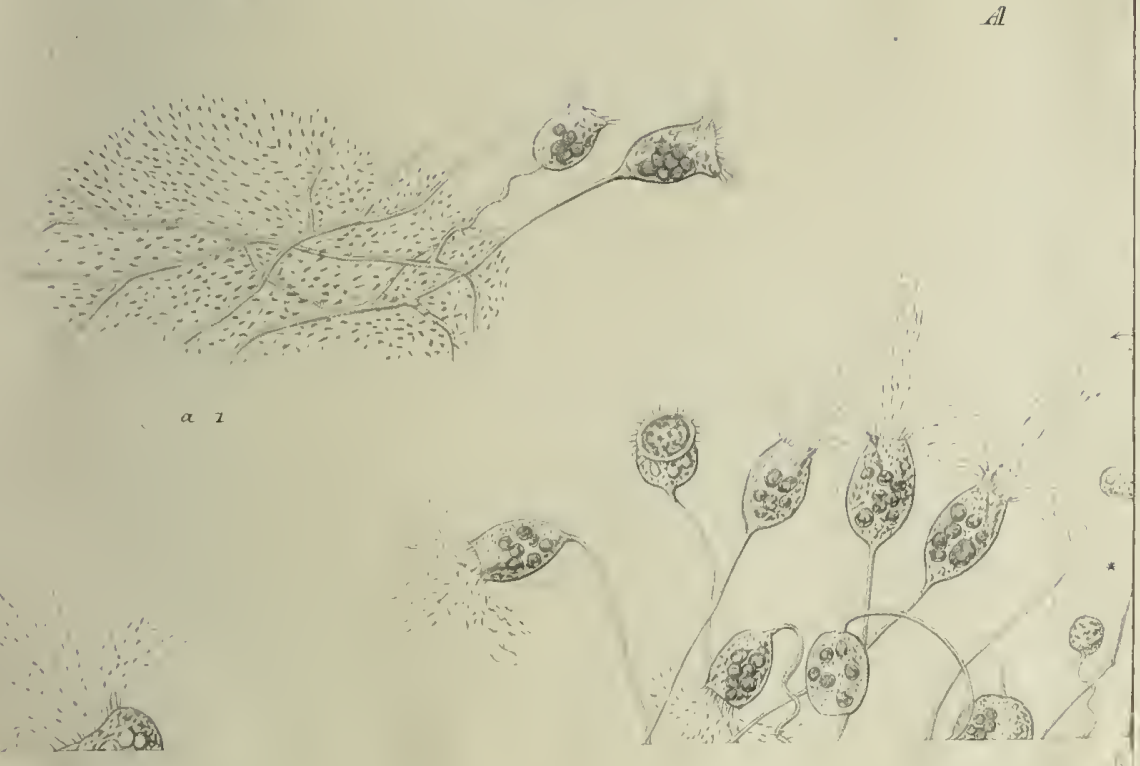


20

st

3.

(अ)

(2)
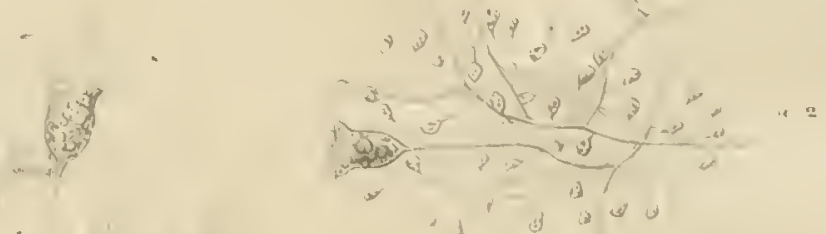

wis

$$
\text { tis }
$$

(1) 3 a
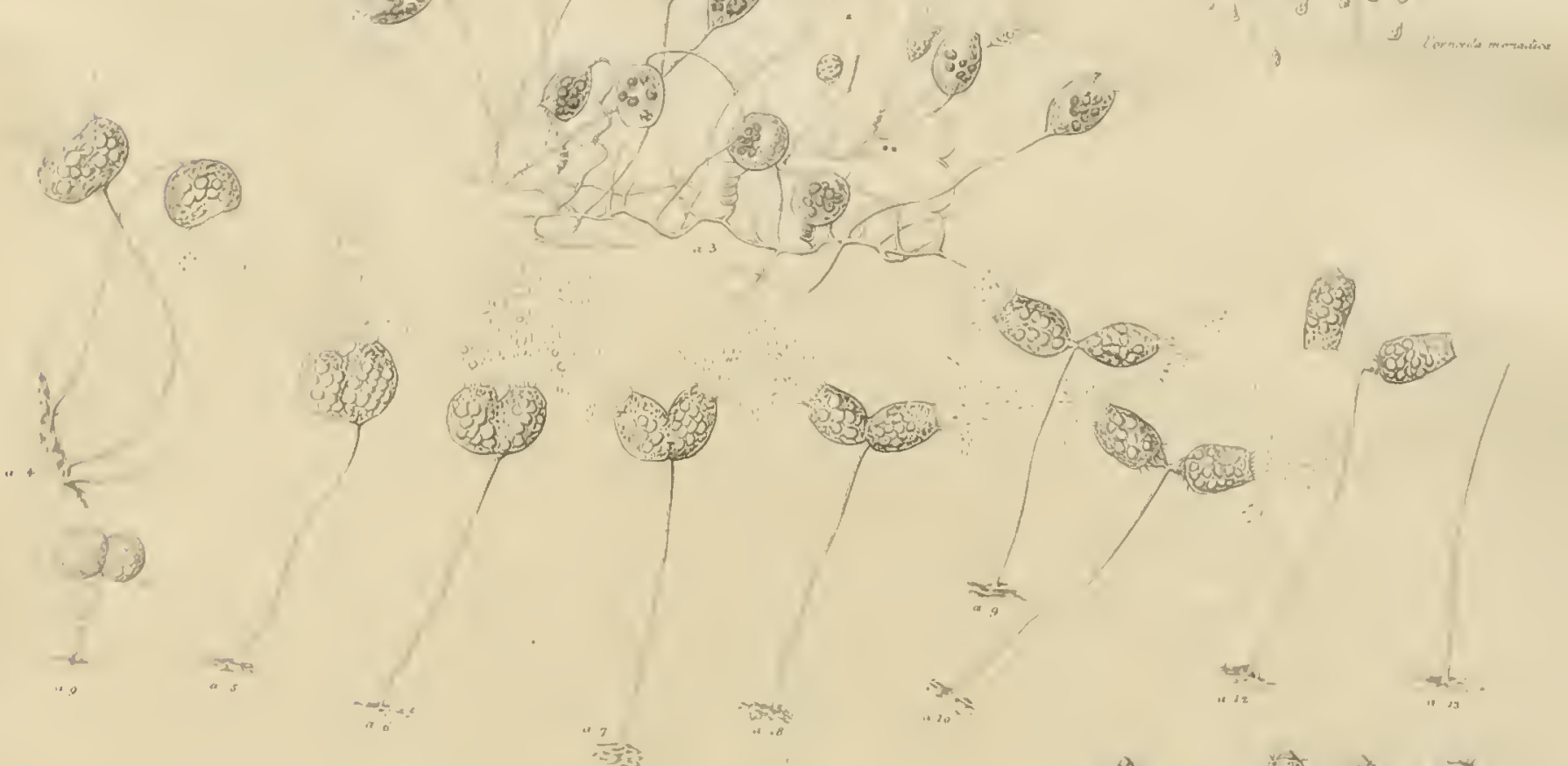

(1), को

asc." (4)

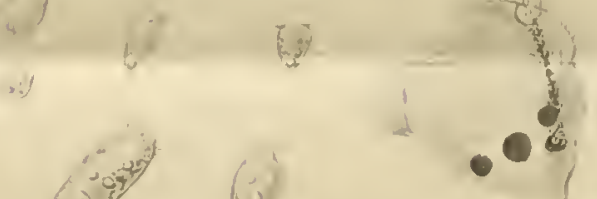

$\therefore 3^{4}$

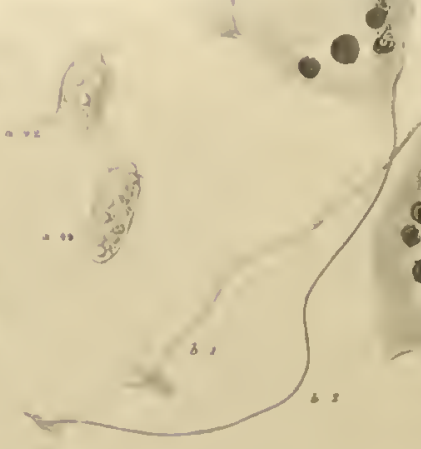

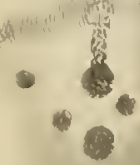

(i)

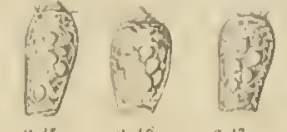
(indy) 
En Elm. Ohrenbergs. Tth. Physik. G1. 1830.

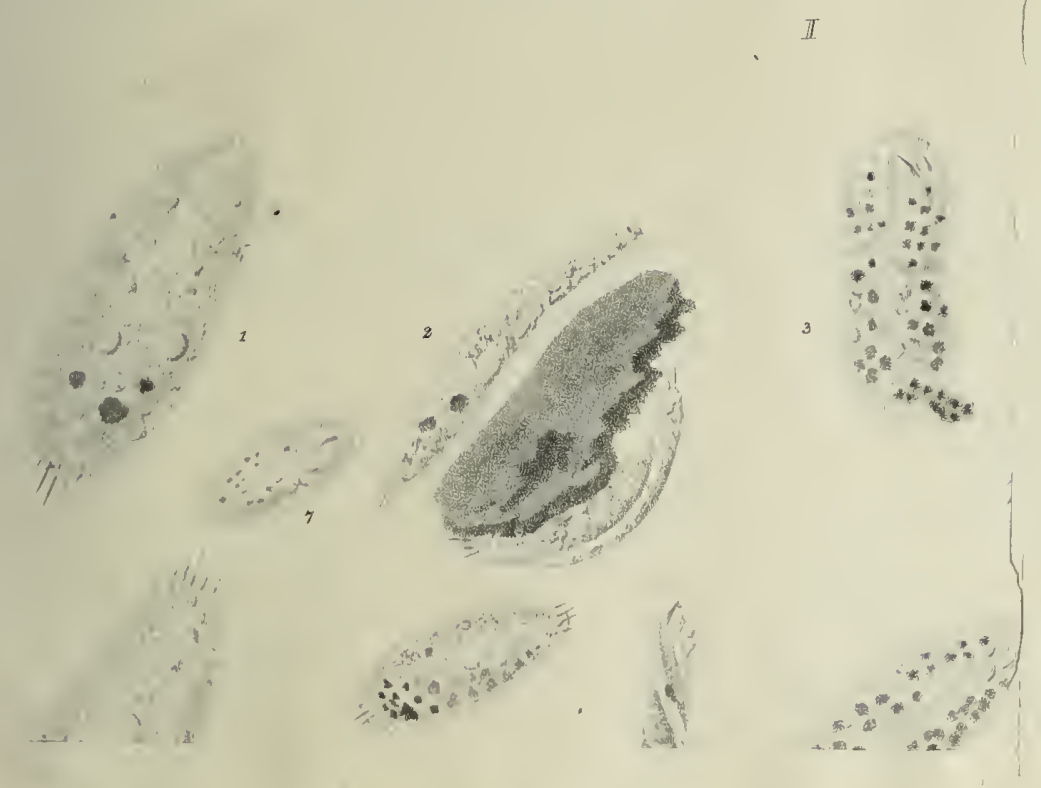




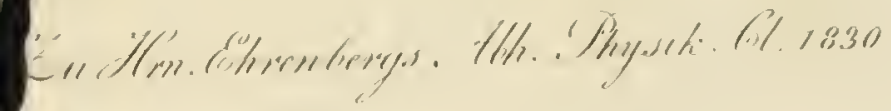

\%. $\%$

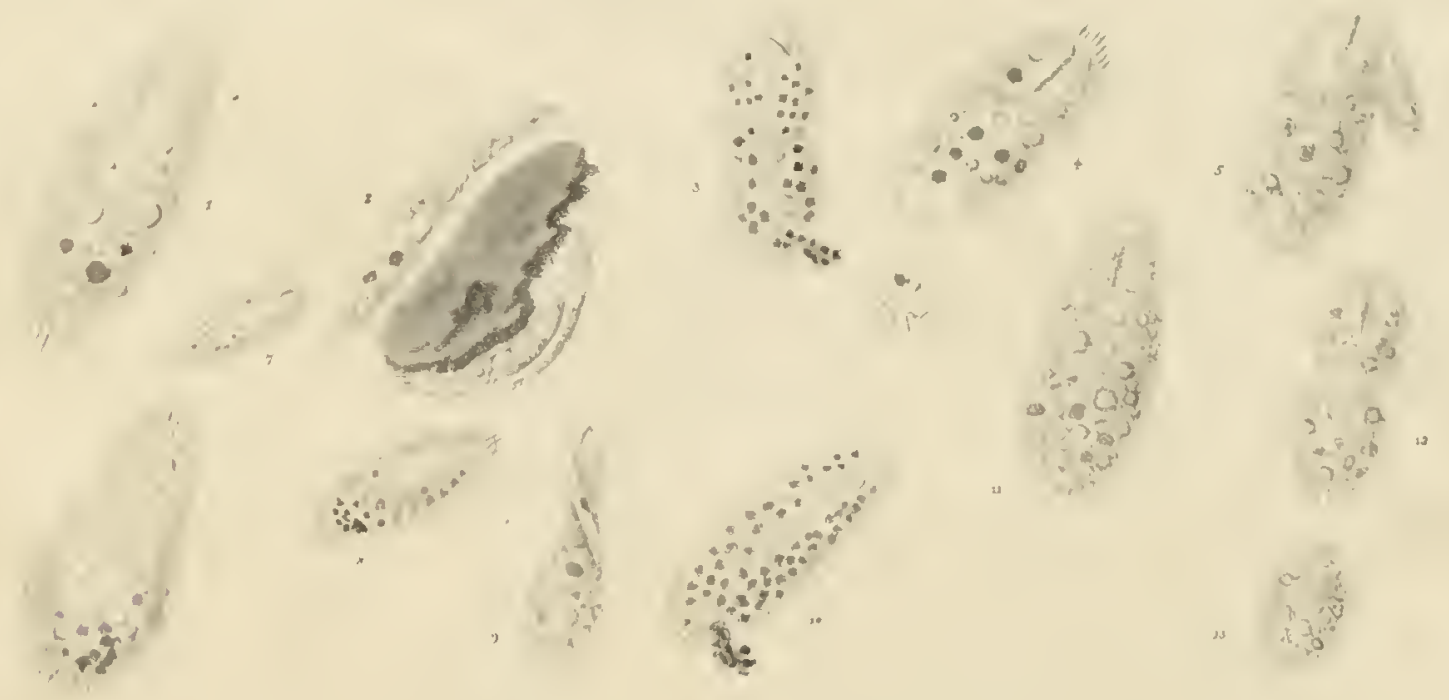

II

(3) $40.6 \%$

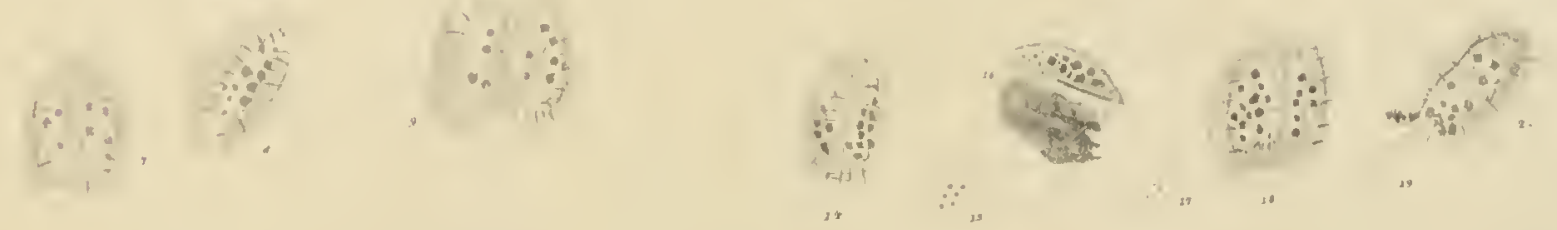

III

\section{$\therefore+\frac{1}{4}$}

. I

1 


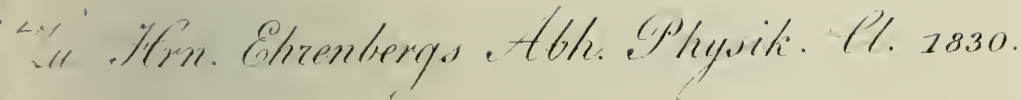
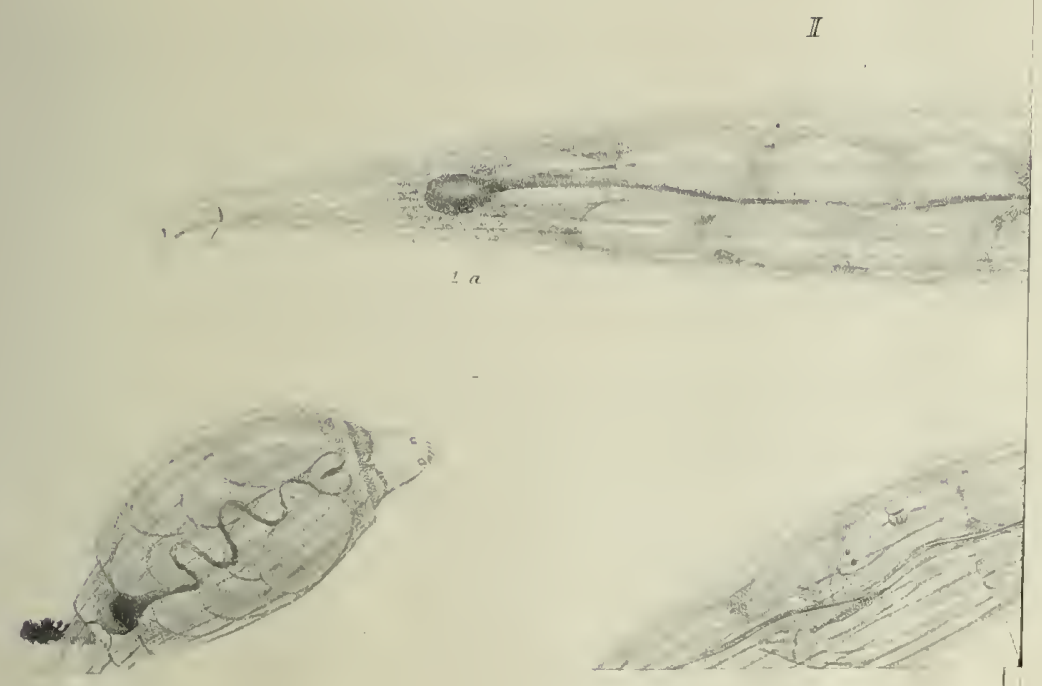


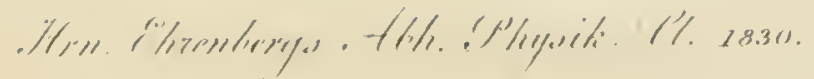

T 771.

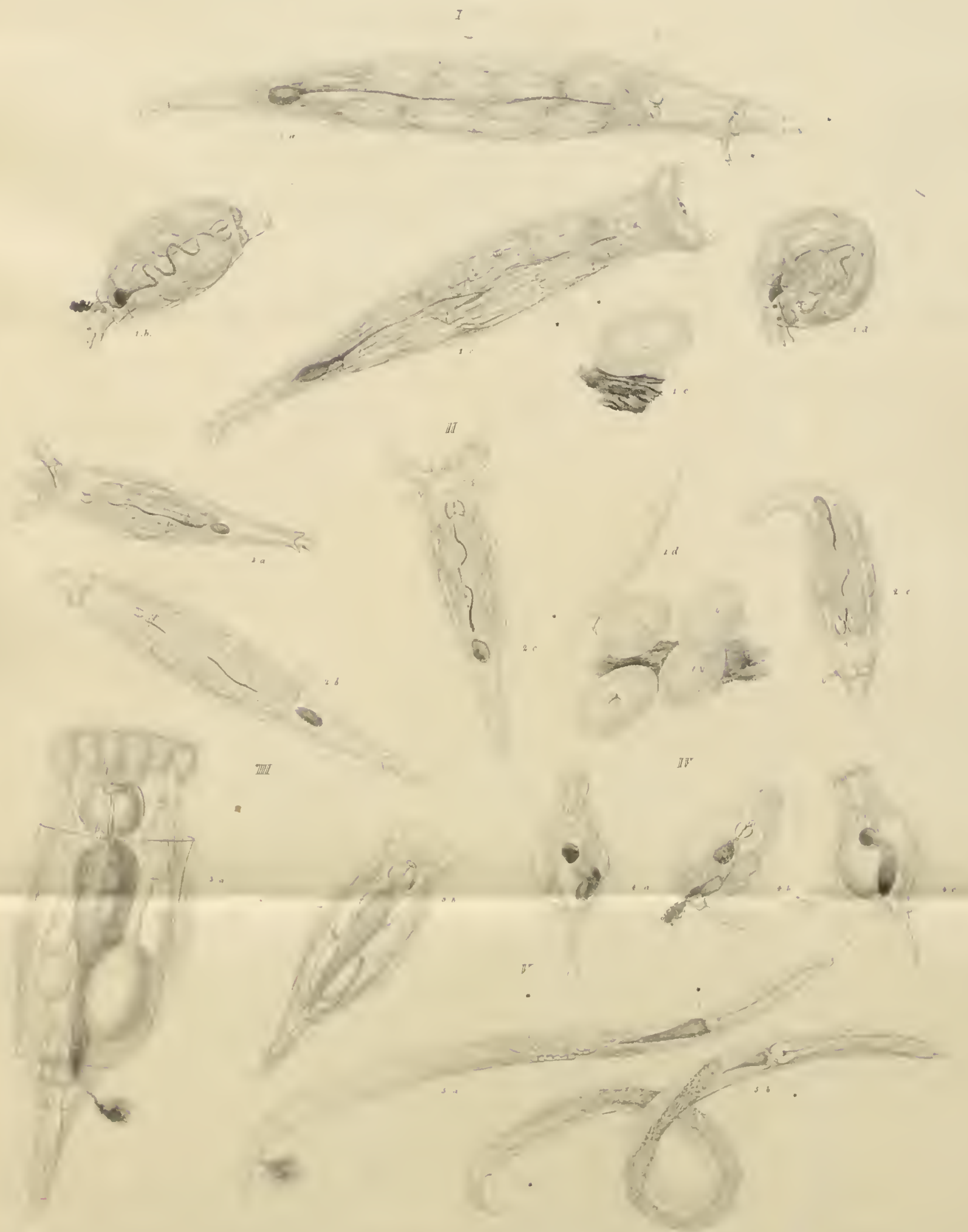

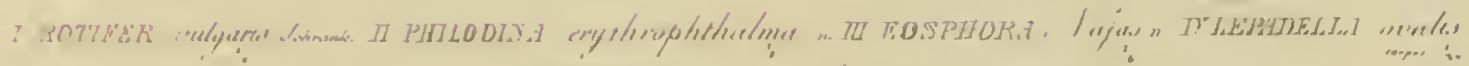

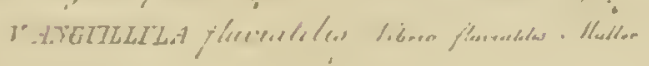




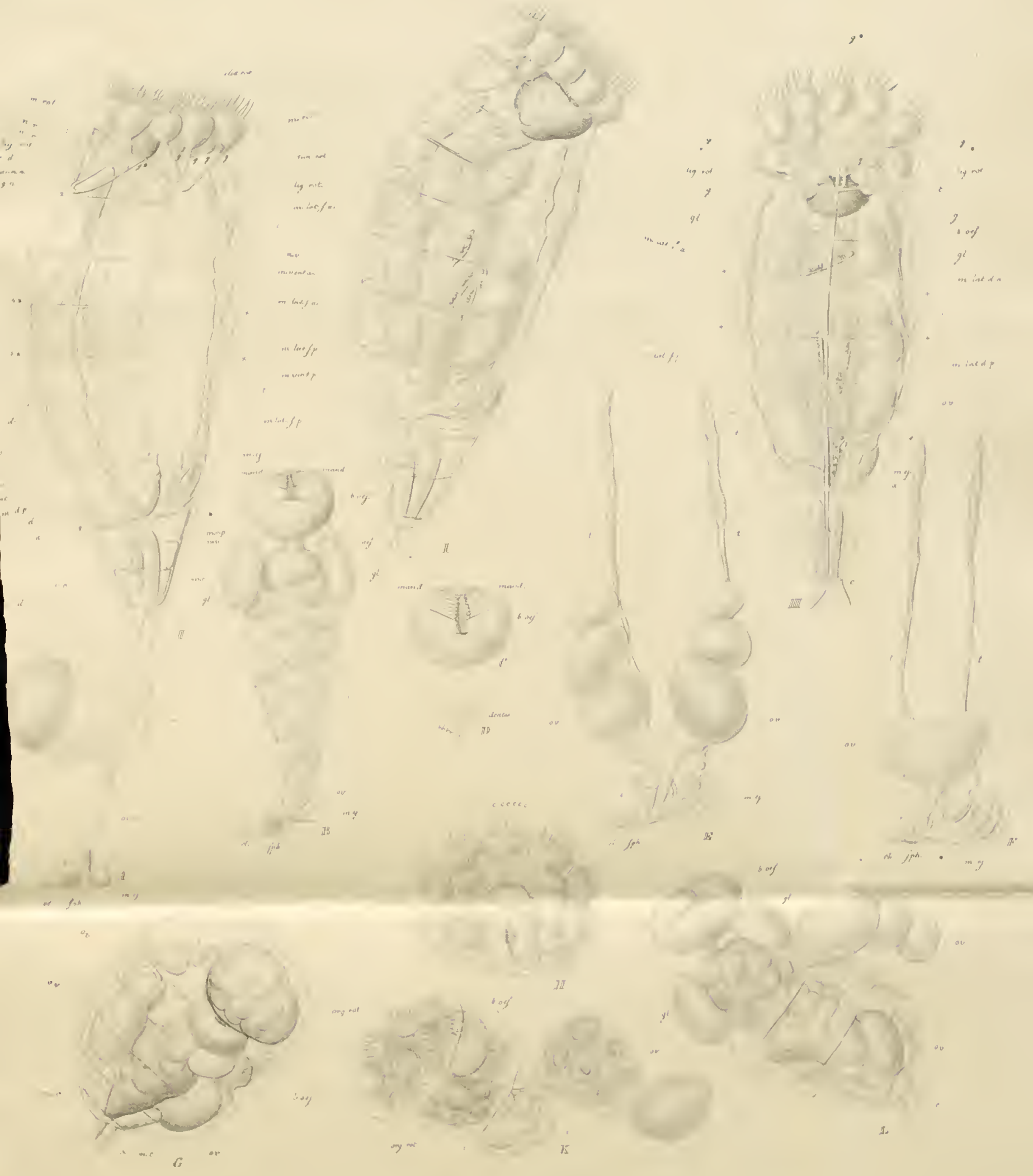

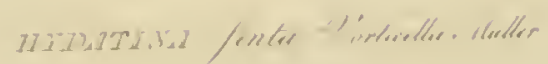


Gaylord Bros.

Makers

Syracuse, N. Y. PAT. JAN. 21, 1908 
